\title{
Modeling $\mathrm{SF}_{6}$ Plume Dispersion in Complex Terrain and Meteorology with a Limited Data Set
}

\author{
Walter William Schalk III
}

October 1996

This is an informal report intended primarily for internal or limited external distribution. The opinions and conclusions stated are those of the author and may or may not be those of the Laboratory.

Work performed under the auspices of the Department of Energy by the Lawrence Livermore National Laboratory under Contract W-7405-Eng-48. 


\section{DISCLAIMER}

This document was prepared as an account of work sponsored by an agency of the United States Government. Neither the United States Government nor the University of California nor any of their employees, makes any warranty, express or implied, or assumes any legal liability or responsibility for the accuracy, completeness, or usefulness of any information, apparatus, product, or process disclosed, or represents that its use would not infringe privately owned rights. Reference herein to any specific commercial product, process, or service by trade name, trademark, manufacturer, or otherwise, does not necessarily constitute or imply its endorsement, recommendation, or favoring by the United States Government or the University of California. The views and opinions of authors expressed herein do not necessarily state or reflect those of the United States Government or the University of California, and shall not be used for advertising or product endorsement purposes.

This report has been reproduced directly from the best available copy.

Available to DOE and DOE contractors from the Office of Scientific and Technical Information

P.O. Box 62, Oak Ridge, TN 37831

Prices available from (615) 576-8401, FTS 626-8401

Available to the public from the

National Technical Information Service

U.S. Department of Commerce

5285 Port Royal Rd.,

Springfield, VA 22161 
TABLE OF CONTENTS

Page

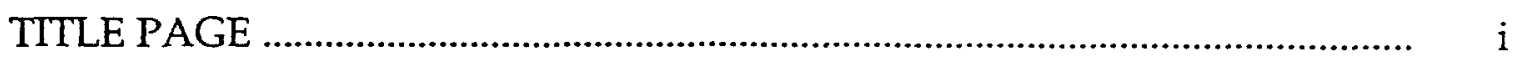

SIGNATURE PAGE ….............................................................................. ii

ACKNOWLEDGMENTS …...........................................................................

TABLE OF CONTENTS .................................................................................. iv

LIST OF TABLES .......................................................................................... vii

LIST OF FIGURES .......................................................................................... viii

LIST OF ACRONYMS ..............................................................................

LIST OF SYMBOLS ......................................................................................

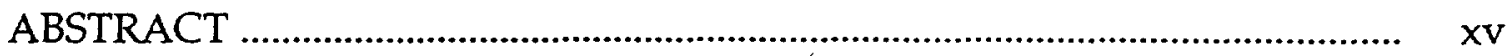

CHAPTER 1

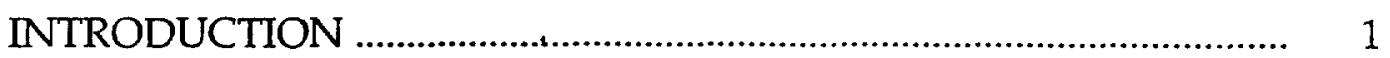

1.1 Objective and Approach ……………….................................. 1

1.2 Background ........................................................................... 2

CHAPTER 2

DESCRIPTION OF MODELS ...............................................................

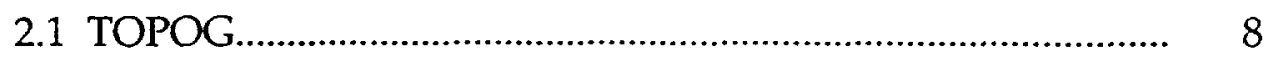

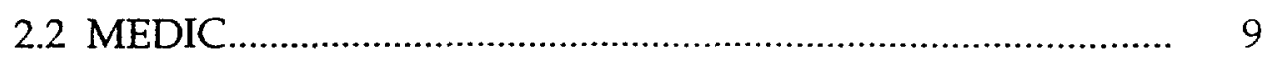

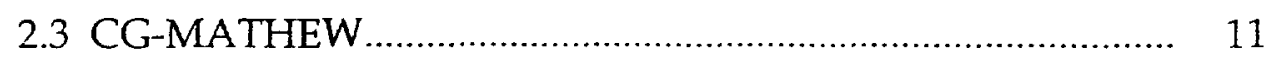

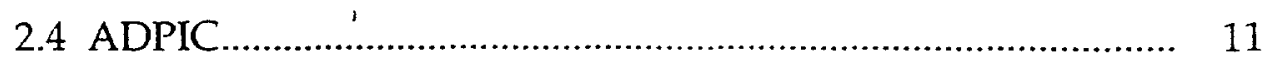

2.5 PLOT_CONTOUR ...................................................................... 15 
CHAPTER 3

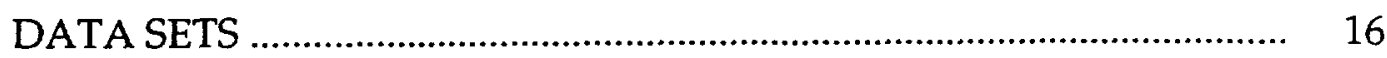

3.1 Tracer Experiment ........................................................... 16

3.1.1 Tracer Study Area ................................................ 16

3.1.2 Meteorological Data ........................................... 18

3.1.3 Tracer Releases .................................................... 19

3.2 Additional Meteorological Data ........................................ 21

\section{CHAPTER 4}

INPUT PARAMETERS AND SENSITIVITY STUDIES ........................ 24

4.1 Selection of Tracer Experiment ............................................ 24

4.2 Release 4 Synoptic Weather Discussion .............................. 24

4.3 Tracer Measurements Data ............................................. 28

4.4 Determination of Model Input ........................................... 31

4.4.1 TOPOG ............................................................ 32

4.4.2 Meteorological Data Input .................................... 34

4.4.2.1 Surface data ............................................ 35

4.4.2.2 Tetroon data ............................................. 35

4.4.2.3 Upper air data ......................................... 38

4.4.2.4 Summary of data quality and quantity used in modeling ..................................... 47

4.4.3 MEDIC/CG-MATHEW/ADPIC Input Parameters 48

4.4.4 PLOT_CONTOUR ............................................... 54

CHAPTER 5

BEST ESTIMATE CALCULATION ............................................ 55

5.1 Calculated Wind Fields ................................................ $5 \overline{5}$ 
5.2 Calculated Plume Dispersion ................................................. 57

5.3 Measurement to Model Comparison .................................. 74

CHAPTER 6

CONCLUSIONS

85

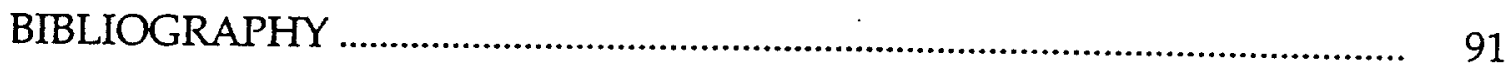

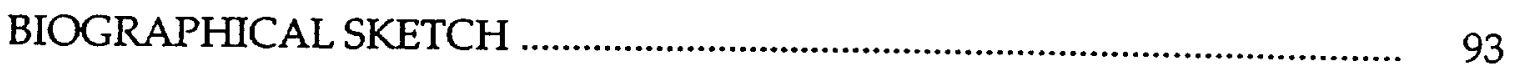




\section{LIST OF TABLES}

Page

Table 3.1 ACE III Tracer Releases …............................................................ 20

Table 4.1 Tetroon 1 flight data and calculated wind ....................................... 36

Table 4.2 Tetroon 2 flight data and calculated wind ....................................... 36

Table 4.3 Rawinsonde data for 1200 UTC 03 November 1993 ........................ 40

Table 4.4 Rawinsonde data for 0000 UTC 04 November 1993 ......................... 40

Table 4.5 Hourly surface observations from Boise, ID and Salt Lake City, UT ……......................................................................... 43

Table 4.6 Success and Failure Criteria …………................................................ 44 


\section{LIST OF FIGURES}

Page

Figure 2.1 ARAC Model Flowchart ................................................................. 8

Figure 3.1 Location of INEL ...................................................................... 16

Figure 3.2 Topography of INEL area. The box outlines the study area and the $\boldsymbol{t}$ is the release location.

Figure 3.3 INEL Tower Network. The box outlines the study area and the + is the release location.

Figure 3.4 Location of NWS Surface (๑) and Upper Air (®) Stations. The box outlines the study area and the $\boldsymbol{t}$ is the release location.

Figure 3.5 Location of GWC Grid points. The box outlines the study area and the + is the release location.

Figure 4.1 US Surface Analysis(a) and North American $500 \mathrm{mb}$ Analysis (b) for 1200 UTC 03 November 1993.

Figure 4.1 US Surface Analysis (c) and North American $500 \mathrm{mb}$ Analysis (d) for 0000 UTC 04 November 1993.

Figure 4.2 Truck (O) and aircraft ( $\square$ ) measurement locations for Release \#4, 03 November 1993.

Figure 4.3 Zoomed-in view of aircraft measurement locations where SF6 was detected.

Figure 4.4 The Model Study Area with TOPOG grid cells. The + denotes the release location.

Figure 4.5 Flight paths of the two tetroons released during Release \#4, 03 November 1993. $\oplus$ denotes the tetroon and tracer release point.

Figure 4.6 Topographic setting of rawinsonde stations and study area. The box outlines the study area, + denotes the release locationn, and $\star$ represents the rawinsonde stations. 
Figure 4.7 Upper air wind and temperature soundings for Salt Lake City, Utah (a), and Boise, Idaho (b) for 1200 UTC 03 November 1993. .

Figure 4.8 Upper air wind and temperature soundings for Salt Lake City, Utah (a), and Boise, Idaho (b) for 0000 UTC 04 November 1993. .

Figure 4.9 Comparison of modeled instantaneous $\mathrm{SF}_{6}$ concentrations at 200 $\mathrm{m}$ AGL (shaded areas above $10 \mathrm{ppt}$ ) with aircraft measurement areas (The triangle represents a measurement area below $10 \mathrm{ppt}$, the oval represents a measurement area above $10 \mathrm{ppt}$ ).

Figure 4.10 Wind profiles generated by the profile (a), and parameterized (b and c) extrapolation methods. (BL denotes the model boundary layer height.)

Figure 4.11 Comparison of modeled instantaneous $\mathrm{SF}_{6}$ concentrations at 1815 UTC and $200 \mathrm{~m} \mathrm{AGL}$ (shaded areas above $10 \mathrm{ppt}$ ) with aircraft measurement areas. (The oval represents a measurement area above $10 \mathrm{ppt}, \mathrm{ML}$ is the mixing layer height, and $\mathrm{BL}$ is the boundary layer height.)

Figure 5.1 Input surface wind barbs and model generated wind fields at 1315 UTC. (Full barb represents $6.5 \mathrm{~m} / \mathrm{s}$ and $\longrightarrow=10 \mathrm{~m} / \mathrm{s}$ ).

Figure 5.2 Input surface wind barbs and model generated wind fields at 1415 UTC. (Full barb represents $6.5 \mathrm{~m} / \mathrm{s}$ and $\longrightarrow=10 \mathrm{~m} / \mathrm{s}$ ).

Figure 5.3 Input surface wind barbs and model generated wind fields at 1515 UTC. (Full barb represents $6.5 \mathrm{~m} / \mathrm{s}$ and $\longrightarrow=10 \mathrm{~m} / \mathrm{s}$ ).

Figure 5.4 Input surface wind barbs and model generated wind fields at 1615 UTC. (Full barb represents $6.5 \mathrm{~m} / \mathrm{s}$ and $\longrightarrow=10 \mathrm{~m} / \mathrm{s}$ )

Figure 5.5 Input surface wind barbs and model generated wind fields at 1715 UTC. (Full barb represents $6.5 \mathrm{~m} / \mathrm{s}$ and $\longrightarrow=10 \mathrm{~m} / \mathrm{s}$ ).

Figure 5.6 Input surface wind barbs and model generated wind fields at 1815 UTC. (Full barb represents $6.5 \mathrm{~m} / \mathrm{s}$ and $\longrightarrow=10 \mathrm{~m} / \mathrm{s}$ ).

Figure 5.7 Input surface wind barbs and model generated wind fields at 1915 UTC. (Full barb represents $6.5 \mathrm{~m} / \mathrm{s}$ and $\longrightarrow=10 \mathrm{~m} / \mathrm{s}$ ).

Figure 5.8 Input surface wind barbs and model generated wind fields at 2015 UTÇ. (Full barb represents $6.5 \mathrm{~m} / \mathrm{s}$ and $\longrightarrow=10 \mathrm{~m} / \mathrm{s}$ ).

Figure 5.9 Input surface wind barbs and model generated wind fields at 2115 UTC. (Full barb represents $6.5 \mathrm{~m} / \mathrm{s}$ and $\longrightarrow=10 \mathrm{~m} / \mathrm{s}$ ). 
Figure 5.10 Input surface wind barbs and model generated wind fields at 2215 UTC. (Full barb represents $6.5 \mathrm{~m} / \mathrm{s}$ and $\longrightarrow=10 \mathrm{~m} / \mathrm{s}$..... 67

Figure 5.11 Model calculated dispersion. Marker dots represent $\mathrm{SF}_{6}$ molecules.

Figure 5.12 Model calculated dispersion. Marker dots represent $\mathrm{SF}_{6}$ molecules.

Figure 5.13 Model calculated dispersion. Marker dots represent $\mathrm{SF}_{6}$ molecules.

Figure 5.14 Model calculated dispersion. Marker dots represent $\mathrm{SF}_{6}$ molecules.

Figure 5.15 Model calculated dispersion. Marker dots represent $\mathrm{SF}_{6}$ molecules.

Figure 5.16 One-minute averaged aircraft flight levels plotted against time (Circles indicate positions where $\mathrm{SF}_{6}$ was detected above $10 \mathrm{ppt}$ ). 75

Figure 5.17 Truck ( $O$ ) and aircraft $(\square)$ measurement locations for Release \#4, 03 November 1993.

Figure 5.18 Modeled Instantaneous Air Concentrations of $\mathrm{SF}_{6}$ at $1.5 \mathrm{~m}$ AGL. (Shaded areas represent areas with concentrations greater than $10 \mathrm{ppt}$ ).

Figure 5.19 Modeled Instantaneous Air Concentrations of $\mathrm{SF}_{6}$ at $200 \mathrm{~m}$ AGL. (Shaded areas represent areas with concentrations greater than $10 \mathrm{ppt}$ ).

Figure 5.20 Modeled Instantaneous Air Concentrations of $\mathrm{SF}_{6}$ at $300 \mathrm{~m}$ AGL. (Shaded areas represent areas with concentrations greater than $10 \mathrm{ppt}$ ).

Figure 5.21 Modeled Instantaneous Air Concentrations of $\mathrm{SF}_{6}$ at $400 \mathrm{~m}$ AGL at 2100 UTC. (Shaded areas represent areas with concentrations greater than $10 \mathrm{ppt}$ ).

Figure 5.22 Modeled Instantaneous Air Concentrations of $\mathrm{SF}_{6}$ at $550 \mathrm{~m}$ AGL at 2215 UTC. (Shaded areas represent areas with concentrations greater than $10 \mathrm{ppt})$. 



\section{LIST OF ACRONYMS}

2-D

3-D

ACE

ADPIC

AFGWC

AFTAC

AGL

APASS

ARAC

ARLFRD

ASL

BOI

CG-MATHEW

FNMOC

GPS

GWC

$\mathrm{H}_{2} \mathrm{~S}_{2} \mathrm{O}_{7}$

INEL

LLNL

MEDIC two-dimensional

three-dimensional

Atmospheric Collection Experiment

Atmospheric Diffusion Particle-In-Cell model

Air Force Global Weather Central

Air Force Technical Applications Center

Above Ground Level

Aerospace Corporation Portable Atmospheric Sampling System

Atmospheric Release Advisory Capability

Atmospheric Research Laboratory Field Research Division

Above Sea Level

Station identifier for Boise, Idaho

Conjugate-Gradient Mass-Adjusted THrEe-dimensional Wind field model

Fleet Numerical Meteorology and Ocenaographic Center

Global Positioning System

Air Force Global Weather Central

oleum

Idaho National Engineering Laboratory

Lawrence Livermore National Laboratory

MEteorological Data Interpolation Code 


$\begin{array}{ll}\text { metdata } & \text { meteorological data } \\ \text { NWS } & \text { National Weather service } \\ \text { NOAA } & \text { National Oceanic and Atmospheric Administration } \\ \text { NCDC } & \text { National Climatic Data Center } \\ \text { PIH } & \text { Station identifier for Pocatello, Idaho } \\ \text { PLOT_CONTOUR } & \text { concentration contouring code } \\ \text { RDM } & \text { Random Displacement Model } \\ \text { SF6 } & \text { sulfur hexafluoride } \\ \text { SLAM } & \text { Short-range Layered Atmospheric Model } \\ \text { SLC } & \text { Station identifier for Salt Lake City, Utah } \\ \text { SO3 } & \text { Sulfur trioxide } \\ \text { TOPOG } & \text { TOPOGraphic grid model } \\ \text { UTC } & \text { Universal Time Coordinates } \\ \text { UTM } & \text { Universal Transverse Mercator } \\ \text { UTME } & \text { Universal Transverse Mercator Easting coordinate } \\ \text { UTMN } & \text { Universal Transverse Mercator Northing coordinate }\end{array}$




\section{LIST OF SYMBOLS}

a

b

c

$c 2$

c3

${ }^{\circ} \mathrm{C}$

$\Delta x$

$\Delta y$

$\Delta z$

BL

deg

$d t$

$d W_{x}$

$d W_{y}$

$d W_{z}$

$d x$

$d y$

$d z$

h

$\mathrm{H}(z)$

k constant dependent upon the inverse Monin-Obukov length constant dependent upon the inverse Monin-Obukov length constant

constant

constant

degrees Celsius

horizontal grid cell dimension in the $x$-direction

horizontal grid cell dimension in the $y$-direction

vertical grid cell dimension in the $\mathrm{z}$-direction

boundary layer height

degrees for wind direction

calculational time step in ADPIC model

an independent random variable in the $x$-direction

an independent random variable in the $y$-direction

an independent random variable in the $\mathrm{z}$-direction

displacement of an ADPIC particle in the $x$-direction

displacement of an ADPIC particle in the y-direction

displacement of an ADPIC particle in the z-direction

height of the tropopause

$K_{z}$ tropopause transition function

von Karman's constant 


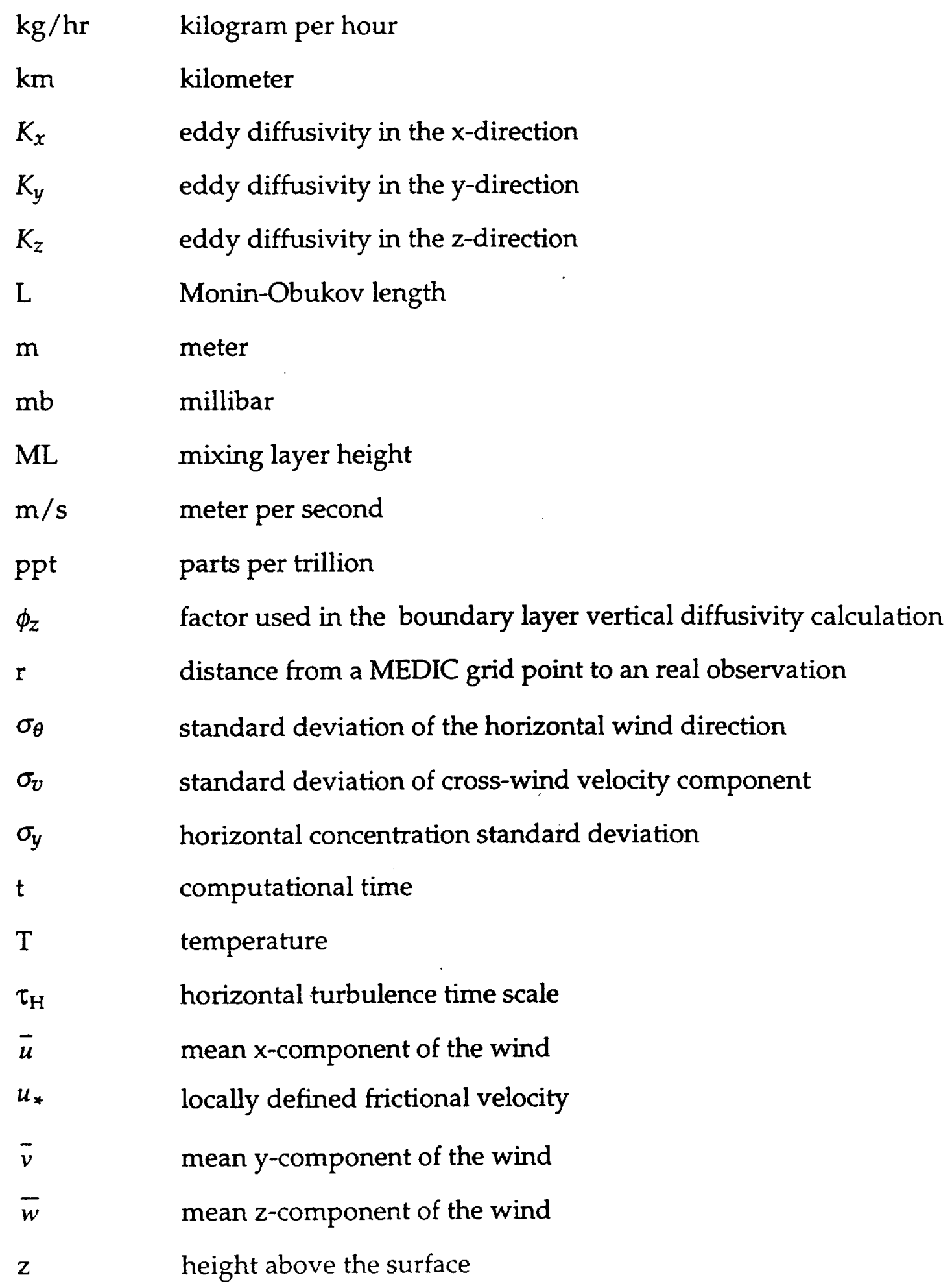




\begin{abstract}
Early actions of emergency responders during hazardous material releases are intended to assess contamination and potential public exposure. As measurements are collected, an integration of model calculations and measurements can assist to better understand the situation.

This study applied a high resolution version of the operational 3-D numerical models used by Lawrence Livermore National Laboratory to a limited meteorological and tracer data set to assist in the interpretation of the dispersion pattern on a $140 \mathrm{~km}$ scale. The data set was collected from a tracer release during the morning surface inversion and transition period in the complex terrain of the Snake River Plain near Idaho Falls, Idaho in November 1993 by the United States Air Force.

Sensitivity studies were conducted to determine model input parameters that best represented the study environment. These studies showed that mixing and boundary layer heights, atmospheric stability, and rawinsonde data are the most important model input parameters affecting wind field generation and tracer dispersion.

Numerical models and limited measurement data were used to interpret dispersion patterns through the use of data analysis, model input determination, and sensitivity studies. Comparison of the best-estimate calculation, to measurement data showed that model results compared well with the aircraft data, but had moderate success with the few surface measurements
\end{abstract}


taken. The moderate success of the surface measurement comparison, may be due to limited downward mixing of the tracer as a result of the model resolution determined by the domain size selected to study the overall plume dispersion. 


\section{CHAPTER 1}

\section{INTRODUCTION}

\subsection{Objective and Approach}

When a hazardous substance is accidentally released into the atmosphere, one of the first actions of an emergency responder should be to execute a numerical or analytical model to assess the potential public exposure. As the hazardous release response continues, air and ground sample measurements from the affected area may be collected. At this time, an integration of model calculations and measurements become necessary to better understand the situation. At first when measurements are sparse, a model may be used to bound the problem. Later, measurements provide a more complete picture and replace model estimates. The purpose of this study is to use a numerical model to assist in the interpretation of the dispersion pattern using limited measurements of a tracer release, similar to the early phases of an emergency response. A second objective is to identify the most important model input parameters that govern the transport and diffusion of the tracer material.

These objectives will be accomplished by applying a high resolution version of the operational 3-D numerical models used by Lawrence Livermore National Laboratory's (LLNL) Atmospheric Release Advisory Capability (ARAC) to a limited meteorological and tracer data set. The data set was collected from tracer releases during the morning surface inversion and transition period in the complex terrain of the Snake River Plain near Idaho Falls, Idaho in October and 
November of 1993 by the United States Air Force. A sequence of model calculations will be made in which model inputs that influence the wind field and dispersion pattern were varied from default values to values supported by the meteorological data set.

A description of the numerical models used in this study is presented in Chapter 2, and Chapter 3 discusses the tracer and meteorological data of the experiment. The set-up of model runs with a discussion of model input parameters are presented in Chapter 4 with the results of the best dispersion model run and comparison to the tracer data in Chapter 5. Chapter 6 includes the conclusions drawn from this study and suggestions for emergency response applications and future work.

\subsection{Background}

The usefulness of information obtained by integrating model calculations and measurements depends on the quantity and quality of the measurements. Only very basic information such as gross plume direction, and possibly source term magnitude can be estimated early in a real-time response when very few measurements are available. Models can be instrumental in understanding the dispersion when limited measurements are available. However, when a tracer data set contains reliable extensive spatial and temporal measurement data, model accuracy can be evaluated and quantified (Draxler 1984, and Foster and Dickerson, 1990).

Greenly and Dickerson (1983) discuss the integration of numerical modeling and measurements with respect to emergency planning and response. The authors present the concept of using numerical models to develop realistic 
accident scenarios that can be used to propose emergency response procedures and actions. In addition, these scenarios can be used to practice and evaluate the developed procedures in an exercise environment. They suggest that in a real event, models with varying degrees of complexity can offer consequence managers useful information. Planning calculations can be used as a very basic first estimate, and a simple Gaussian calculation gives a close-in estimate, however, a 3-D model offers a better estimation of the wind field and dispersion pattern in a complex meteorology or terrain environment.

Greenly and Dickerson believe that applying field measurement data to model calculations can provide estimates of source terms, aid in field team deployment, bound the extent of the affected area, provide a consistency check between models and measurements, and present a means for post-accident analysis.

The authors summarize that models of varying complexity, while being a basic tool, can be combined with field measurements and experience to give emergency responders the best available information to assess the situation in which public health and safety is involved. In addition, this interaction must be flexible and on-going since every incident evolves and takes on unique and changing characteristics.

An example of a recent response illustrates the limited amount of information obtained from very few measurements and also shows the sensitivity of the model to these measurements. Baskett, et al. (1994) describe a real-time response and comparison to very limited measurement data of a hazardous chemical release in Richmond, Califomia using the ARAC models. In late July 1993 during a transfer operation at a chemical facility, a pressure relief 
valve on a railroad tank car loaded with 35 grade $(35 \%)$ oleum $\left(\mathrm{H}_{2} \mathrm{~S}_{2} \mathrm{O}_{7}\right)$ failed, causing sulfur trioxide $\left(\mathrm{SO}_{3}\right)$ to be released to the atmosphere. The initial, worstcase, scenario released the entire contents of the tank car, 50,000 liters, in 90 minutes into a 750 meter deep mixed layer capped by a subsidence inversion with winds generally from the west throughout the layer. Surface and upper air wind data were obtained from four local airports within $32 \mathrm{~km}$ and used as input to the wind field models. In addition, wind data from a Bay Area Air Quality Management District tower was obtained and adjusted the overall wind field to better correspond with the on-scene reported winds which were from the southwest. The initial hazard prediction had the plume moving to the northeast with an east-northeast bend at the farthest extent.

During post-accident analysis, a revised source term of approximately one-twelfth the initial amount released non-uniformly over 3.75 hours was determined. Wind data from an additional meteorological tower near the release point was obtained. This additional data generated a plume prediction that was rotated up to $40^{\circ}$ clockwise for a short period with substantially less downwind extent.

A single sulfuric acid 3-hour average air sampler measurement located 2.3 $\mathrm{km}$ downwind, but east of modeled plume centerline was taken. Initial, refined, and post-accident analysis model results were within a factor of 2 compared to the measurement. The post-accident analysis results with the revised source term and additional wind information generated results within a factor of 1.3. It is important to note that a single measurement can not determine the actual dispersion pattern, but can point out the best model calculation. 
Baskett, et al., concluded that the accuracy of real-time 3-D numerical modeling of toxic release events depends on the number, accuracy, and representativeness of the available wind data. In addition, the modeling of these events would benefit from access to local area networks of data as well as improved diagnostic and prognostic wind field models.

In contrast, an example of a well-instrumented tracer study shows that models can be evaluated and limitations can be identified. Reible, Shair, and Kauper (1981) conducted three studies to characterize the transport and dispersion of gaseous pollutants emitted into wind flows with directional shear with altitude. The first of these tests was conducted near Lost Hills in the western San Joaquin Valley. The San Joaquin Valley is the southern half of California's Central Valley and extends $400 \mathrm{~km}$ in length and $80 \mathrm{~km}$ in width. The Sierra Nevada Mountains define the eastern edge, and the coastal mountains border to the west. Sulfur hexafluoride $\left(\mathrm{SF}_{6}\right)$ was released at $30 \mathrm{~m}$ AGL in the mid-afternoon in early December. Results showed that surface releases during light upslope surface wind flows with vertical shear aloft were directed by the flow aloft.

The second and third tests of Reible, Shair, and Kauper were conducted in the Clear Lake region of the Northern California coastal mountains. Each of these surface tracers were released at $30 \mathrm{~m}$ AGL from elevations of $640 \mathrm{~m}$ and 730 $m$ ASL. The second study involved a two hour release on a mid-June night where a uniform stable westerly marine flow created a near directionally shearless vertical environment. As a result, the material detected roughly compared with the Gaussian plume solution under neutral assumptions. 
The third tracer was released for 6 hours on a late-June night. The wind flow pattern on this night had west winds above $90 \mathrm{~m}$ and a southerly surface drainage flow below $90 \mathrm{~m}$ at the release location. As a result, a dramatic directional shear existed near $90 \mathrm{~m}$ causing distinct plume bifurcation. Measurements showed that approximately $80 \%$ of the $\mathrm{SF}_{6}$ was transported to the east by the synoptically driven flow aloft, and $20 \%$ was transported by the surface drainage winds to the north.

Reible, Shair, and Kauper concluded that a general model applicable to mountainous or hilly terrain did not exist. However, they estimated concentrations using a Gaussian model by increasing the stable diffusion rates that were developed over flat terrain. The resulting modeled concentrations were accurate to within a factor two. The first and third cases showed that in cases of extreme wind shear vertically or with distance, Gaussian models can not accurate predict downwind concentrations. However, if the low-level and upper-level flows can be represented by distinct wind values, an upper bound for concentrations can be determined with the Gaussian models using flat terrain assumptions.

The examples of Baskett et al. (1994) and Reible, Shair, and Kauper (1981) illustrate extremes of model and measurement integration, from basic comparison to detailed comparison with results suggesting limitations of the model. In between is an area where models and measurements can complement each other to achieve a better understanding of tracer dispersion. This is the area to be explored in this study. 


\section{CHAPTER 2 DESCRIPTION OF MODELS}

The suite of models used in this study are a higher resolution version of the standard operational codes used by the Atmospheric Release Advisory Capability (ARAC). The ARAC is a Program within the Environmental Programs Directorate of the Department of Energy's Lawrence Livermore National Laboratory in Livermore, California. The mission of the ARAC as tasked by the Department of Energy and the Department of Defense is to provide timely and credible assessment advisories to emergency managers for radiological (and other hazardous material) releases to the atmosphere and thereby minimize the exposure to the population at risk.

Figure 2.1 illustrates the five codes that constitute the ARAC model run stream. The first model creates a topographic grid bottom for the modeling domain and defines the grid resolution, TOPOG. The next model, MEDIC, interpolates and extrapolates observational and gridded wind data to a 3-D modeling grid. CG-MATHEW adjusts the interpolated and extrapolated wind field to be mass consistent and include the effects due to terrain. The dispersion code, ADPIC, simulates the 3-D transport and diffusion of a release to the atmosphere using a random displacement methodology. The final model, PLOT_CONTOUR, creates isopleth maps based on the concentration files generated by the dispersion code. 


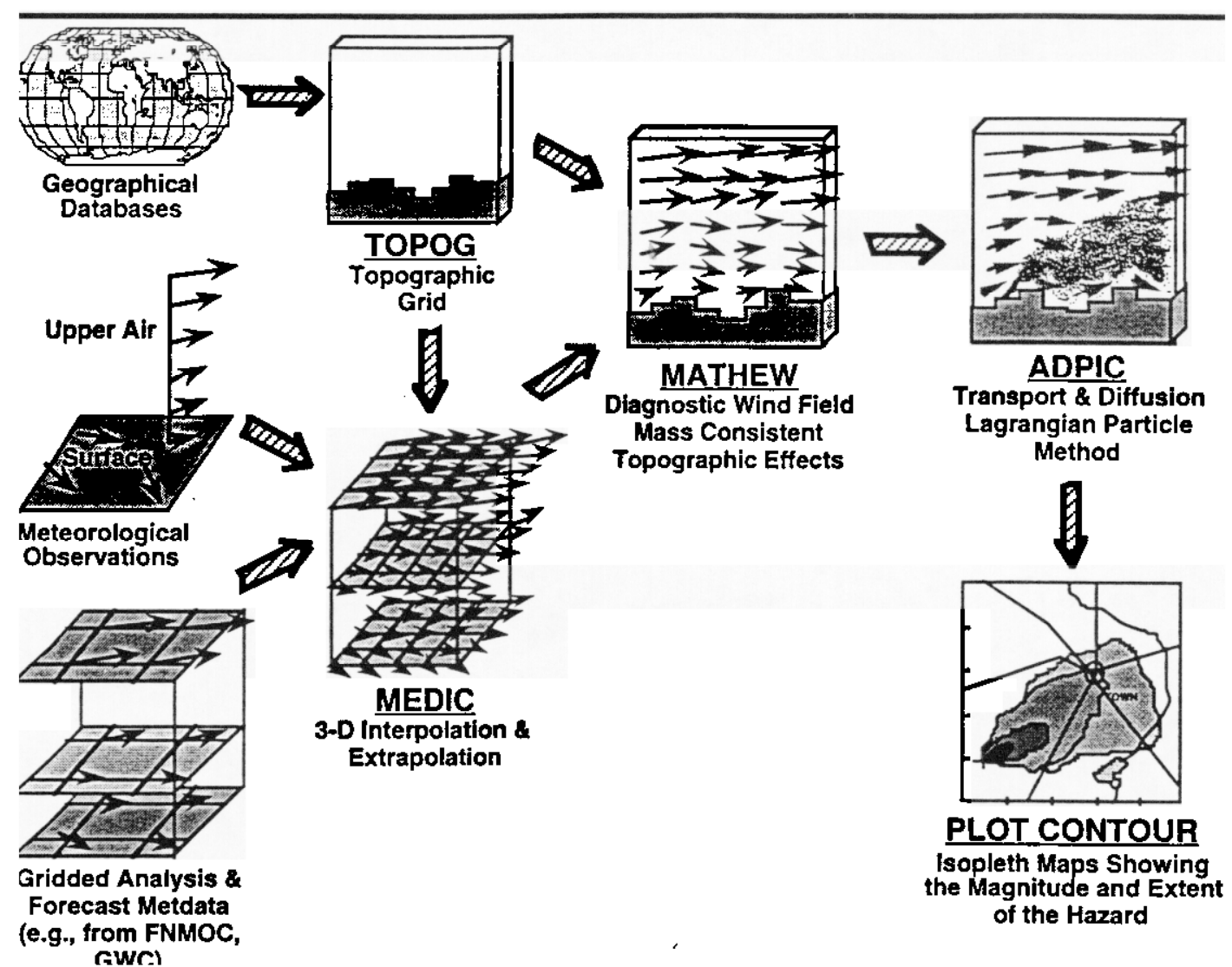

Figure 2.1 ARAC Model Flowchart

\subsection{TOPOG}

The TOPOGraphic code (TOPOG) builds the model grid bottom in a "building block" format by averaging terrain heights from an on-line worldwide database with $500 \mathrm{~m}$ resolution that was derived from Defense Mapping Agency $100 \mathrm{~m}$ resolution data. TOPOG defines the horizontal and vertical grid resolution $(\Delta x, \Delta y, \Delta z)$ of the modeling domain and for each grid cell. In addition, TOPOG examines each cell in the domain and compares it with the surrounding cells. If a cell is found to be at least one $\Delta z$ less than the surrounding eight cells, the cell's height is then filled by averaging the cells 
around it. If left uncorrected, these single cell depressions would allow ADPIC particles to diffuse into them and remain trapped. The volume defined by TOPOG is used by the CG-MATHEW and ADPIC models for wind field generation and plume dispersion calculations, respectively.

\section{$\underline{2.2 \text { MEDIC }}$}

The MEteorological Data Interpolation Code (MEDIC) uses surface, tower, and upper air observations and gridded data to generate a 3-D gridded $(51 \times 51 \times$ 31 grid points) wind field in the volume defined by TOPOG. Three layers each treated uniquely by MEDIC are the surface layer, boundary layer, and geostrophic layer. The model generates a surface layer with no directional shear and diminishing wind speeds toward the surface. A geostrophic layer is constructed where the winds are free of surface effects and is shearless in direction and speed. Between these layers is the boundary layer which contains the wind field where the shear effects of the transition from the surface layer to the geostrophic layer exist.

The basic interpolation and extrapolation method used by MEDIC is the inverse square formula applied to the four closest observations. The vertical structure of the wind field is calculated in one of two ways, parameterized and profile methods. Both methods normalize the surface observations to a reference height using a power law and apply the $1 / \mathrm{r}^{2}$ weighting to determine wind speed and direction for all grid points at the user defined reference height. The parameterized extrapolation method uses the inverse square formula to determine a wind speed and direction in each grid column at the boundary layer height from the upper air observations. With the winds at these two levels 
defined, the wind data for the rest of the grid points in each column are defined. In the surface layer, the wind speed at the surface is zero and increases according to the power law while direction is constant to the top of the surface layer. The wind speeds and directions in the boundary layer are calculated using a differencing technique between the winds at the top of the surface layer and the top of the boundary layer. This interpolation is usually linear, however, the exponent can be varied to extrapolate surface effects upward or upper level effects downward. Above the boundary layer, if still within the modeling domain, the wind direction and speed are constant with height.

The profile extrapolation method uses the same method for calculating winds at a reference height near the surface, but uses a different vertical extrapolation scheme. This method first uses the inverse square formula applied to the upper air observation to determine wind speeds for each column of grid points, "synthesized profile". The wind speeds at the reference level are then integrated with the "synthesized profile" using a weighting factor where the reference level wind speed has more influence than the "synthesized profile" wind speed near the surface. Below the top of the surface layer the wind speed approaches zero at the surface. Above the top of the boundary layer the extrapolated wind speed and direction match that of the observed data. The wind direction in the surface layer is constant, but in the boundary layer the direction is calculated with the same integration technique as the wind speed.

Once the extrapolation and interpolation are completed by one of the two methods, the terrain is added to the wind field. Conserving the three layer structure, the terrain is pushed up through the bottom of the grid displacing the calculated winds upward. This results in the surface, boundary, and geostrophic 
layer boundaries taking on the shape of the terrain. The $u$ - and $v$-components of the wind at each grid point are then passed to CG-MATHEW.

\section{$\underline{2.3}$ CG-MATHEW}

The Conjugate-Gradient Mass-Adjusted THrEe-dimensional Wind code (CG-MATHEW) minimally adjusts the 3-D interpolated wind field generated by MEDIC to be mass-consistent and maintain atmospheric stability characteristics. A detailed discussion of the methodology is given by Sugiyama et al. (1994).

Initially, the grid point wind data from MEDIC are interpolated and defined at each grid cell face center. Finite difference methods used with a conjugate gradient solution are applied to minimize the variance between input observed, MEDIC, and output adjusted winds. The normal and tangential wind component adjustments are constrained by the mass-consistency assumption and boundary conditions that are applied to each grid cell face. In addition, the normal wind component of grid cell faces at terrain surfaces is set to zero. The relative amount of horizontal and vertical adjustment are controlled by the atmospheric stability.

Once the adjustment is complete, the grid cell face centered wind components are interpolated back to grid points retaining the mass-consistent adjustment. These grid point vectors are used as the input wind field for the transport component of the ADPIC dispersion code.

\subsection{ADPIC}

ADPIC, Atmospheric Diffusion Particle-In-Cell, employs a Lagrangian, grid-independent, random walk solution to the 3-D advection-diffusion 
equation. The model uses thousands of marker particles to simulate the airborne material released into the flow field. Ermak, et al (1994) present a detailed discussion of this methodology known as the Random Displacement Method (RDM). (Although the model name implies particle-in-cell methodology, the diffusion scheme was replaced by the RDM in 1995, and the ADPIC name was retained for historical reasons.) The displacement of each particle is given by the following equations.

$$
\begin{gathered}
d x=\bar{u} d t+\left(2 K_{x}\right)^{1 / 2} d W_{x \prime} \\
d y=\bar{v} d t+\left(2 K_{y}\right)^{1 / 2} d W_{y \prime} \\
d z=\bar{w} d t+\frac{\partial K_{z}}{\partial z} d t+\left(2 K_{z}\right)^{1 / 2} d W_{z^{\prime}}
\end{gathered}
$$

$d W_{x, y, z}$ are three independent random variables with a mean of zero, and a variance $d t . K_{x, y, z}$ are the eddy diffusivities in the three coordinate directions, and $K_{x}=K_{y}$ since the horizontal turbulence is assumed to be homogeneous. The mean wind components, $\bar{u}, \bar{v}$, and $\bar{w}$ are obtained from the gridded wind fields of CG-MATHEW. $d t$ is the calculational time step, which is restricted to prevent a particle from moving more than one grid cell in a single time step.

ADPIC uses a horizontal eddy diffusivity, $K_{H}(=K x=K y)$, based on Draxler's (1976) semi-empirical relationship for $\sigma_{y}$ as a function of time and the standard deviation of cross-wind velocity component $\left(\sigma_{v}\right)$. Using the approximation $\sigma_{v} \approx \sigma_{\theta} \bar{u}$ the horizontal eddy diffusivity is defined as

$$
K_{H}=\frac{\bar{u}^{2} \sigma_{\theta}{ }^{2} t\left[1+\frac{d}{2}\left(\frac{t}{\tau_{H}}\right)^{K_{2}}\right]}{\left[1+d\left(\frac{t}{\tau_{H}}\right)^{1 / 2}\right]^{3}} .
$$


(Note: $\sigma_{\theta}$ is in radians) where $t$ is the computational time, $\tau_{\mathrm{H}}$ is the horizontal turbulence time scale, $\sigma_{\theta}$ is the standard deviation of the horizontal wind direction, and $\bar{u}$ is the mean horizontal wind.

The vertical eddy diffusivity profile, $K_{z}$, is based on surface and boundary layer scaling parameters given by Lange (1989). A single equation is used that provides a quick transition from boundary layer values to tropopause values. The vertical eddy diffusivity profile is given as

$$
K_{z}=H(z) K_{z}^{\mathrm{bl}}(z)+[1-H(z)] K_{z}^{\text {tropo }},
$$

where

$$
\begin{gathered}
H(z)=e^{-\left(y c_{2}\right)^{c_{3}},}, \\
K_{z}^{\mathrm{bl}}(z)=\frac{k u_{*} z}{\phi_{z}} e^{-c z / h}, \\
\phi_{z}=\left(1+a \frac{z}{L}\right)^{b}, \\
a=\left\{\begin{array}{c}
-15, \text { if } 1 / L<0 \\
0, \text { if } 1 / L=0 \\
4.5, \text { if } 1 / L>0
\end{array}\right. \\
b=\left\{\begin{array}{c}
-0.25, \text { if } 1 / L<0 \\
1, \text { if } 1 / L \geq 0, \text { and } \\
c=4 . \\
K_{z} \text { tropo }=0.01 \mathrm{~m}^{2} / \mathrm{s}, \\
c_{2}=1.5, \text { and } \\
c_{3}=8 .
\end{array}\right.
\end{gathered}
$$

$z$ is the height above the surface, $h$ is the height of the tropopause, $k$ is von Karman's constant (0.4), and $u_{*}$ is the locally defined frictional velocity.

Currently, ADPIC is configured to resolve up to nine separate pollutant sources (combinations of source type, rate, geometry, etc.). The release rates and 
center heights of each source are independent and variable with time. Within each source, the initial position ( $x, y$, and $z$ coordinates) of each marker particle representing the source geometry is distributed by using a Gaussian distribution along the $x-, y-$ and $z$-axes. The particle size distribution of each source can also be specified as separate log-normal distributions. ADPIC has the ability to remove particles through dry deposition by gravitational settling based on particle size and flux of material from the surface layer to the ground based on a specified deposition velocity. Information on deposited particles is retained in the event ground contamination calculations are required. Various time-varying atmospheric parameters can be adjusted. These include stability class, mixing layer height, and Monin-Obukhov length.

ADPIC also has the capability to calculate time-dependent plume rise. The final height of buoyant sources depend on wind speed, atmospheric stability, environmental and release temperatures, and the atmospheric lapse rate. To improve the near-source concentration sampling, four nested grids of diminishing size and smaller $\Delta x$ and $\Delta y$ are used. Each interior grid has twice the resolution of the next outer grid; the innermost grid has $1 / 16$ the $\Delta x$ and $\Delta y$ of the outermost grid.

ADPIC can generate several types of output concentration files at any level within the modeling domain at any time within the model run. The concentration file output can be of instantaneous concentrations ("snapshot"), time-integrated concentration, average air concentrations over a time period, a short-term peak air concentration, and total deposition. Up to thirty unique files can be generated by one ADPIC model run. These files are passed to PLOT_CONTOUR for post processing. 


\subsection{PLOT CONTOUR}

The horizontal 2-D gridded concentration files output from ADPIC are used by PLOT_CONTOUR to generate isopleth maps that delineate areas of varying concentration. The five general types of plots that can be created by PLOT_CONTOUR based on the type of ADPIC output are total deposition, integrated air concentration, instantaneous air concentration, short-term peak air concentration, and average air concentration. Total deposition is the amount of material mass or activity per unit area accumulated on the ground from the beginning to the end of the model calculation. Integrated air concentration is the amount of material mass or activity per unit volume summed in time over the model calculation at a pre-determined height. Instantaneous air concentration is the amount of material mass or activity per unit volume at a "snapshot" in time at a pre-determined height. Short-term peak air concentrations are the maximum concentrations calculated at a point over a short time interval for all points in the grid at a specified height. Average air concentration is the time-averaged air concentration over a pre-determined sampling interval and height.

Within PLOT_CONTOUR various conversion factors can be applied to the concentrations to generate output units familiar to the user. In addition, materials released simultaneously but dispersed uniquely in ADPIC can be combined to determine a cumulative effect. Currently, up to five different isopleth levels selected automatically or input directly can be generated on the same map. 


\section{CHAPTER 3}

\section{DATA SETS}

\subsection{Tracer Experiment}

The Air Force Technical Applications Center (AFTAC) conducted a series Atmospheric Collection Experiment (ACE) air sampling tests to investigate monitoring methods. Each experiment consisted of a collection of meteorological data and forecasts, dispersion model results, effluent release rates and, air and ground sampling data. The third ACE experiment conducted on the Idaho National Engineering Laboratory (INEL) site near Idaho Falls, Idaho involved six tracer releases between 12 October and 9 November 1993. The purpose of this experiment was to determine if low-level concentrations of sulfur hexafluoride $\left(\mathrm{SF}_{6}\right)$ could be detected greater than $50 \mathrm{~km}$ from the release point.

\subsubsection{Tracer Study Area}

Figure 3.1 shows the INEL site located in southeastern Idaho in the high desert area of the Snake River Plain. The area is surrounded by complex terrain with mountain peaks reaching more than $3065 \mathrm{~m}$ ASL to the east and west (Figure 3.2). The base of the Plain averages $1500 \mathrm{~m} \mathrm{ASL}$ and is oriented northeast-southwest between the Tetons to the east and the Salmon River Mountains to the west. The Plain gradually rises about $200 \mathrm{~m}$ at $150 \mathrm{~km}$ northeast where the sagebrush and potato fields turn into coniferous forest. Southwest of the site, the grassy plain slowly drops away. 


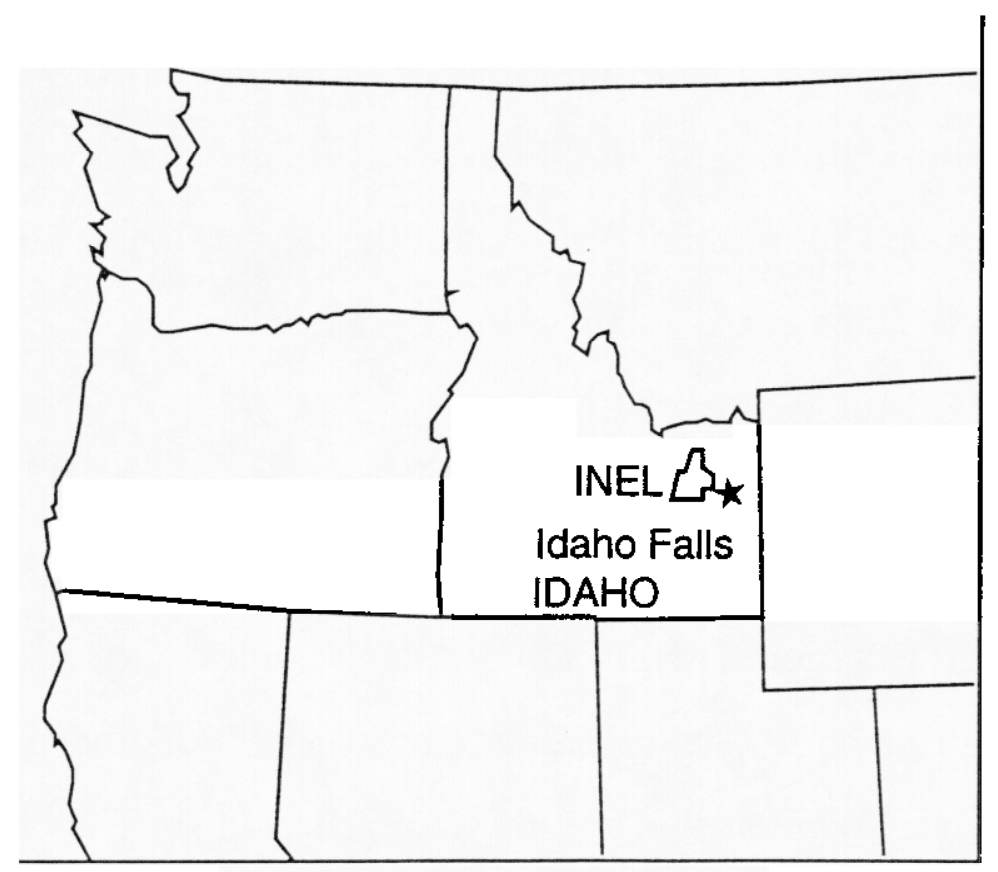

Figure 3.1 Location of INEL

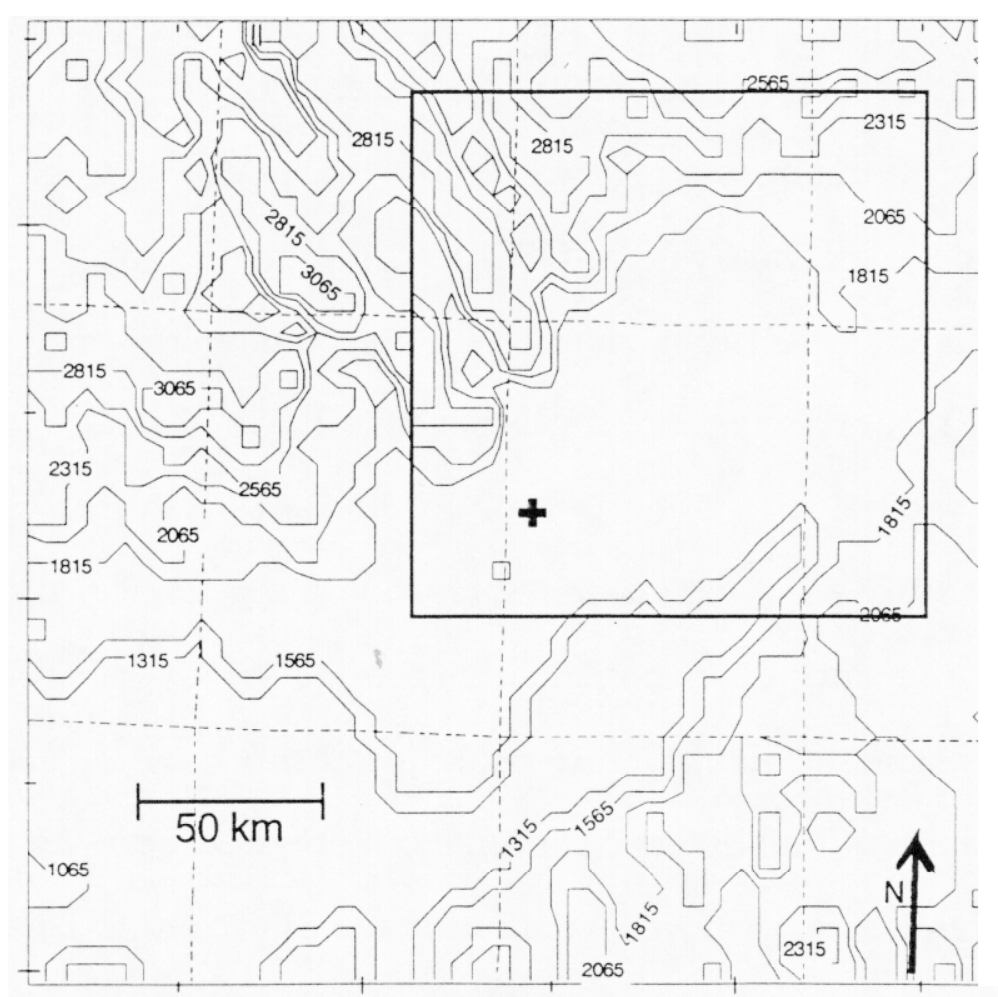

Figure 3.2 Topography of INEL area. The box outlines the study area and the $\boldsymbol{+}$ is the release location. 
There is also a significant amount of basalt rock covering the plain. Wide northwest-southeast oriented passes in the mountains to the northwest funnel down-slope winds onto the Plain and receive up-slope flow from the Plain. Buttes extend more than $750 \mathrm{~m}$ from the desert floor generating eddies in the valley flow. The area is not densely populated.

\subsubsection{Meteorological Data}

Wind speed, wind direction and temperature data were collected during each of the six release events. The Atmospheric Research Laboratory Field Research Division (ARLFRD) of the National Oceanic and Atmospheric Administration (NOAA) operates a 31-tower network that collects 5-min average temperature, wind speed, and wind direction data. The network is set-up in a 26,000 square $\mathrm{km}$ area centered on INEL as shown in Figure 3.3.

ARLFRD personnel released balloons weighted to drift at predetermined density altitudes, tetroons, during the tracer releases. The tetroons were used in an attempt to determine general plume transport. Each tetroon was equipped with Global Position System (GPS) transponders to relay location information during flight. The flight level of the tetroons were set to the middle of the forecast transport layer, which was between 150 to $275 \mathrm{~m}$.

A vertical atmospheric sounder and a portable rawinsonde unit were operated during the experiment. However, mechanical difficulty resulted in unusable data and was not included in the dataset.

Experiment operators executed a transport and diffusion model in realtime in an attempt to determine plume centerline and downwind concentrations. The model was a modified version of the Short-range Layered Atmospheric Model (SLAM) developed by ENSCO Inc. Hourly averaged air concentrations 
on a $0.25^{\circ}$ latitude by $0.25^{\circ}$ longitude grid square were generated using surface meteorological input data from the local tower network.

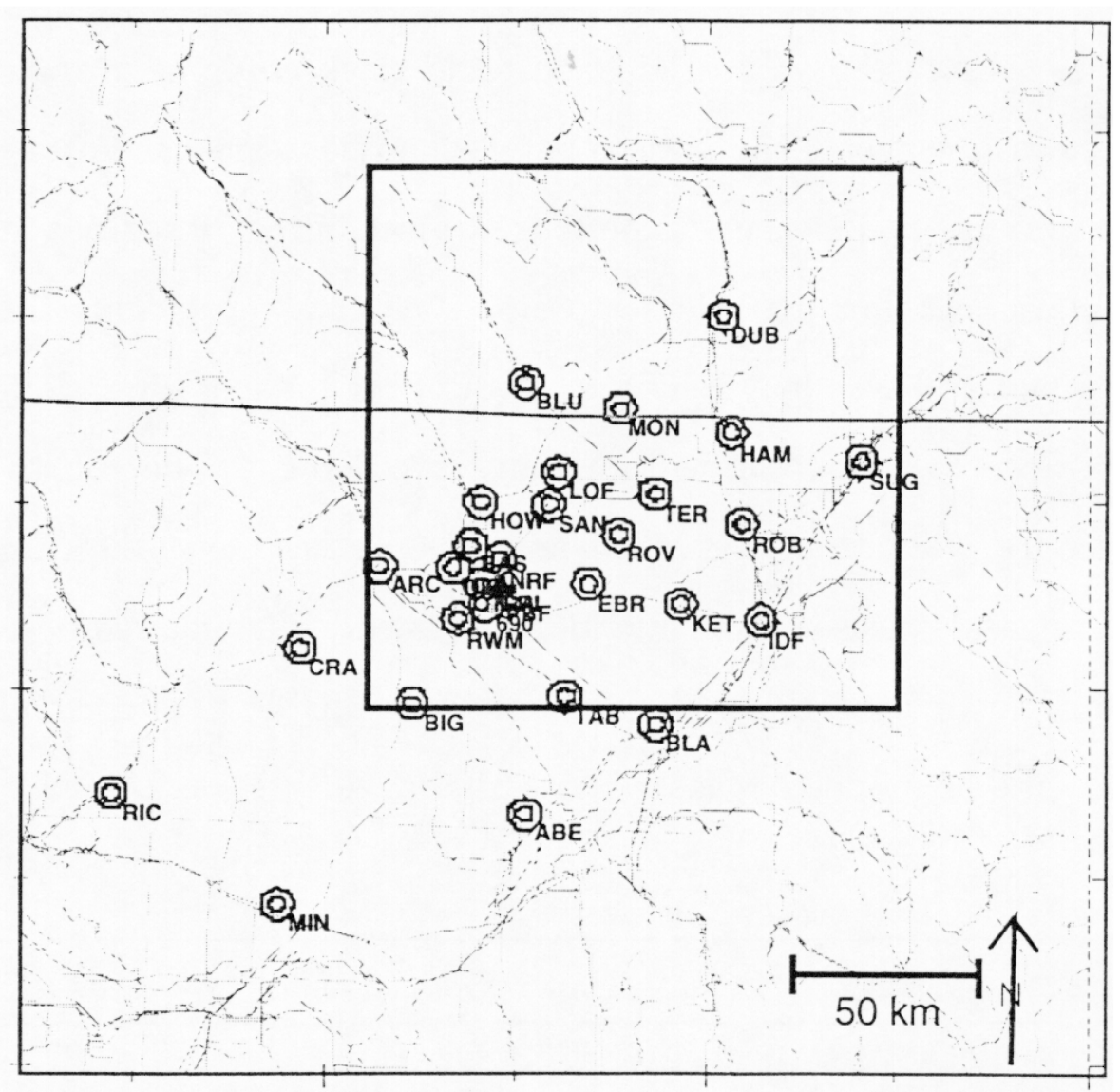

Figure 3.3 INEL Tower Network. (The box outlines the study area and the + is the release location.)

\subsubsection{Tracer Releases}

Six separate 3-hour releases of $\mathrm{SF}_{6}$ from a 15-m high stack with a $25.4 \mathrm{~cm}$ diameter were conducted. An aircraft engine start cart blew hot air into the stack generating a tracer exit velocity of $12 \mathrm{~m} / \mathrm{s}$ at a temperature of $200^{\circ} \mathrm{C}$. The $\mathrm{SF} 6$ was released at a rate of $60 \mathrm{~kg} / \mathrm{hr}$.

The criteria for an ideal release were defined as follows: 1) no precipitation at the release site or within $18.5 \mathrm{~km}$ of predicted plume path, 2) 2.5 to $12.5 \mathrm{~m} / \mathrm{s}$ 
transport winds, 3) a stable atmosphere, and 4) transport winds from either the northeast or southwest.

Table 3.1 lists the release times, dates, and special notes for each tracer release. Release 0 was used to test the stack equipment and the sampling detectors, however, a comparison between model results and measurements was not conducted. Release 1 experienced mechanical difficulty with the release apparatus causing the release to stop. After a short delay the release was continued and was lengthened to account for the lost time. Releases 2 and 3 went according to plan without any problems. The fourth release also proceeded without any problems and was used as the case for this study. The final release, Release 5, was intentionally extended in an attempt to lengthen the plume, however, the sampling teams were unable to successfully locate the plume and no model to measurement comparison was performed.

\section{Table 3.1 ACE III Tracer Releases}

\begin{tabular}{cccl}
\hline Release & Date & Release Time & Special Notes \\
\hline 0 & 12 OCT 93 & 1800 - 2100 UTC & Dry run \\
1 & 20 OCT 93 & 1600 - 1930 UTC & $\begin{array}{l}\text { Release extended to account for } \\
\text { mechanical difficulties }\end{array}$ \\
2 & 25 OCT 93 & 1245 - 1545 UTC & - \\
3 & 29 OCT 93 & $1400-1700$ UTC & \\
4 & 03 NOV 93 & 1315 - 1615 UTC & Used for this study \\
5 & 09 NOV 93 & 0700 - 1044 UTC & Release extended to lengthen plume \\
\hline
\end{tabular}

\subsubsection{Tracer Sampling}

A truck and an aircraft $\mathrm{SF}_{6}$ tracer measurement platform were employed in the tracer study. Each platform was instrumented with a Scientech TGA-4000 Electron Capture Detector that is capable of detecting $\mathrm{SF}_{6}$ above 10 ppt for real- 
time sampling at one-second intervals. Up to 60 one-second samples were averaged to produce the basic one-minute average tracer data set used to compare with model calculations. A truck mounted system attempted to intercept the plume using surface roads in the area. A C-90 King Air aircraft from NOAA was used to aerially intercept the plume and collect samples. The aircraft also measured and recorded GPS location, altitude, pressure, and temperature.

The truck and the aircraft both used an Aerospace Corporation Portable Atmospheric Sampling System (APASS) to collect the SF6 for laboratory analysis. The APASS traps in the truck were located at the ambient air inlet in which air was pumped through at 1.3 liters per minute. The aircraft pumped air through a $1 \mathrm{~m}$ long inlet tube leading to the APASS traps at 1.8 liters per minute. Prior to sampling, both systems were pre-conditioned by passing air through the traps.

Pre-positioning of the truck and the aircraft were attempted by the study team. However, the team met with minimal success due to the difficulty in forecasting the plume centerline in this complex environment. The sampling conducted by the truck was not continuous, and successful measurements were sporadic due to difficulty in accessing the plume via regular surface roads. However, aircraft samples successfully intercepted the plume during several legs of the flights.

\subsection{Additional Meteorological Data}

In addition to the data collected from the tower network during the study, more meteorological data was assembled for this modeling study. The additional data was initially only upper air data, but expanded to additional 
surface stations when the data was found to be available. This data was integrated with the tower data to provide a more complete rendering of the wind field. In most cases, model results are improved with more input information .

Additional hourly surface and upper air National Weather Service (NWS) data was obtained through the National Climatic Data Center's (NCDC) home page on the Internet. Figure 3.4 illustrates the locations of the NWS stations used in this study. These data include temperature, dew point temperature, wind direction, wind speed, and pressure.

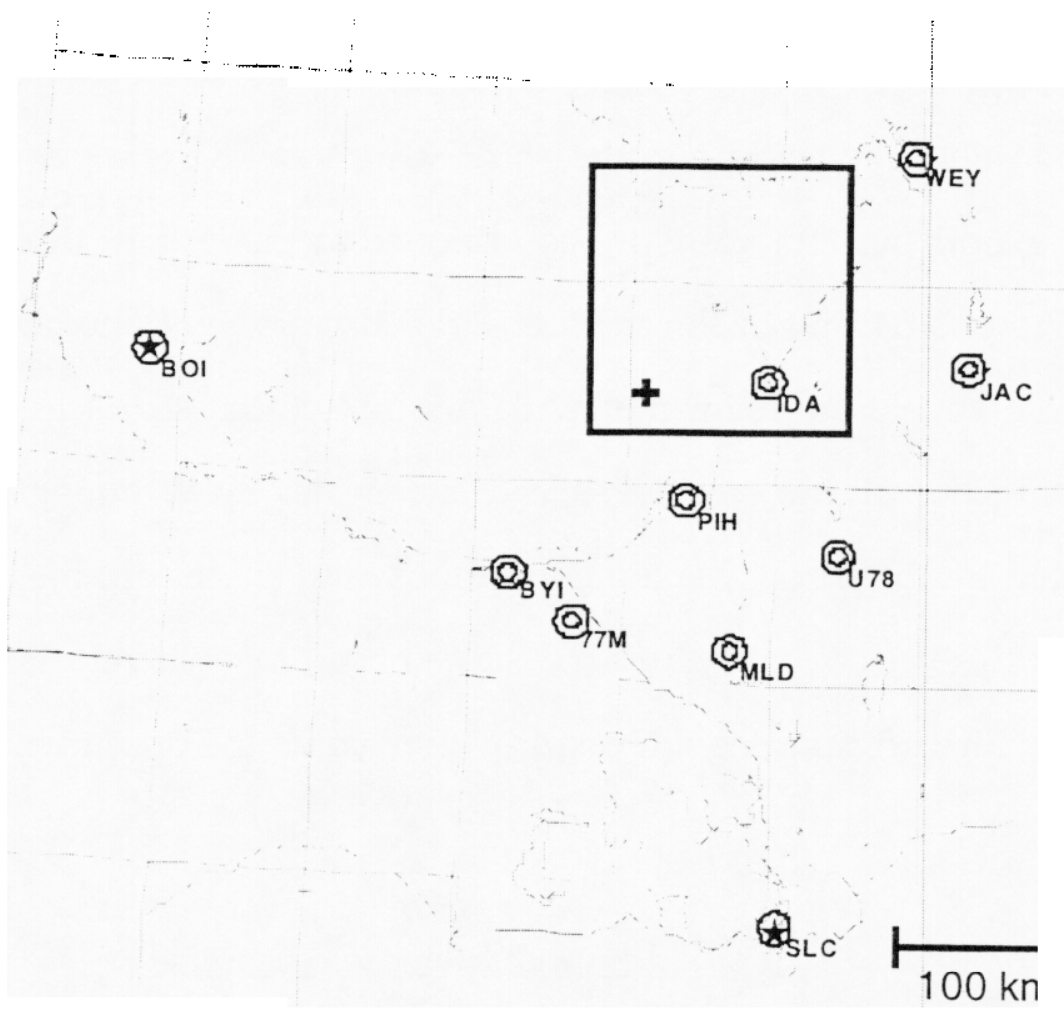

Figure 3.4 Location of NWS Surface (๑) and Upper Air (®) Stations. (The box outlines the study area and the + is the release location.) 
The ARAC has a Memorandum of Understanding with the Air Force Global Weather Central (AFGWC) to provide hourly surface data for the United States, synoptic and hourly data worldwide upon request, and worldwide gridded wind field analyses every 12 hours. ARAC receives AFGWC gridded wind fields with a horizontal resolution of $381 \mathrm{~km}$ for 15 levels in the vertical $(1000,850,700,500,400,300,250,200,150,100,70,50,30,20$, and $10 \mathrm{mb})$. These wind fields are an interpolation from the $2.5 \times 2.5$ degree latitude-longitude, 15 vertical level AFGWC model output. Figure 3.5 shows the location of the grid points from the gridded wind field used in this study to represent the synoptic flow.

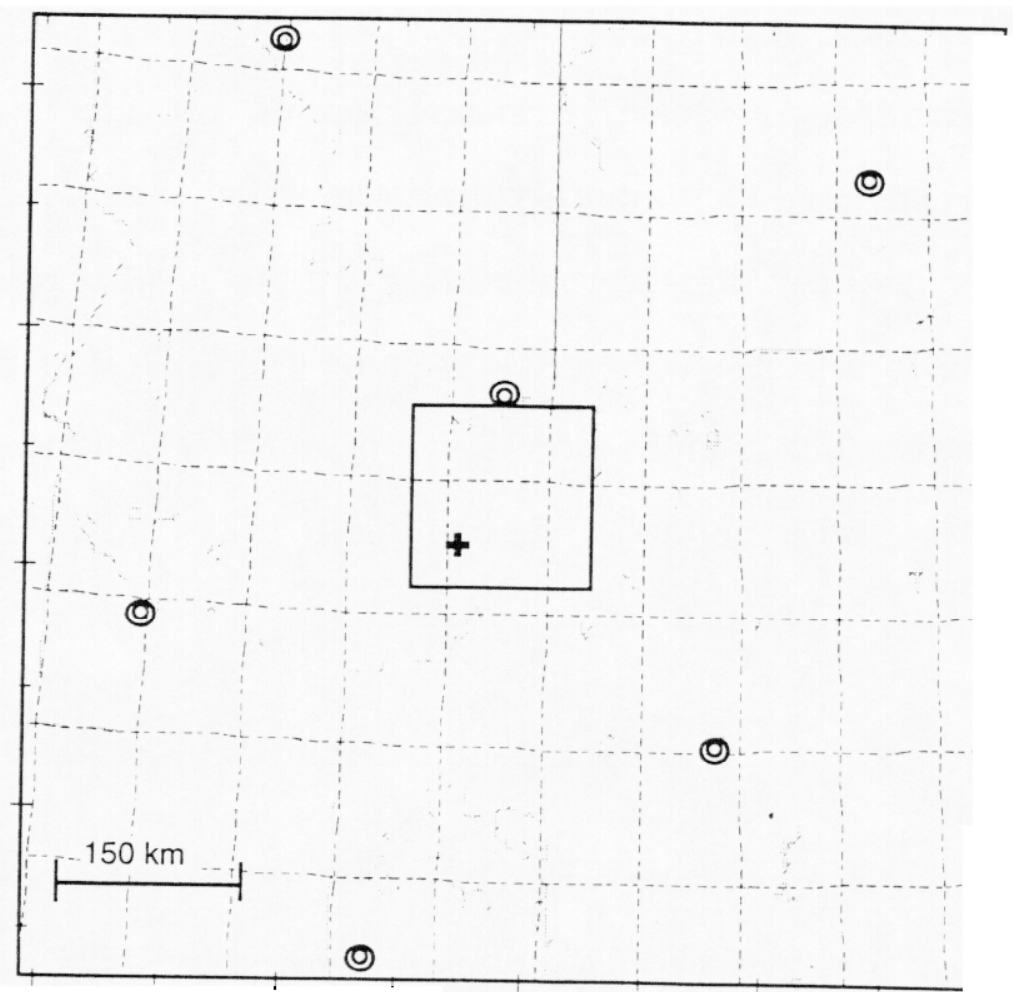

Figure 3.5 Location of AFGWC Grid points. (The box outlines the study area and the + is the release location.) 


\section{CHAPTER 4}

\section{INPUT PARAMETERS AND SENSITIVITY STUDIES}

\subsection{Selection of Tracer Experiment}

The ARAC models were compared to Releases 1 through 4 of the six AFTAC ACEIII tests at INEL. The two other releases, Release 0 and 5, were not compared due to incomplete data. Of the four comparisons one tracer release was selected to be the focus of this study to explain the comparison process in detail.

The major criterion for selection was the completeness of the meteorological, aircraft and truck sampling data. The data received from the Air Force was examined for continuity throughout the study period and discussions with experiment personnel revealed they had the most confidence in the quality of the data from Release 4 on 3 November 1993. During Release $4, \mathrm{SF}_{6}$ was released between 1315 and 1615 UTC, and sampling continued until 2315 UTC. The study period is defined as beginning at 1315 UTC 3 November 1993 and concluding at 2315 UTC 3 November 1993.

\subsection{Release 4 Synoptic Weather Description}

Figure 4.1 present the surface weather and $500 \mathrm{mb}$ isoheight charts at 1200 UTC 03 November 1993 and 1200 UTC 04 November 1993. At 1200 UTC on 03 November 1993, Figure 4.1(a), an area of weak high pressure was located over the four corners region of New Mexico, Arizona, Colorado and Utah, and an area 
of low pressure was centered in Alberta, Canada. Trailing to the south and southwest of the low was a combined cold and stationary front that extended off the continent near the Washington-Oregon state border that generated some coastal precipitation in Washington. Another stationary front extended westward into the Gulf of Alaska.

The 1200 UTC $500 \mathrm{mb}$ chart of 03 November 1993, Figure 4.1(b), shows an area of low heights centered in northwestern Ontario over Hudson's Bay. A trough extended south from this area through western Illinois. Another trough existed in northwestern Alberta and extended through the western edge of Washington state. A ridge was also building off the west coast of North America. The winds at $500 \mathrm{mb}$ were generally from the northwest in our region of interest.

The surface pattern changed significantly over the next 24 hours. Figure 4.1(c) shows that the high pressure in the four corners area significantly weakened and drifted south. The low pressure center moved southeast from central Alberta to northwestern Iowa, and a front passed through the study area bringing cooler temperatures and scattered traces of precipitation, however, no precipitation was reported during the study period. An area of high pressure began to build over the Pacific Northwestern United States forcing a second frontal system eastward and away from our study region.

The 1200 UTC $500 \mathrm{mb}$ pattern for 04 November also changed significantly, Figure 4.1(d). The low over northwestern Ontario filled and moved east, and the western trough associated with the front in northwestern Alberta deepened and moved into western North Dakota. The amplitude of the ridge off the west coast increased the northern component of the wind in the study area. 


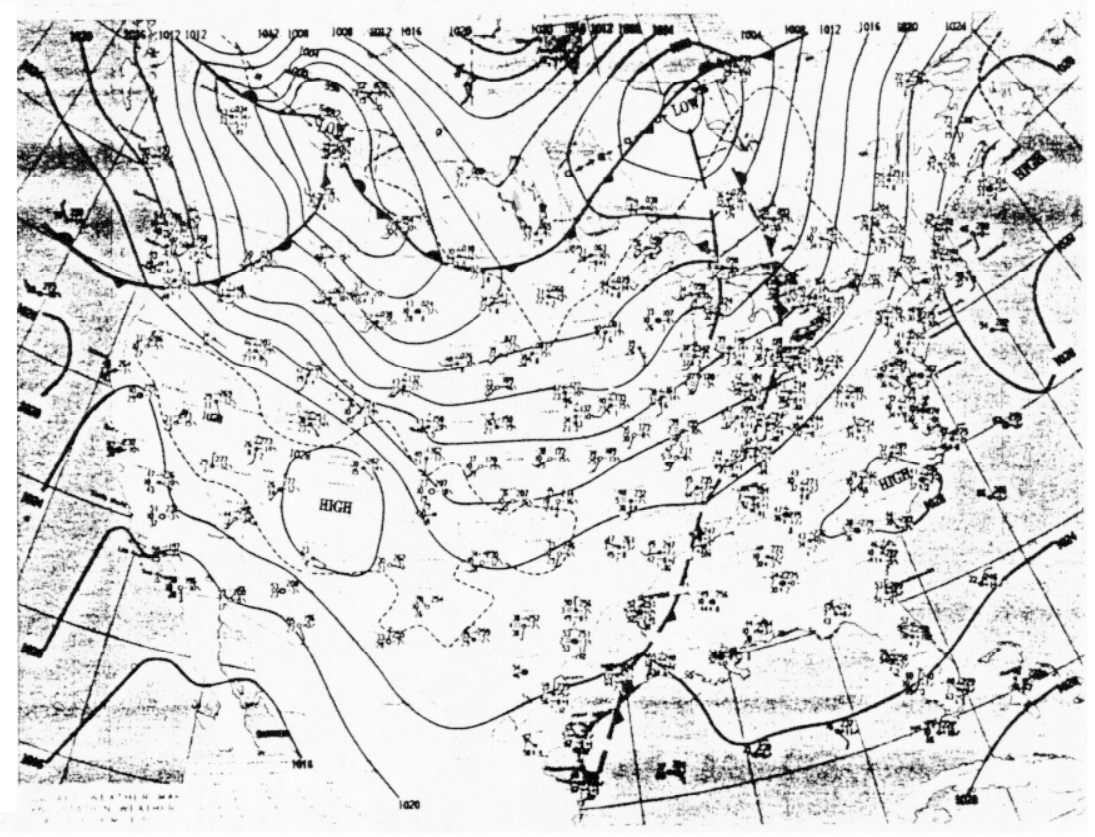

(a)

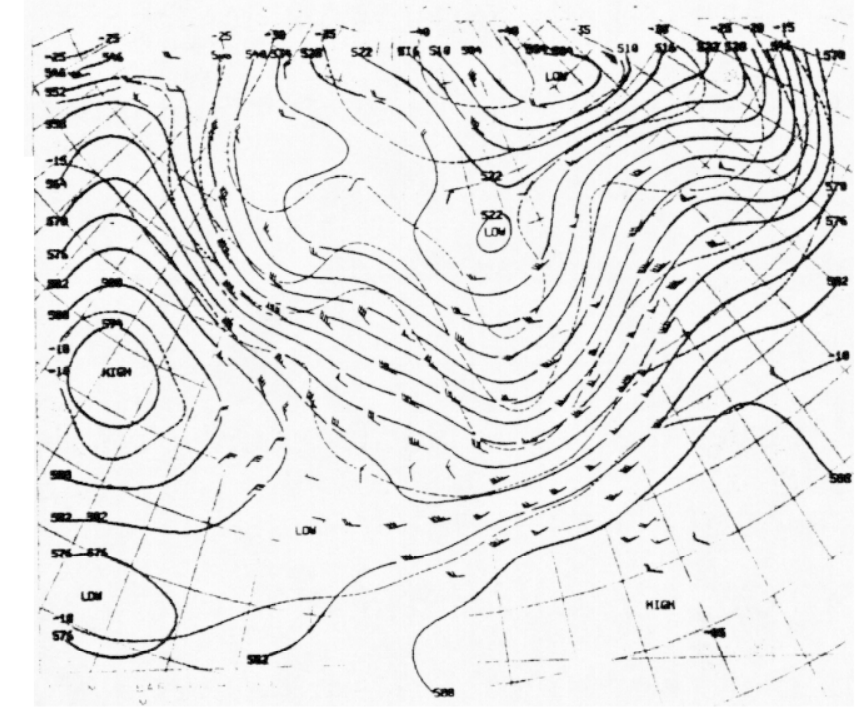

(b)

Figure 4.1 US Surface Analysis (a) and North American $500 \mathrm{mb}$ (b) Analysis for 1200 UTC 03 November 1993. 


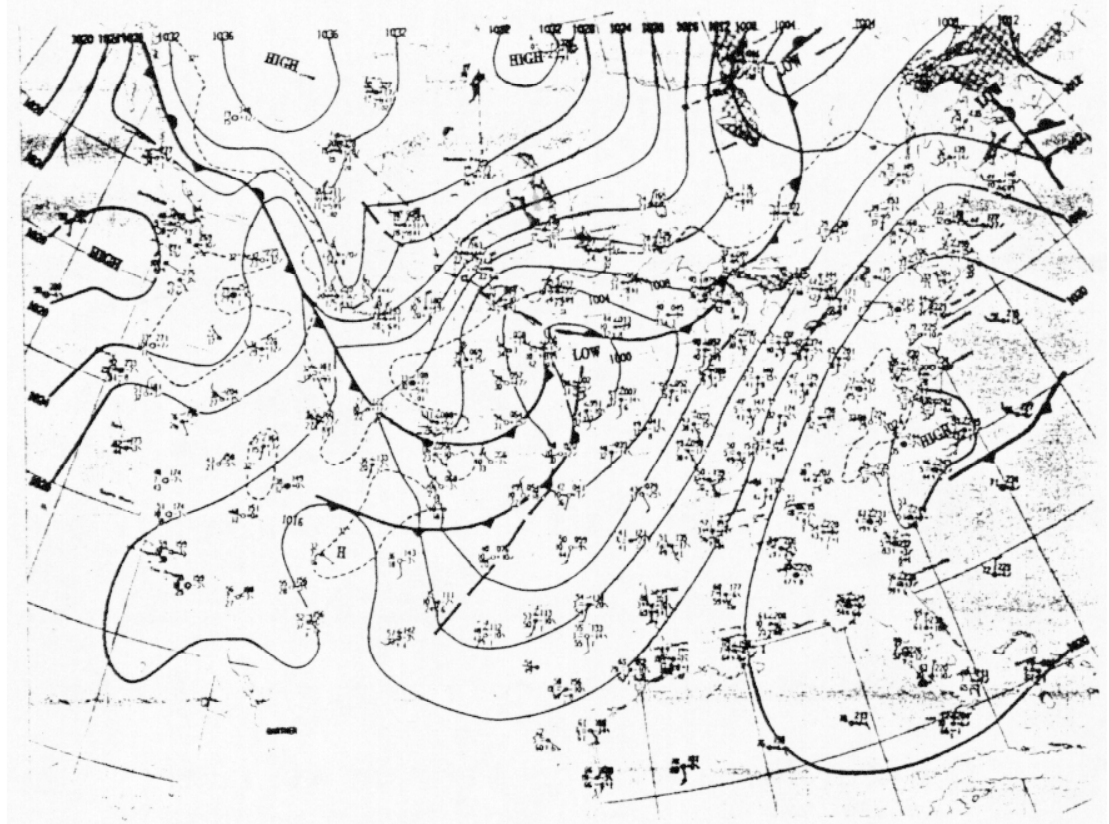

(c)

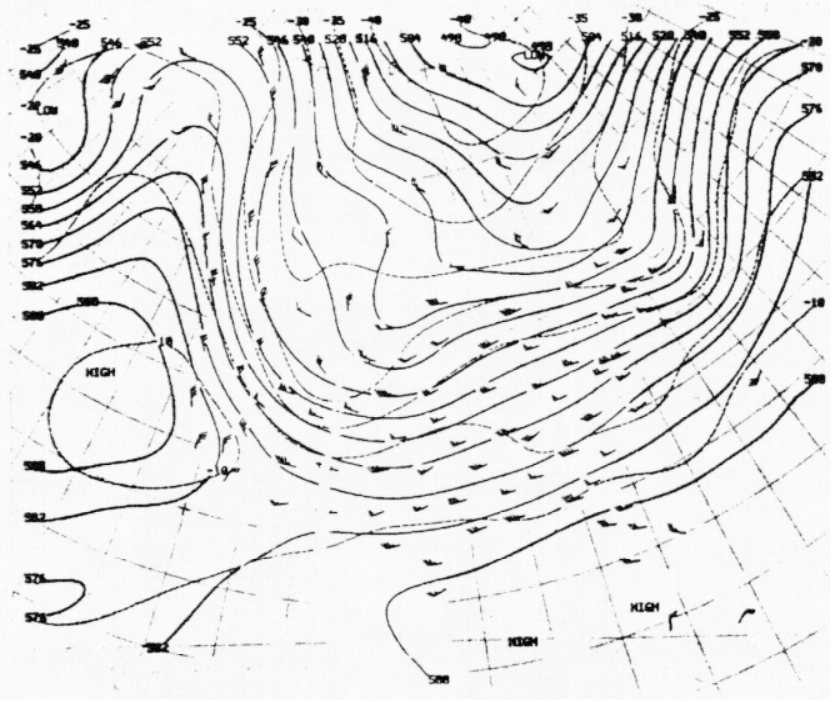

(d)

Figure 4.1 US Surface Analysis (c) and North American $500 \mathrm{mb}$ (d) Analysis for 1200 UTC 04 November 1993. 


\subsection{Tracer Measurement Data}

The comparison between the models and measurements is presented qualitatively due to the small number of samples and a lack of verifiable quantitative tracer concentration values. For example some measurements by the truck were reported simply as "hits", or "no plume", but without measurement values. Figures 4.2 and 4.3 display the limited amount of aircraft and truck $\mathrm{SF}_{6}$ measurement data used to compare with model calculations. The data are represented as a "hit" or a "miss", where a "hit" (filled circle or box) is when $\mathrm{SF}_{6}$ was detected by the truck or aircraft, and a "miss" (open circle or box) is when a one-minute average measurement was taken but the $\mathrm{SF}_{6}$ concentration was below the 10 ppt detection limit.

Figure 4.2 shows that the first measurement taken by the truck at 1413 UTC was a "hit". The truck continued northeast and sampled at 1445 UTC, but $\mathrm{SF}_{6}$ was not detected. The next two measurements near the center of the domain at 1515 UTC and 1545 UTC also detected no tracer. Another truck sample back to the west at 1651 UTC did not detect $\mathrm{SF}_{6}$. However, $\mathrm{SF}_{6}$ was detected at 1719 UTC near the center of the study area, and to the east at 2019 UTC. The final truck measurement in the extreme north of the domain at 2106 UTC was a "miss".

The truck sampling data was determined to be of low quantity with only seven measurements taken over the 10-hour study period. This data was also determined to be of low quality as discussions with experiment personnel revealed that truck data had been questionable and unreliable in earlier ACE studies. 


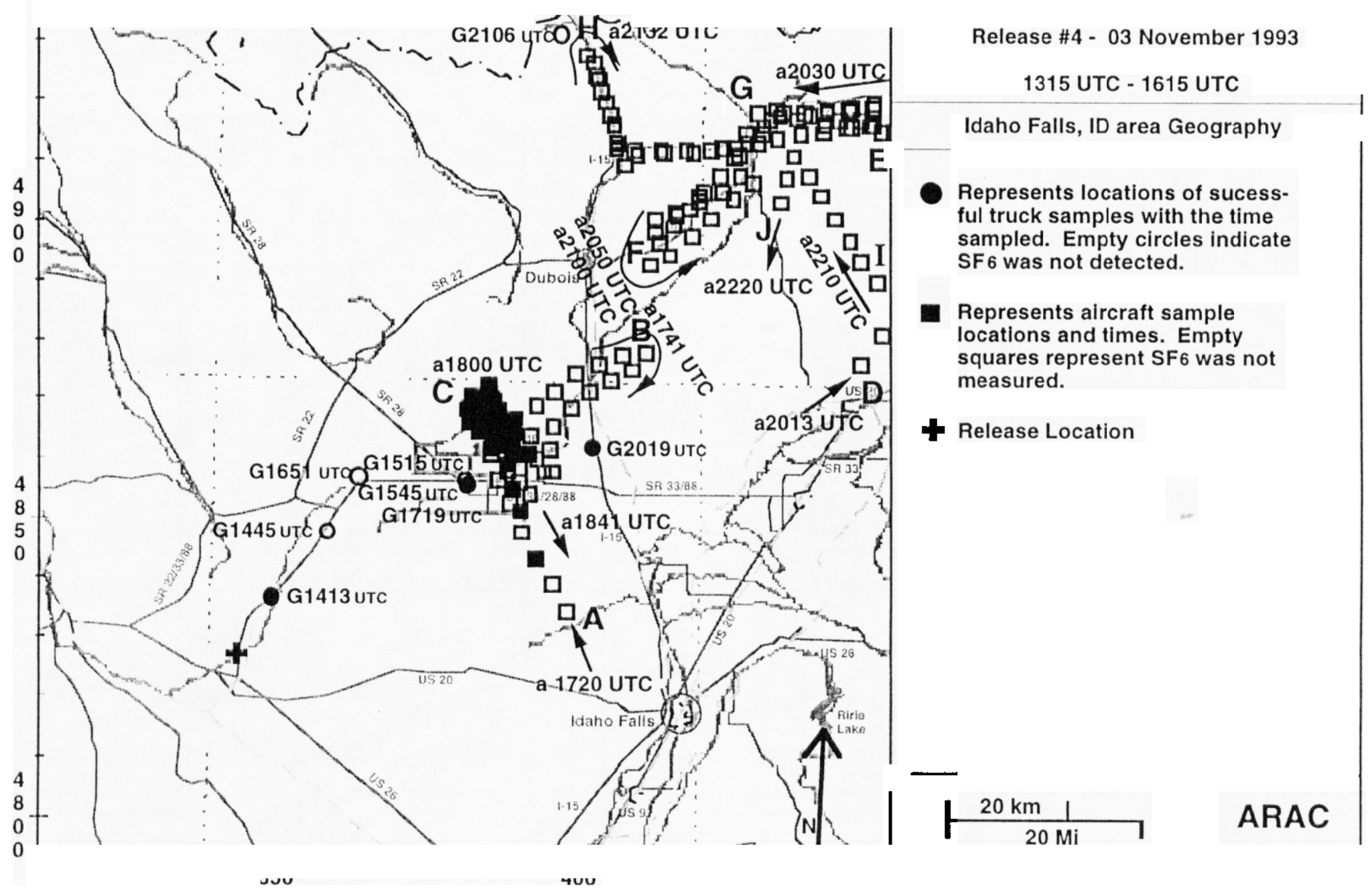

Figure 4.2 Truck ( O ) and aircraft ( $\square$ ) measurement locations for Release \#4, 03 November 1993. 


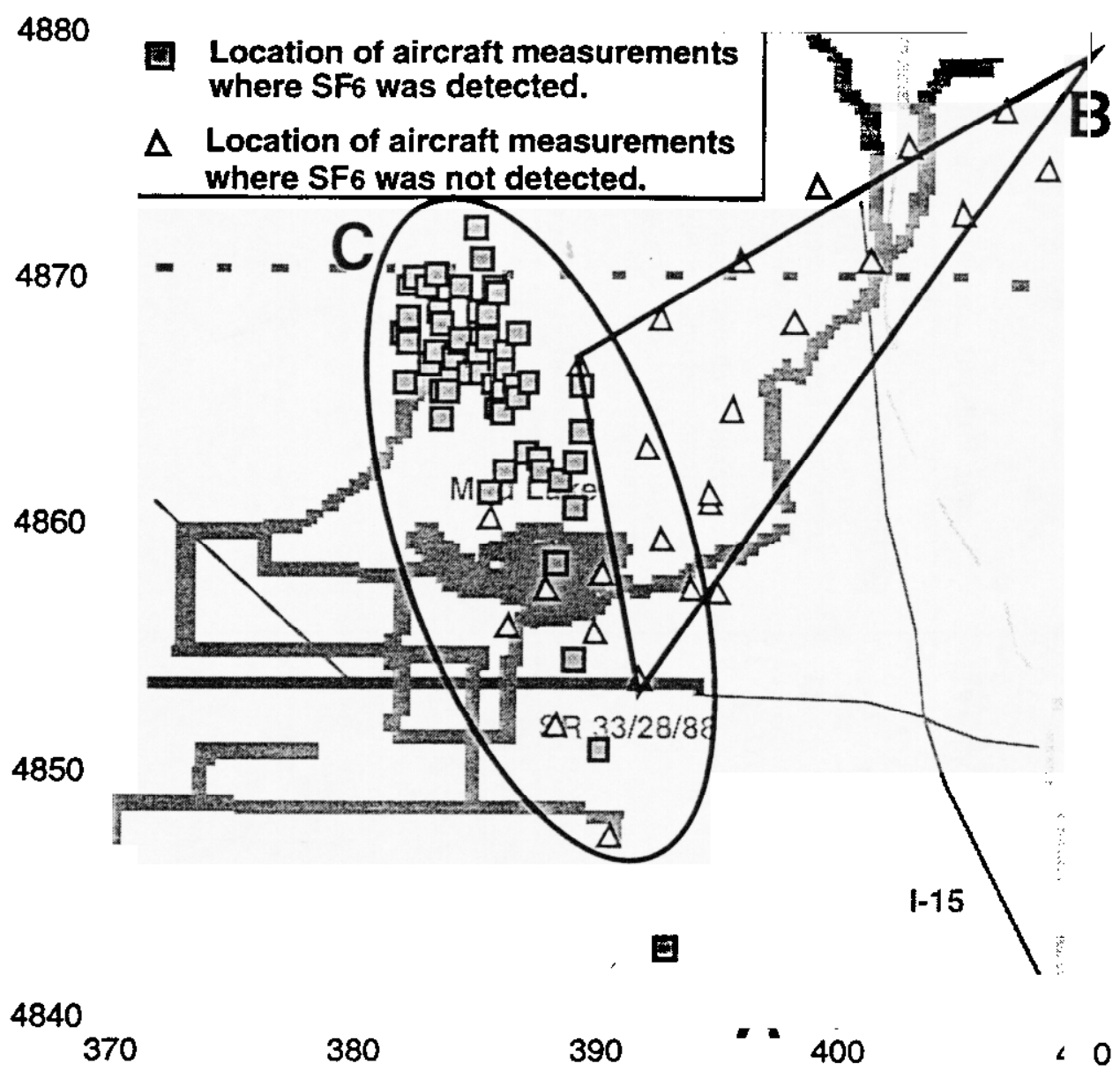

Figure 4.3 Zoomed-in view of aircraft measurement locations where SF6 was detected (oval outline), and was not detected (triangle outline).

The squares in Figure 4.2 and the squares and triangles in Figure 4.3 represent the locations of the one-minute averaged $\mathrm{SF}_{6}$ measurement data from the aircraft. Figure 4.2 illustrated the flight path of the aircraft that began at point $A$ at 1720 UTC. The plane flew north and then northeast to point B at 1740 UTC. The aircraft proceeded back towards the center of the domain to point $C$, and flew many circles in this area until 1840 UTC when tracer measurement stopped, and the aircraft returned to base. The measurements restarted at point $D$ at 2010 UTC and went out of the domain, but re-entered at 2030 UTC at point E. The 
aircraft flew two loops between point $F$ and point $G$ at 2050 UTC and 2100 UTC, and then returned to point $E$ at 2115 UTC. The plane flew the path through point $G$ to point $H$, and then returned to point $E$ once again. After reaching point $E$ at 2150 UTC the aircraft went out of the domain, but reentered at point I at 2210 UTC and flew to point $J$ where the measurements ended at 2220 UTC. The entire flight varied from $125 \mathrm{~m}$ to $750 \mathrm{~m}$ above the surface. The aircraft only detected $\mathrm{SF}_{6}$ between 1748 and 1841 UTC southeast of point $C$ at $200 \mathrm{~m}$ above the surface.

The aircraft measurement data was considered to be of good quality as the equipment was monitored and calibrated several times during flight. Although measurements were taken once-per-second and averaged to a one-minute value, the aircraft collected only a line of instantaneous point measurements and thereby provided a limited amount of information on plume dispersion. In addition, the aircraft data was determined to be of low quantity since the aircraft only intercepted the $\mathrm{SF}_{6}$ plume for 53 minutes of the 5-hour flight in a small area about $55 \mathrm{~km}$ from the source. Without a set of tracer data in a structured scheme from fixed samplers or in regular sampling patterns, a true determination of plume path is difficult.

\subsection{Determination of Model Input}

Several sensitivity studies were done in order to determine the best model input parameter values for modeling the release scenarios. The models were executed with parameter values taken from the raw data, and compared to the tracer measurement data to decide what input values best represented the study area environment. When model results and tracer measurements did not match, 
the raw data was re-examined and new input values were selected to re-execute the models. These sensitivity studies represent the integration of numerical modeling and limited tracer measurements in an attempt to better interpret the dispersion pattern.

Realistic simulation of plume dispersion requires that the transport layer be well characterized by both model inputs and model physics. The input parameters that define the transport layer in TOPOG, MEDIC, CG-MATHEW, and ADPIC are grid dimension, grid resolution, atmospheric stability, turbulent diffusion, boundary layer height, wind field, and mixing layer height. The importance of selecting appropriate values for each of these parameters determines how well the model calculations will agree with measurement data.

\subsubsection{TOPOG}

Care must be taken to select an appropriate model domain and grid depth. Too shallow of a grid, albeit higher resolution, may be useless if there are significant terrain features and tracer sampling at higher elevations. Similarly, if a grid is too deep, terrain features which affect flows may not be well represented. Consequently, TOPOG was executed several times to find the "bestfit" grid. The final grid was selected to be $1200 \mathrm{~m}$ deep, this was sufficient to incorporate the majority of the higher terrain features, yet shallow enough to resolve some of the smaller features. The vertical grid is constructed above the lowest elevation point within the domain, which was $1368 \mathrm{~m}$ ASL, so grid cells that have an average terrain height above $2568 \mathrm{~m}$ ASL extend above the modeling domain. The effects of excluding the mountain peaks are not significant, since the main transport area is in the lower $600 \mathrm{~m}$ of the grid. To 
include the mountain peaks would cause a smoothing of the grid bottom, and remove significant terrain features thus having an effect on plume dispersion.

The modeling grid also needs to encompass the truck and aircraft sampling locations, horizontally and vertically. For this study the grid domain was selected to be approximately $140 \times 140 \mathrm{~km}$ horizontally with the release point located in the southwest corner. The release point was positioned in this location to maximize the use of space within the grid domain in the direction of plume transport.

A set of codes with higher resolution than the standard operational version was used in this study. The factor of two increase in vertical resolution was the primary reason the enhanced version ( $50 \times 50 \times 30$ grid cells) of the operational models ( $40 \times 40 \times 14$ grid cells) were used. This provided better resolution of the terrain and wind vectors in the region where the tracer is transported. Each grid cell was $2.813 \mathrm{~km}$ by $2.813 \mathrm{~km}$ horizontally, and $40 \mathrm{~m}$ vertically. Figure 4.4 shows the model domain defined by TOPOG, where the darkest areas represent the lowest terrain, and the white areas represent terrain extending above the domain. Each gray shade represents a range of six $\Delta z$ (240 $\mathrm{m})$.

The models use the Universal Transverse Mercator (UTM) coordinate projection. This is a widely accepted projection in regional mapping of areas less than $1000 \mathrm{~km}$ that generates minimal distortion. The UTM projection defines the earth as 60 cylinders of $6^{\circ}$ longitude where each cylinder is defined by the central meridian. In the Northern Hemisphere the origin of each cylinder is the Equator and the Central Meridian, with an $x$, Easting (UTME), value of $500 \mathrm{~km}$ and a $y$, Northing (UTMN), value of $0 \mathrm{~km}$ (Snyder, 1987). The UTM format is a conformal 
projection in which relative directions scale correctly to a Cartesian coordinate system by simple vector rotation.

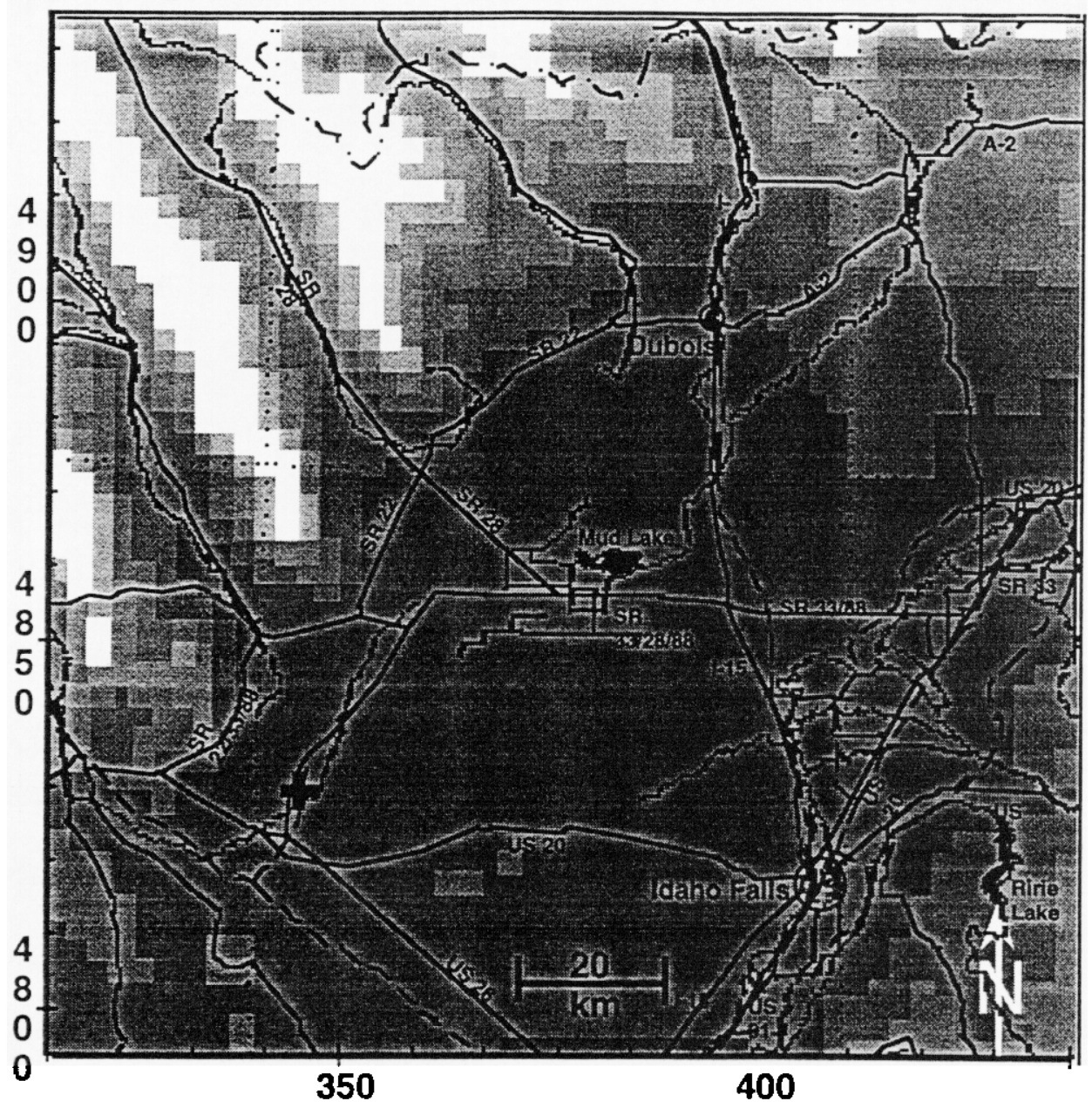

Figure 4.4 The Model Study Area with TOPOG grid cells. (The + denotes the release location.)

\subsubsection{Meteorological Data Input}

The generation of the wind field is one of the most critical components to the entire model run. In most cases, the more input data available, the better the result. With this in mind, a search for all available meteorological data in this 
region during the study period was conducted. All the data acquired was integrated into 15-min data sets for the 10-hour model run.

4.4.2.1 Surface data. The 5-min data from the 31-tower INEL network were averaged into 15-min data sets ending each quarter hour. The temperatures were scalar averaged and the winds were vector averaged. Forty 15-minute data sets were used in the 10-hour model run from 1315 to 2315 UTC. The dense tower data were quality assured by ARLFRD. They represent high quality and excellent coverage at the surface in the study area.

Each hour of the model run was broken into four quartiles of 15 minutes each. These quartiles were used to define the valid time of the NWS surface observations. The 1-minute manual NWS observations were only used during the quartile in which they were taken. For example, an observation taken at Pocatello, PIH, at 1550 UTC was input into the 1600 UTC quartile data set valid from 1545 to 1600 UTC. Compared to the INEL tower network data the NWS data was of low quality and low quantity.

4.4.2.2 Tetroon data. Wind data were also derived from the tetroon flights. Two tetroons were released and tracked during tracer Release 4 . The first flight began at 1230 UTC, 45 minutes prior to the start of the tracer release, and continued until 1620 UTC. A second tetroon flight occurred between 1621 and 2117 UTC, after the tracer release ended. Tables 4.1 and 4.2 list the recorded locations of the tetroons during Release 4 with the calculated wind speed and direction and Figure 4.5 shows the flight paths of these two balloons. Average wind speeds and directions were calculated based on the times and locations reported during flight and were assumed to be constant between reports. The wind data from the tetroon was input into the appropriate quartile 
meteorological data (metdata) set at the reported height. Although the tetroon data was able to provide some information about the estimated transport layer, the limited number of data points and overall representativeness compared to the INEL tower network was of low quality and quantity.

Table 4.1 Tetroon 1 flight data and calculated wind

\begin{tabular}{cccccc}
\hline $\begin{array}{c}\text { Time } \\
(\text { UTC })\end{array}$ & $\begin{array}{c}\text { UTME } \\
(\mathrm{km})\end{array}$ & $\begin{array}{c}\text { UTMN } \\
(\mathrm{km})\end{array}$ & $\begin{array}{c}\text { Height } \\
(\mathrm{m})\end{array}$ & $\begin{array}{c}\text { Wirection } \\
(\mathrm{deg})\end{array}$ & $\begin{array}{c}\text { Wind } \\
\text { Speed } \\
(\mathrm{m} / \mathrm{s})\end{array}$ \\
\hline 1230 & 343.261 & 4828.357 & - & - & - \\
1330 & 365.155 & 4850.664 & 310 & 225 & 8.7 \\
1400 & 374.072 & 4854.545 & 255 & 247 & 5.4 \\
1415 & 380.004 & 4857.891 & 120 & 241 & 7.6 \\
1430 & 387.361 & 4862.750 & 250 & 237 & 9.8 \\
1445 & 394.922 & 4868.547 & 140 & 233 & 10.6 \\
1515 & 407.603 & 4878.467 & 200 & 232 & 8.9 \\
1545 & 414.974 & 4892.732 & 234 & 207 & 8.9 \\
1600 & 415.015 & 4899.030 & 100 & 180 & 7.0 \\
1620 & 410.977 & 4904.550 & 150 & 144 & 5.7 \\
\hline
\end{tabular}

Table 4.2 Tetroon 2 flight data and calculated wind

\begin{tabular}{cccccc}
\hline $\begin{array}{c}\text { Time } \\
(\mathrm{UTC})\end{array}$ & $\begin{array}{c}\text { UTME } \\
(\mathrm{km})\end{array}$ & $\begin{array}{c}\text { UTMN } \\
(\mathrm{km})\end{array}$ & $\begin{array}{c}\text { Height } \\
(\mathrm{m})\end{array}$ & $\begin{array}{c}\text { Wind } \\
\text { Direction } \\
(\mathrm{deg})\end{array}$ & $\begin{array}{c}\text { Wind } \\
\text { Speed } \\
(\mathrm{m} / \mathrm{s})\end{array}$ \\
\hline 1621 & 343.261 & 4828.357 & - & - & - \\
1630 & 349.061 & 4830.542 & 135 & 250 & 11.5 \\
1710 & 374.365 & 4850.440 & $\mathrm{M}$ & 232 & 13.4 \\
1800 & 386.764 & 4872.459 & 260 & 209 & 8.4 \\
1900 & 392.498 & 4884.218 & 200 & 206 & 3.6 \\
2000 & 401.554 & 4886.531 & 140 & 256 & 2.6 \\
2100 & 412.310 & 4895.033 & $\mathrm{M}$ & 232 & 3.8 \\
\multicolumn{7}{l}{ M denotes missing values } & & & \\
\hline
\end{tabular}




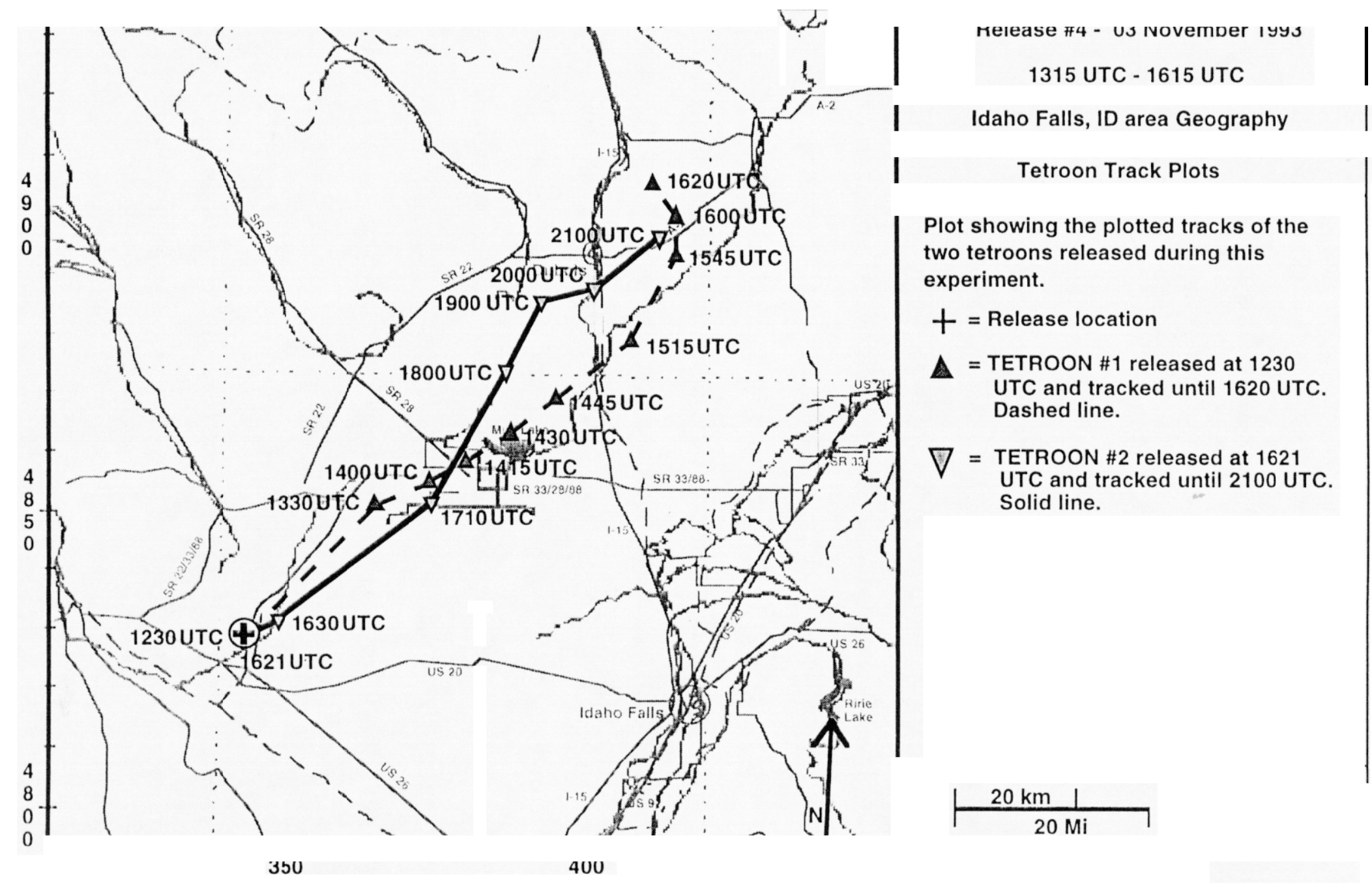

Figure 4.5 Flight paths of the two tetroons released during Release \#4, 03 November 1993. -9 denotes the tetroon and tracer release point. 
4.4.2.3 Upper air data. The INEL tower network data provided a good foundation for the surface and lower level wind fields of the study domain with additional support from the NWS surface stations and tetroons. NOAA operated a portable rawinsonde unit and a vertical atmospheric sounder at the release site. However, this equipment experienced mechanical problems and did not produce any usable data. Therefore, sources of other upper air data were explored in order to provide adequate model inputs. The initial data acquired were the gridded fields generated by the GWC. As was previously shown, most data grid points were not located near to the study region and only the data at standard pressure levels were available. The GWC gridded upper air data was of low quantity and moderate quality, and was only used to construct a gross vertical structure in the general region surrounding the study area.

NWS rawinsonde data from the Boise, Idaho and Salt Lake City, Utah were obtained for 1200 UTC 03 November 1993 and 0000 UTC 04 November 1993. This data provides more vertical structure detail than the GWC gridded data. However, these stations were 260 and $320 \mathrm{~km}$ from the release site. In addition, both of these reporting stations are in different topographic settings as illustrated in Figure 4.6. Boise, Idaho is located in the Snake River Plain west of the study area, but is in a northwest-southeast oriented valley. Salt Lake City, Utah is on the eastern edge of the Great Salt Lake and Great Salt Lake Desert with scattered north-south oriented ridges. Tables 4.3 and 4.4 list and Figures 4.7 and 4.8 show the rawinsonde data from these stations for 1200 UTC 03 November and 0000 UTC 04 November 1993. Both 1200 UTC rawinsonde reports had surface winds from the southeast that veered to the west-northwest with height. However, the 0000 UTC soundings were different, where the Salt 
Lake City wind data continued to veer to the west-northwest with height, but the surface wind changed to be from the northeast. At Boise, the surface winds changed to be from the northwest and backed slightly with height with the upper level winds from the west-northwest.

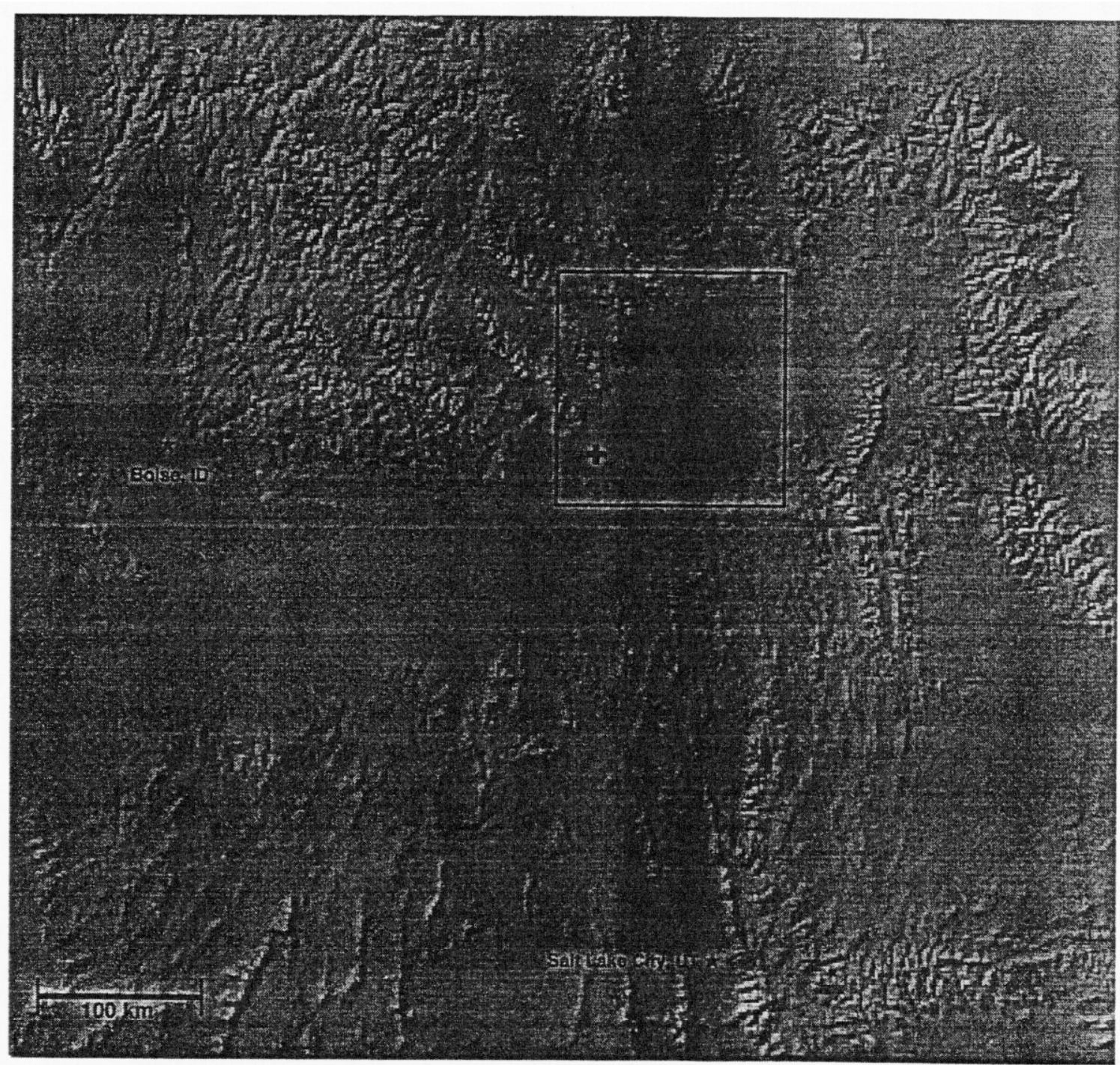

Figure 4.6 Topographic setting of rawinsonde stations and study area. (The box outlines the study area, $\downarrow$ denotes the release location, and $\star$ represents the rawinsonde stations.) 
Table 4.3 Rawinsonde data for 1200 UTC 03 November 1993.

\begin{tabular}{cccc||cccc}
\hline (SLC) & \multicolumn{2}{c||}{ Salt Lake City, Utah } & (BOI) & \multicolumn{3}{|c}{ Boise, Idaho } \\
\hline $\begin{array}{c}\text { Height } \\
\text { above } \\
\text { surface } \\
(\mathrm{m})\end{array}$ & Temperature & $\begin{array}{c}\text { Wind } \\
\text { Direction } \\
(\mathrm{deg})\end{array}$ & $\begin{array}{c}\text { Wind } \\
\text { Speed } \\
(\mathrm{m} / \mathrm{s})\end{array}$ & $\begin{array}{c}\text { Height } \\
\text { above } \\
\text { surface } \\
(\mathrm{m})\end{array}$ & $\begin{array}{c}\text { Temperature } \\
\text { (C) }\end{array}$ & $\begin{array}{c}\text { Wind } \\
\text { Direction } \\
\text { (deg) }\end{array}$ & $\begin{array}{c}\text { Wind } \\
\text { Speed } \\
(\mathrm{m} / \mathrm{s})\end{array}$ \\
\hline 1 & 3.3 & 130 & 4 & 1 & 7.4 & 120 & 4 \\
11 & 3.9 & 132 & 4 & 81 & 12.0 & 135 & 5 \\
71 & 4.1 & 140 & 6 & 111 & 12.3 & 141 & 5 \\
161 & 6.2 & 152 & 8 & 191 & 11.8 & 155 & 5 \\
281 & 6.0 & 165 & 10 & 661 & 9.5 & 255 & 8 \\
391 & 5.7 & 166 & 9 & 801 & 8.3 & 262 & 10 \\
591 & 6.7 & 177 & 7 & 1161 & 7.1 & 278 & 12 \\
771 & 5.7 & 206 & 4 & 1341 & 6.4 & 284 & 13 \\
1291 & 1.9 & 273 & 7 & 1691 & 3.7 & 287 & 15 \\
1401 & 1.2 & 276 & 8 & 1711 & 3.4 & 287 & 15 \\
1471 & 0.7 & 279 & 8 & & & & \\
1531 & 0.1 & 282 & 8 & & & & \\
\hline
\end{tabular}

Table 4.4 Rawinsonde data for 0000 UTC 04 November 1993.

\begin{tabular}{|c|c|c|c|c|c|c|c|}
\hline (SLC) & Salt Lake C & ity, Utah & & (BOI) & Boise, Ida & & \\
\hline $\begin{array}{c}\text { Height } \\
\text { above } \\
\text { surface } \\
\text { (m) }\end{array}$ & $\begin{array}{c}\text { Temperature } \\
\text { (C) }\end{array}$ & $\begin{array}{l}\text { Wind } \\
\text { Direction } \\
\text { (deg) }\end{array}$ & $\begin{array}{l}\text { Wind } \\
\text { Speed } \\
(\mathrm{m} / \mathrm{s})\end{array}$ & $\begin{array}{l}\text { Height } \\
\text { above } \\
\text { surface } \\
\text { (m) }\end{array}$ & $\begin{array}{c}\text { Temperature } \\
\text { (C) }\end{array}$ & $\begin{array}{l}\text { Wind } \\
\text { Direction } \\
\text { (deg) }\end{array}$ & $\begin{array}{l}\text { Wind } \\
\text { Speed } \\
(\mathrm{m} / \mathrm{s})\end{array}$ \\
\hline 1 & 12.8 & 15 & 4 & 1 & 15.3 & 310 & 7 \\
\hline 51 & 12.5 & 40 & 4 & 31 & 15.3 & 310 & 8 \\
\hline 201 & 11.6 & 114 & 5 & 61 & 14.8 & 310 & 9 \\
\hline 491 & 10.6 & 191 & 5 & 131 & 14.3 & 311 & 10 \\
\hline 701 & 8.8 & 220 & 4 & 611 & 10.0 & 312 & 13 \\
\hline 1231 & 4.7 & 263 & 10 & 1111 & 5.6 & 300 & 11 \\
\hline \multirow[t]{3}{*}{1791} & 0.2 & 275 & 15 & 1301 & 3.8 & 289 & 12 \\
\hline & & & & 1631 & 0.8 & 279 & 13. \\
\hline & & & & 1711 & 0.1 & 277 & 14 \\
\hline
\end{tabular}


(km) ASL / AGL

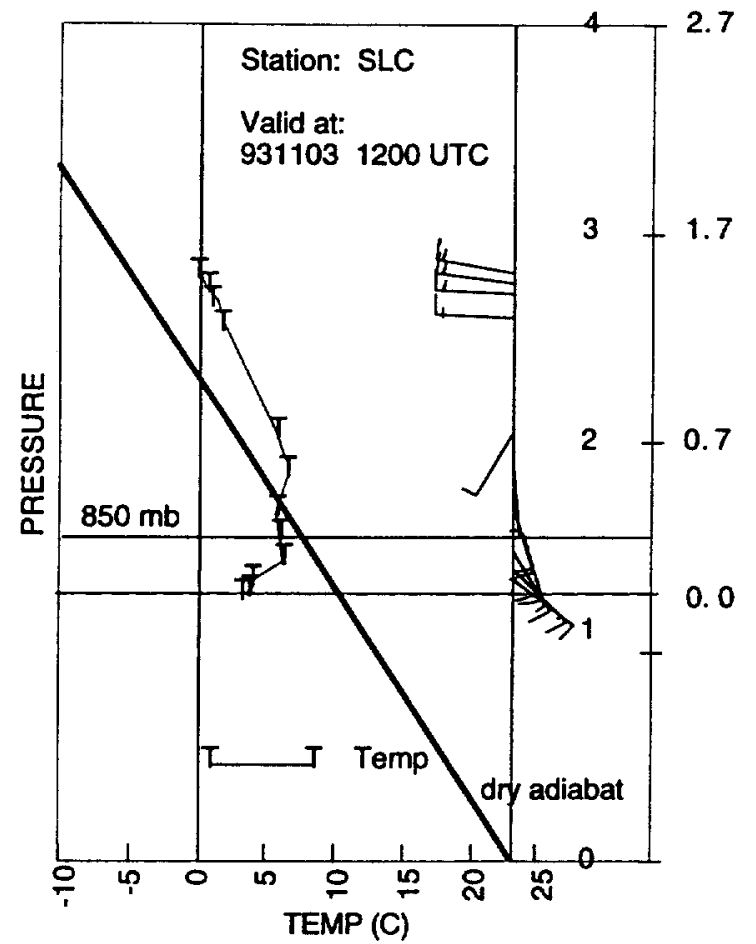

(a)

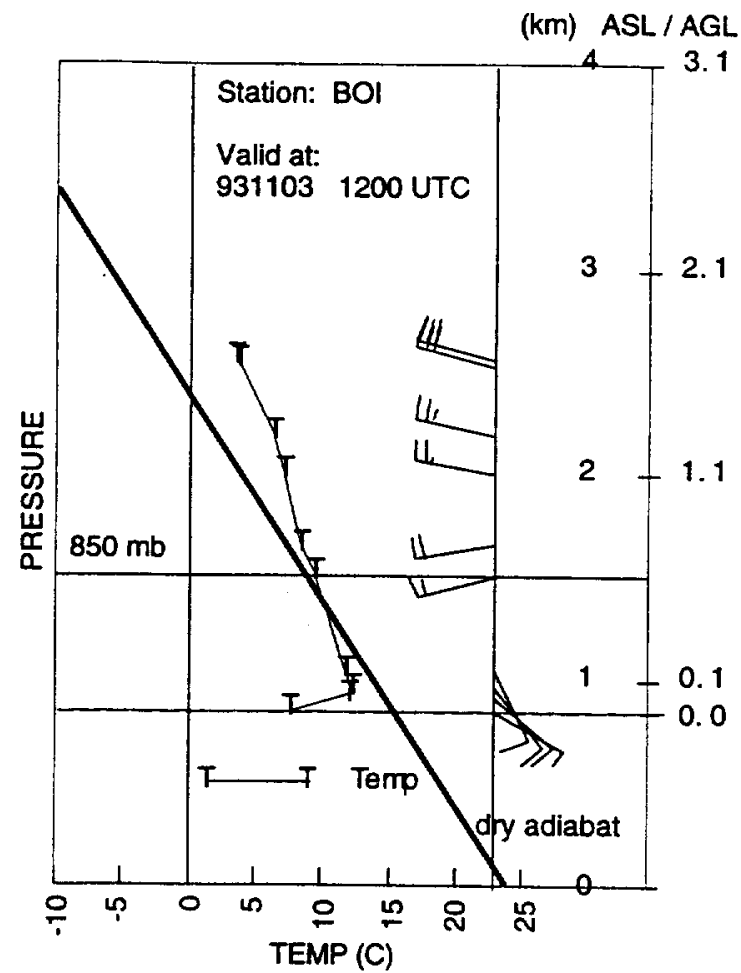

(b)

Figure 4.7 Upper air wind and temperature soundings for Salt Lake City, Utah (a), and Boise, Idaho (b) for 1200 UTC 03 November 1993.

Even though the Boise and Salt Lake City soundings were the best data available and were of similar structure, a difference of at least 60 degrees exists between the 1200 UTC rawinsonde data below $300 \mathrm{~m}$ and the tetroon data. This difference shows that the lower level rawinsonde data does not represent the lower level wind field of the study area. However, the profile extrapolation method used in MEDIC to generate the wind fields weighs the surface observations more heavily than the upper air data below the mixing layer height. This minimizes the effect the southeast rawinsonde winds have upon the modeled lower level study area wind fields. The overall modeled lower level winds in the study area were from the southwest and veered with height. 
(km) ASL/AGL

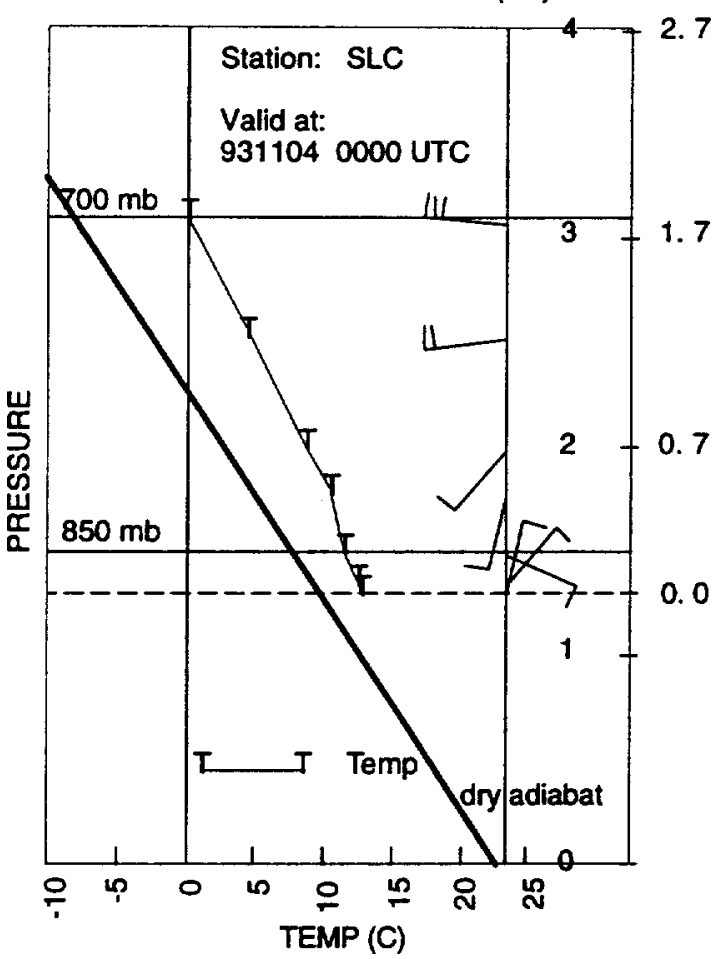

(a)

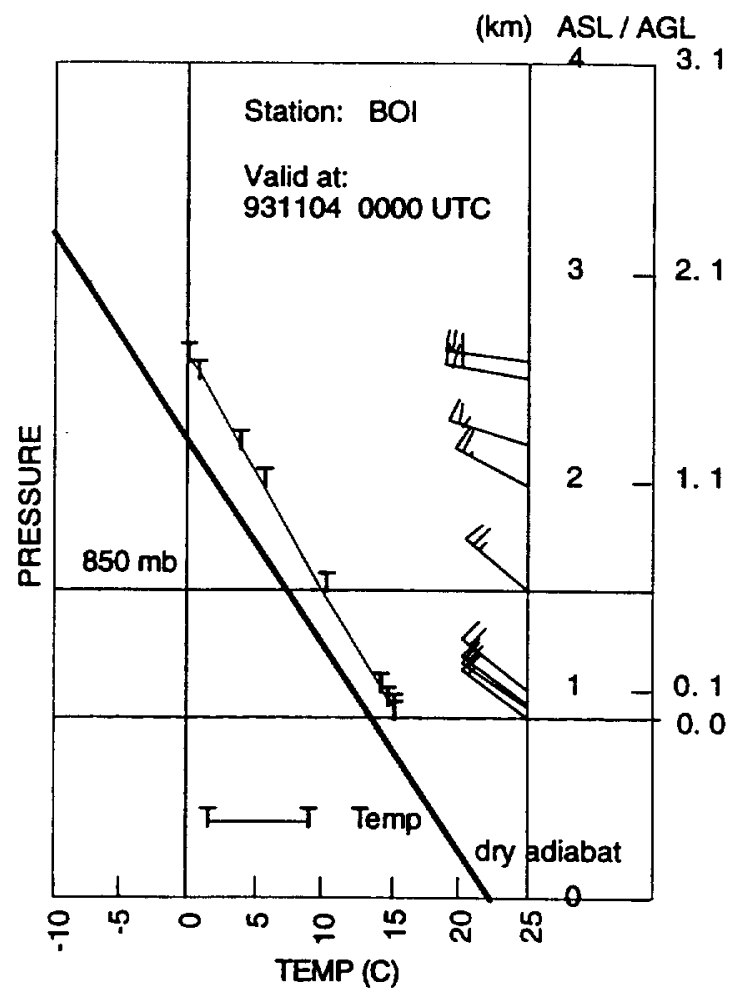

(b)

Figure 4.8 Upper air wind and temperature soundings for Salt Lake City, Utah (a), and Boise, Idaho (b) for 0000 UTC 04 November 1993.

To determine model input parameters that best represent the environment of the study domain and period, model calculations were compared to measurements. Aircraft measurements were compared with modeled $\mathrm{SF}_{6}$ concentrations generated at aircraft flights levels and measurement times to determine a "success" or "failure", Table 4.6. A "success" was defined as an instance when modeled concentration levels agreed with aircraft measurements at similar time, height, and location. A failure was defined as an instance when modeled concentrations and aircraft measurements did not agree. The models need to produce a result similar to the aircraft measurements in order for the model run to be acceptable. 
Table 4.6 Success and Failure Criteria

\begin{tabular}{c|c|c||c|c}
\hline & SUCCESS & SUCCESS & FAILURE & FAILURE \\
\hline Aircraft detected & YES & NO & NO & YES \\
& & & & \\
Model Generated & $>10 \mathrm{ppt}$ & $<10 \mathrm{ppt}$ & $>10 \mathrm{ppt}$ & $<10 \mathrm{ppt}$ \\
Concentrations & & & & \\
\hline
\end{tabular}

The primary area of comparison was the center of the study domain between 1735 and 1841 UTC. Within this time and area, a triangular and an oval region were defined from aircraft measurement locations (see Figure 4.2). The triangle outlines the aircraft's first flight through the center of the study area between 1735 and 1747 UTC at about $200 \mathrm{~m}$ AGL. During this time no $\mathrm{SF}_{6}$ was detected, which suggests that measurable quantities of the tracer had not yet been transported into this area by this time. The oval outlines the aircraft's subsequent flights in this same area between 1748 and 1841 UTC at $200 \mathrm{~m}$ AGL. By this time the aircraft did detect $\mathrm{SF}_{6}$, which suggests that the plume was being transported through the oval area during this time period at this height.

The changeover from the 1200 UTC to the 0000 UTC soundings is an important issue when upper air profiles are used over an extended period. Since the rawinsonde data was only available every 12 hours, the 1200 UTC data was used in the model for several hours beginning at 1315 UTC and the data valid at 0000 UTC 04 November was used several hours prior to 0000 UTC. The time of the upper air data change was initially chosen to be when the wind speed and direction of the surface observation exhibited similar characteristics to that of the lowest 0000 UTC sounding level. Table 4.5 lists the hourly observations from Salt Lake City and Boise. Comparing the Boise hourly wind direction and speed observations to the 0000 UTC rawinsonde data yields a similarity in the 1853 
UTC observation. However, no similarity is found between the Salt Lake City rawinsonde lower observation and the hourly observations. As a result, the Boise data suggests that the change from the 1200 UTC to 0000 UTC upper air data may occur between 1752 and 1853 UTC. Model calculations using this changeover time did not produce results shown in the tracer sampling data. Several model runs were executed to determine the upper air data changeover time that would best reflect measured tracer data.

Table 4.5 Hourly surface observations from Boise, ID and Salt Lake City, UT

\begin{tabular}{cccc||cccc}
\hline \multicolumn{4}{c||}{ Salt Lake City, Utah } & \multicolumn{4}{c}{ Boise, Idaho } \\
\hline Time & $\begin{array}{c}\text { Temp. } \\
\text { Tirection } \\
\text { (UTC) }\end{array}$ & $\begin{array}{c}\text { Wind } \\
\text { (C) }\end{array}$ & $\begin{array}{c}\text { Speed } \\
(\mathrm{deg})\end{array}$ & $\begin{array}{c}\text { Time } \\
(\mathrm{m} / \mathrm{s})\end{array}$ & $\begin{array}{c}\text { Temp. } \\
\text { (UTC) }\end{array}$ & $\begin{array}{c}\text { Wind } \\
\text { Direction } \\
(\mathrm{deg})\end{array}$ & $\begin{array}{c}\text { Wind } \\
\text { Speed } \\
(\mathrm{m} / \mathrm{s})\end{array}$ \\
\hline 1251 & 3.5 & 130 & 6.7 & 1250 & 8.0 & 130 & 4.6 \\
1350 & 3.5 & 150 & 3.1 & 1350 & 8.0 & 140 & 4.1 \\
1451 & 4.6 & 130 & 4.1 & 1450 & 9.1 & 100 & 4.1 \\
1550 & 6.9 & 130 & 5.1 & 1550 & 9.1 & 140 & 3.1 \\
1650 & 8.5 & 170 & 4.6 & 1650 & 10.8 & 110 & 3.1 \\
1750 & 10.8 & 150 & 4.6 & 1752 & 13.5 & 90 & 4.6 \\
1850 & 11.9 & 180 & 4.1 & 1853 & 16.9 & 290 & 11.3 \\
1950 & 12.4 & 180 & 4.1 & 1951 & 16.9 & 290 & 11.8 \\
2053 & 12.4 & 170 & 4.1 & 2050 & 19.1 & 280 & 11.3 \\
2150 & 13.0 & 170 & 3.6 & 2150 & 17.4 & 270 & 9.8 \\
2250 & 13.0 & 150 & 3.6 & 2250 & 16.9 & 300 & 5.7 \\
2350 & 12.4 & 180 & 2.6 & 2352 & 15.8 & 320 & 6.2 \\
\hline
\end{tabular}

Figures 4.9 (a) - (f) show three model results at the $200 \mathrm{~m}$ flight level with sounding changeover times of 1800 UTC, 1700 UTC, and 1600 UTC, respectively. The shaded area represents model calculated $\mathrm{SF}_{6}$ concentrations above $10 \mathrm{ppt}$ at 1745 and 1815 UTC. 


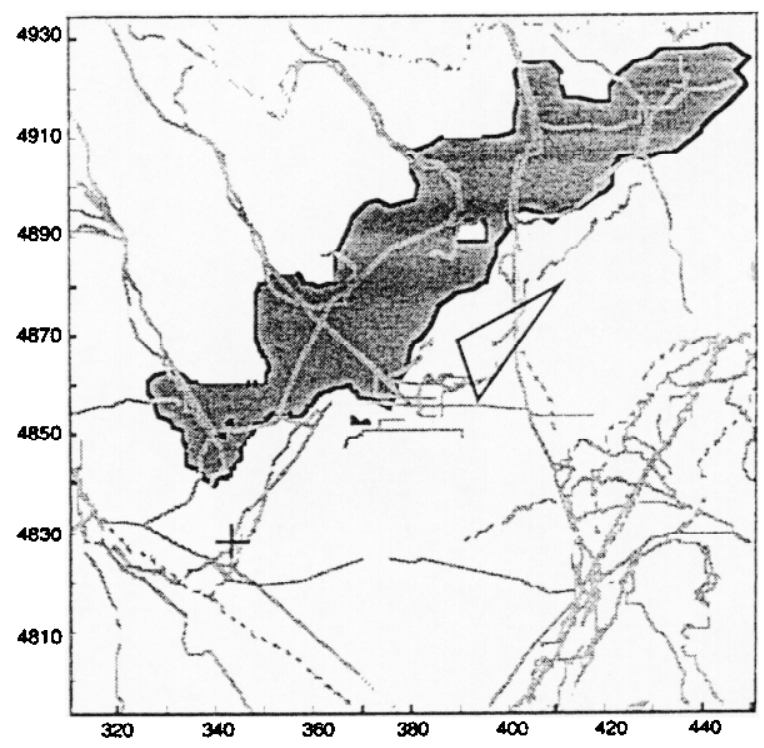

(a) Modeled $\mathrm{SF}_{6}$ concentrations at 1745

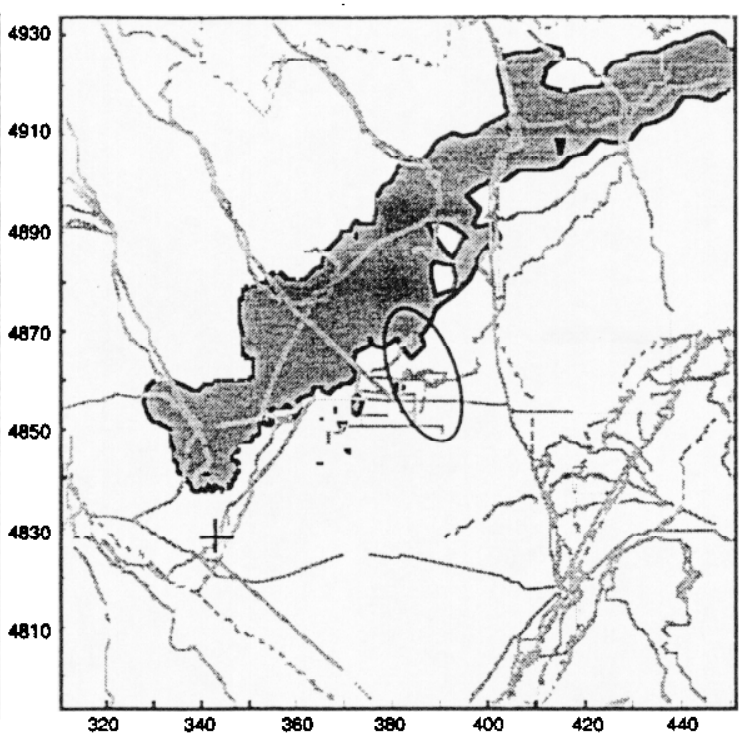

(b) Modeled $\mathrm{SF}_{6}$ concentrations at 1815 UTC with 1800 UTC sounding changeover. UTC with 1800 UTC sounding changeover.

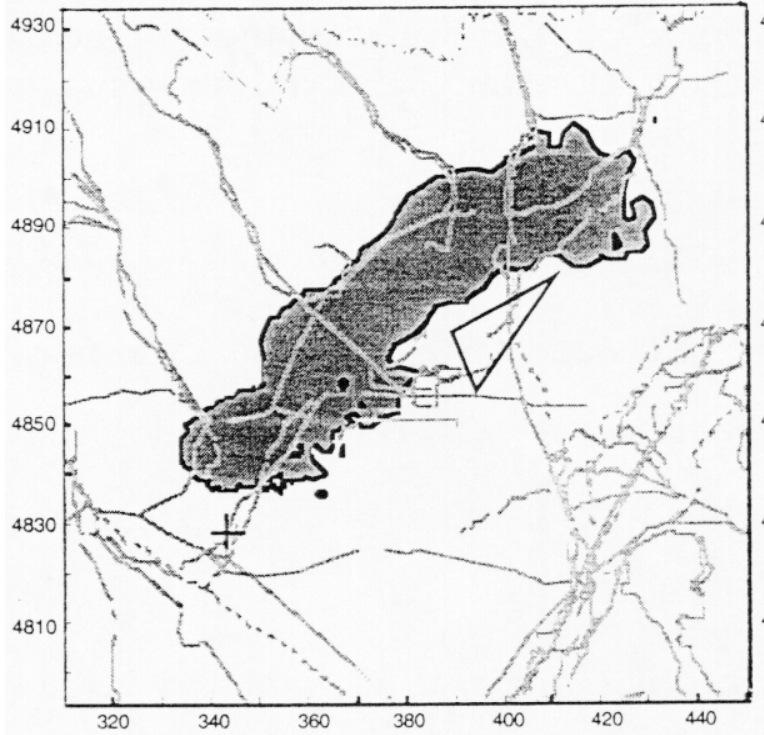

(c) Modeled $\mathrm{SF}_{6}$ concentrations at 1745

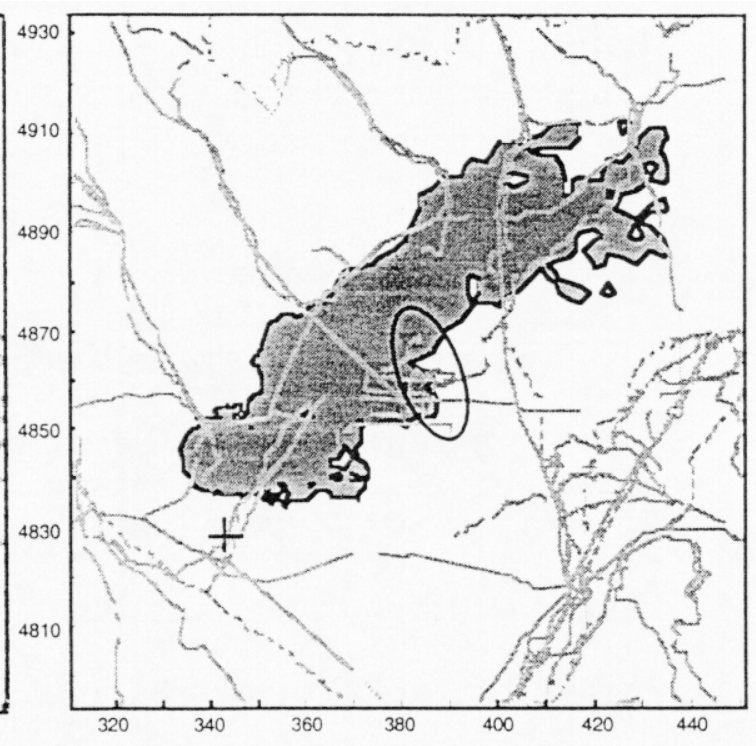

(d) Modeled $\mathrm{SF}_{6}$ concentrations at 1815 UTC with 1700 UTC sounding changeover. UTC with 1700 UTC sounding changeover.

Figure 4.9 Comparison of modeled instantaneous $\mathrm{SF}_{6}$ concentrations at $200 \mathrm{~m}$ AGL (shaded areas above $10 \mathrm{ppt}$ ) with aircraft measurement areas (The triangle represents a measurement area below $10 \mathrm{ppt}$, the oval represents a measurement area above $10 \mathrm{ppt}$ ). 


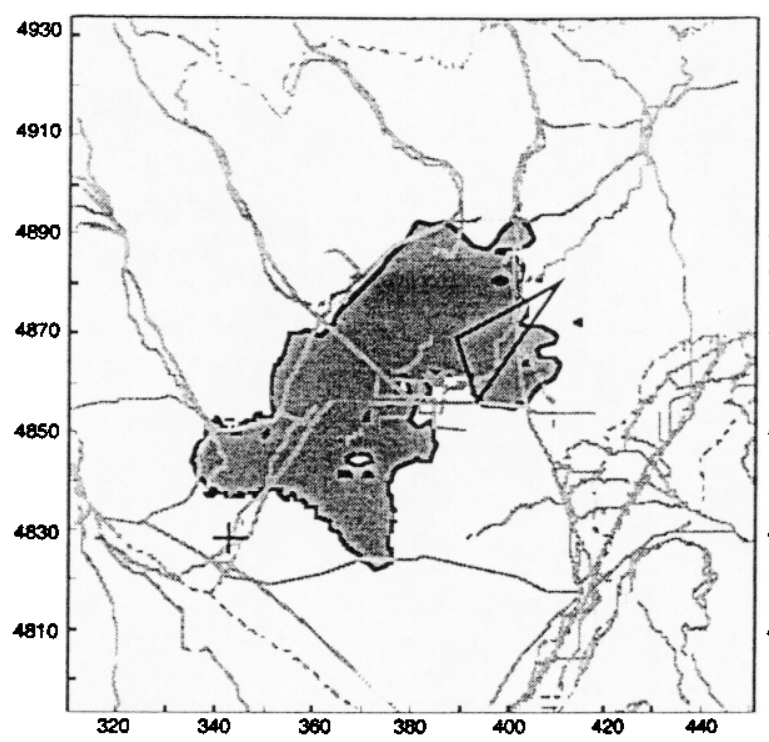

(e) Modeled $\mathrm{SF}_{6}$ concentrations at 1745 UTC with 1600 UTC sounding changeover.

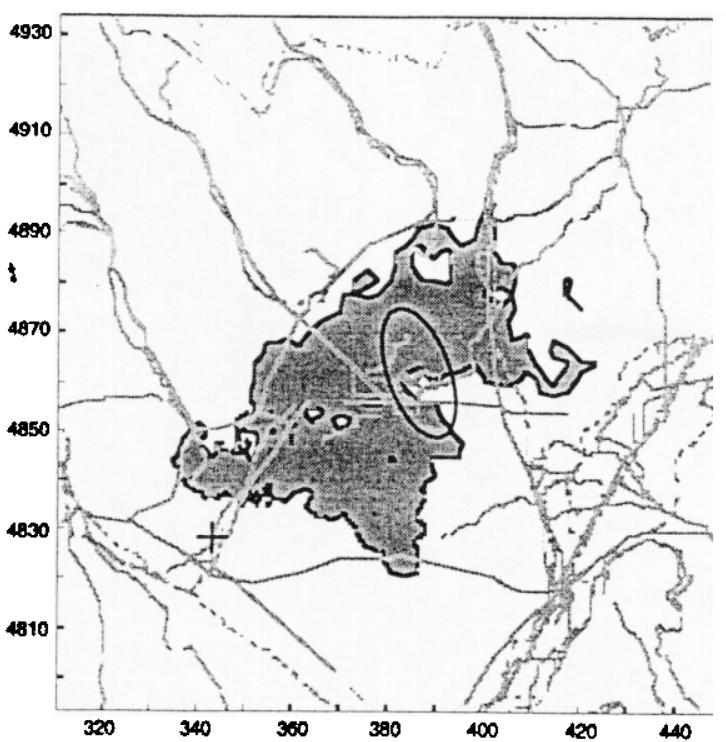

(f) Modeled $\mathrm{SF}_{6}$ concentrations at 1815

Figure 4.9 (Completed) Comparison of modeled instantaneous $\mathrm{SF}_{6}$ concentrations at $200 \mathrm{~m}$ AGL (shaded areas above $10 \mathrm{ppt}$ ) with aircraft measurement areas (The triangle represents a measurement area below $10 \mathrm{ppt}$, the oval represents a measurement area above $10 \mathrm{ppt}$ ).

Figures 4.9(a) and (b) illustrate the result of a sounding changeover at 1800 UTC, where the winds have had a longer time to transport the tracer northwest into the mountain valleys before the flow reversal occurs to transport the tracer back to the east across the valley. The model does not produce detectable tracer levels within the triangular area of Figure 4.9(a) which agrees with measurements, however, the model has minimal agreement with the $\mathrm{SF}_{6}$ measurements within the aircraft oval as seen in Figure 4.9(b).

When the changeover time is retrograded, the transport of tracer into the mountain valleys is decreased, as seen in Figures $4.9(\mathrm{c})-(\mathrm{f})$. As a result, the time of the flow reversal is retrograded allowing the tracer to be transported out of the mountain valleys and eastward across the valley earlier. Figures $4.9(\mathrm{c})$ and $(\mathrm{d})$ show the model results of a sounding changeover at 1700 UTC, where no 
detectable tracer levels are produced within the triangular area at 1745 UTC, and $50 \%$ of the oval area contains tracer levels above detection by 1815 UTC. Retrograding the changeover time to 1600 UTC caused the tracer to be transported to the east too early as shown in Figure 4.9(e), where the triangular area of no measured values was almost completely filled with model generated detectable tracer levels even though there was good agreement at 1815 UTC, Figure 4.9(f). Based on this analysis, the best 1200 UTC to 0000 UTC sounding changeover time was determined to be 1700 UTC.

4.4.2.4 Summary of data quality and quantity used in modeling. Due to the number of meteorological surface stations in the study area and the frequency of observations throughout the study period, especially the INEL towers, the input for the surface wind fields was considered adequate. In contrast, the upper air data was considered poor because the observation points are located far from the study area, consist of only two widely temporally spaced soundings during the study period, and as a result did not adequately represent the low-level winds in the study area as shown by the tetroon data. The tetroon data was also considered to be poor as a result of the low number of data points and the small flight path in comparison to the large study area. However, this data did provide additional information and was used with the surface data to generate the low-level wind fields. A study by Baskett, Nasstrom, and Lange (1990) points out that on-site Doppler acoustic sounders can provide valuable information to characterize the local vertical wind profile, and that modeling the vertical wind structure can have an important effect on the ground-level air concentrations. More confidence would be given to the upper air data input if the on-site sounding equipment were operational. However, the GWC gridded 
data and NWS rawinsonde data were the only data available to use as upper air input to the models.

The limited tracer measurement and observed upper air data made determination of the tracer pattern difficult. Even though the surface wind input was good, the surface tracer measurements were few and not always reliable. The aircraft tracer measurements were of better quality and quantity than the surface measurements, but were still limited spatially and temporally. The representativeness of the upper air wind observations is questionable because of distance and terrain differences from the study area. So, it is difficult to determine which vertical level of winds most heavily influenced the tracer dispersion.

\subsubsection{MEDIC/CG-MATHEW/ADPIC Input Parameters}

As discussed earlier, the MEDIC model uses one of two extrapolation methods to generate the 3D wind fields. Figure 4.10 shows model generated wind profiles for 1330 UTC at the center of the modeling domain using both the profile and parameterized extrapolation methods. Profile (a) was generated by the profile extrapolated method, and profiles (b) and (c) were generated by the parameterized extrapolation method. Profiles (a) and (b) used the same input parameters with different extrapolation methods and produced similar wind profiles. However, the profile extrapolation method produced profiles with winds better duplicating the rawinsonde wind observations above the boundary layer height. Profile (c) used a boundary layer height more appropriate to the parameterized method, and produced a wind profile veering smoothly with height, which does not represent typical wind conditions present during an 
inversion. So, the profile extrapolation method (a) was selected to generate the wind field for this study.

There are many input parameters in these three models, but the key parameters controlling the modeled wind field for tracer dispersion are the boundary layer height, mixing layer height and the stability of the atmosphere. The values of these model inputs were determined by conducting sensitivity studies using information from experimental logs, data from the INEL tower network, rawinsonde data, and surface metdata.

(a)

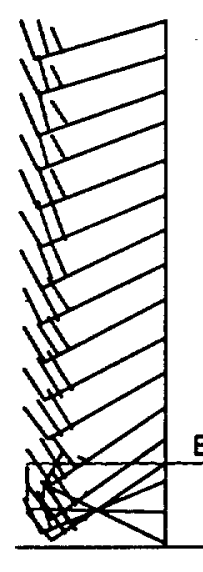

(b)

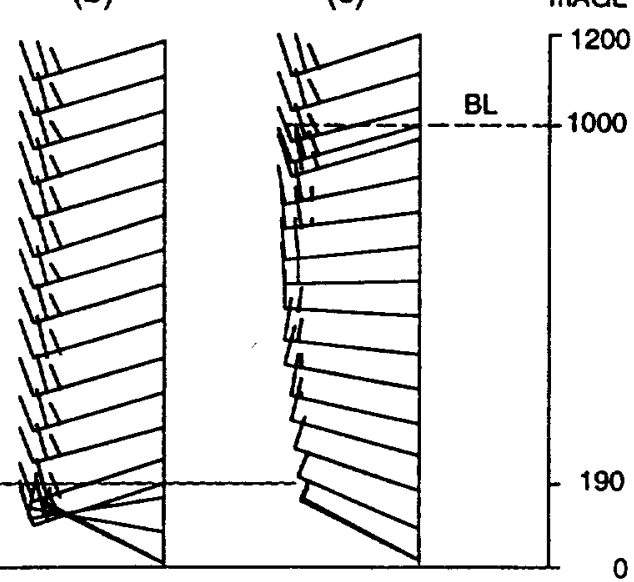

Figure 4.10 Wind profiles generated by the profile (a), and parameterized (b and c) extrapolation methods. (BL denotes the model boundary layer height.)

The boundary and mixing layer heights in the model do not necessarily represent the normal meteorological definitions. The boundary layer height is defined in MEDIC as the height above which the extrapolated profile matches the observed profile when using the profile extrapolation method. The mixing layer height is defined in ADPIC as the height below which the atmosphere is well mixed. In most cases, the mixed layer height can be defined by the height of 
an elevated temperature inversion base or a change in the vertical wind structure.

The rawinsonde data was the only data available to assist in determining the mixing layer height, however, the same representativeness limitations exist as previously discussed. Table 4.3 and Figure 4.7 indicate that surface-based temperature inversions existed at both Salt Lake City and Boise on 03 November 1993 at 1200 UTC extending to $161 \mathrm{~m}$ and $111 \mathrm{~m}$, respectively. In addition, Salt Lake City had an elevated inversion extending from $391 \mathrm{~m}$ to $591 \mathrm{~m}$. Changes in the wind can also provide information in determining mixing layer height. A significant wind direction change of $100^{\circ}$ occurred between $191 \mathrm{~m}$ and $661 \mathrm{~m}$ at Boise with an increase in wind speed. A $30^{\circ}$ change in wind direction occurred at Salt Lake City between $591 \mathrm{~m}$ and $771 \mathrm{~m}$ with a decrease in wind speed.

Several model runs using this information were constructed to determine the best estimate of mixing and boundary layer heights for the study area. Figure 4.11 shows the results of three different mixing and boundary layer height cases at 1815 UTC at the $200 \mathrm{~m}$. aircraft flight level, where the oval outline denotes the area in which $\mathrm{SF}_{6}$ was detected between 1748 and 1841 UTC. Figure 4.11(a) shows the result of a boundary layer height of $750 \mathrm{~m}$ and a mixing layer height of $300 \mathrm{~m}$, which are typical default daytime value used by ARAC. The winds in this case did not disperse detectable levels of tracer into the area where $\mathrm{SF}_{6}$ was detected, and northward transport was limited.

The case shown in Figure 4.11(b) used mixing layer and boundary layer heights of $450 \mathrm{~m}$ and $520 \mathrm{~m}$, respectively. The boundary layer height was placed within 2 grid cells above the mixing layer height, since there can be a significant change in the winds above an inversion. The mixing layer height in this case was 
determined by using a height within the range of the Salt Lake City elevated inversion and the range where a significant wind shift occurred in the Boise wind profile. This case did generate some detectable tracer levels within the measurement oval, but of minimal extent with the majority of the plume still much further to the west.

Model results from mixing and boundary layer heights of $120 \mathrm{~m}$ and 190 $\mathrm{m}$, respectively, determined from the surface inversion heights at Boise and Salt Lake City are shown in Figure 4.11(c). These wind fields transported detectable levels of the tracer into the oval measurement area and northward as observed by experiment personnel. These cases illustrate the importance of determining appropriate mixing and boundary layer heights. Based on this analysis, mixing and boundary layer heights of $120 \mathrm{~m}$ and $190 \mathrm{~m}$, respectively, were selected for approximately the first four hours of the study period while under the influence of the surface inversion. The mixing layer was increased to $1000 \mathrm{~m} \mathrm{AGL}$ at 1700 UTC after the surface inversion was determined to have dissipated and the atmospheric stability became more neutral.

The stability of the atmosphere is important because it directly relates to the vertical and horizontal dispersion of the tracer. The atmosphere usually exhibits stable characteristics below surface-based inversion, and was modeled this way in this study. However, during the study period the surface inversion dissipated and the atmosphere became neutrally stable. The changeover from stable to neutral stabilities was determined by using the soundings and the hourly surface observations at Boise. Using a Skew T-log p diagram, the temperature at the top of the surface inversion was translated to the surface dry adiabatically, and the resulting temperature was compared to the hourly surface 
observations. From Figure 4.7(b) at Boise, the surface inversion top temperature of $12.3^{\circ} \mathrm{C}$ translated dry adiabatically to a surface temperature of about $13^{\circ} \mathrm{C}$. Comparing this temperature to the hourly surface reports, Table 4.5 , yields a changeover time between 1650 and 1752 UTC, which was typically the time the surface inversions were observed to dissipate.

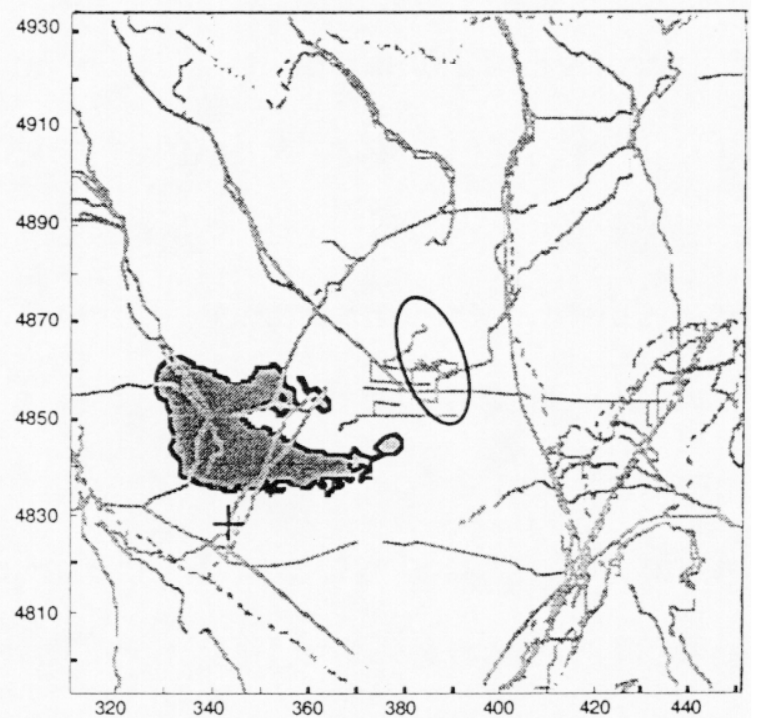

(a) Modeled $\mathrm{SF}_{6}$ concentrations with $\mathrm{ML}=300 \mathrm{~m}$ and $\mathrm{BL}=750 \mathrm{~m}$.

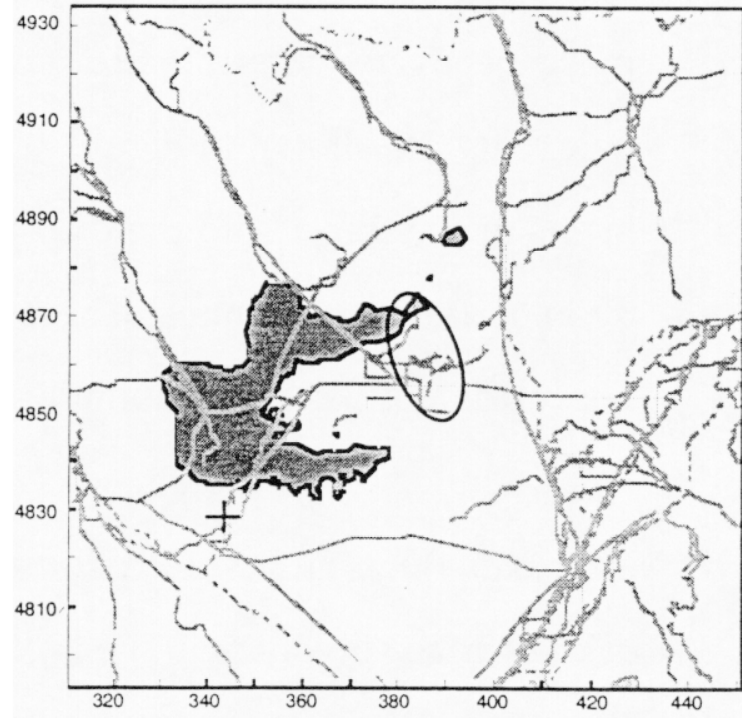

(b) Modeled $\mathrm{SF}_{6}$ concentrations with $\mathrm{ML}=450 \mathrm{~m}$ and $\mathrm{BL}=520 \mathrm{~m}$.

Figure 4.11 Comparison of modeled instantaneous $\mathrm{SF}_{6}$ concentrations at 1815 UTC and $200 \mathrm{~m} \mathrm{AGL}$ (shaded areas above $10 \mathrm{ppt}$ ) with aircraft measurement areas. (The oval represents a measurement area above $10 \mathrm{ppt}, \mathrm{ML}$ is the mixing layer height, and $\mathrm{BL}$ is the boundary layer height.)

INEL tower network data was also examined to ascertain if a stability changeover time could determined. Significant increases in wind speed and temperature were identified as potential indicators of stability change. Towers that exhibited these changes suggested a stability changeover occurred by 1700 UTC. In addition, the 0000 UTC Boise and Salt Lake City soundings, Figures 4.8(a) and (b), exhibited neutral stability, and were used beginning at 1700 UTC. 
A stability changeover time of 1700 UTC was used in the models since this time corresponded with the time period suggested by the Boise sounding and surface data comparison, the INEL tower network data, and the 1200 UTC to 0000 UTC sounding changeover time.

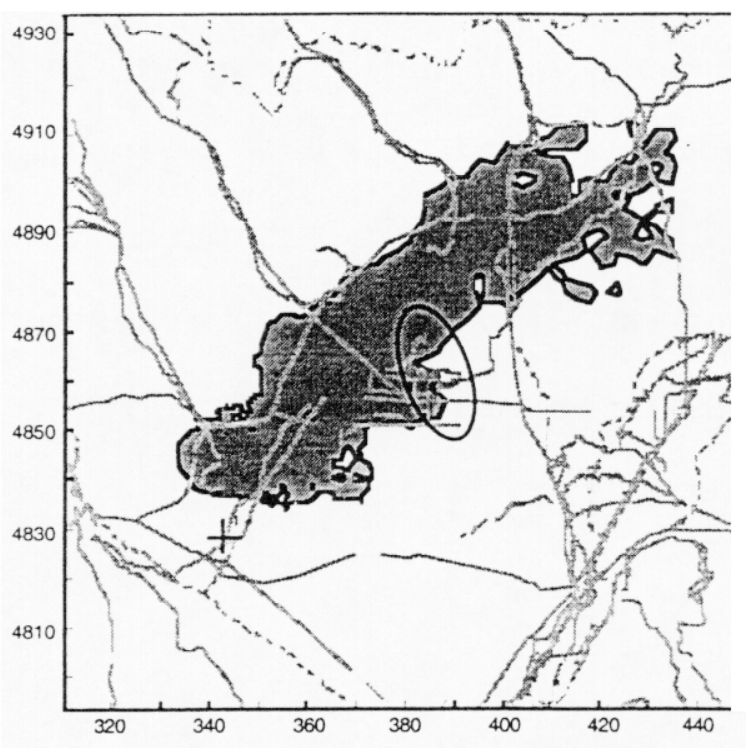

(c) Modeled $\mathrm{SF}_{6}$ concentrations with $\mathrm{ML}=120 \mathrm{~m}$ and $\mathrm{BL}=190 \mathrm{~m}$.

Figure 4.11(Completed) Comparison of modeled instantaneous $\mathrm{SF}_{6}$ concentra -tions at 1815 UTC and $200 \mathrm{~m}$ AGL (shaded areas above $10 \mathrm{ppt}$ ) with aircraft measurement areas. (The oval represents a measurement area above $10 \mathrm{ppt}, \mathrm{ML}$ is the mixing layer height, and BL is the boundary layer height.)

The plume rise of the $\mathrm{SF}_{6}$ was calculated in ADPIC based on the temperature of the released effluent $\left(200^{\circ} \mathrm{C}\right)$, stack exit velocity $(12 \mathrm{~m} / \mathrm{s})$, and ambient temperature $\left(-3^{\circ} \mathrm{C}\right.$, from the nearest tower). Plume rise acted upon the tracer only during the release phase between 1315 and 1615 UTC, during which time the atmospheric stability was slightly stable under the influence of the surface inversion. During the 3-hour release the plume-rise calculation produced a $50 \mathrm{~m}$ final rise above the stack in about 90 seconds for a final plume height of 65 
$\mathrm{m}$ above the surface. This minimal rise was due to the small diameter of the release orifice $(25.4 \mathrm{~cm})$ which allowed for rapid entrainment of cooler ambient air.

\subsubsection{PLOT CONTOUR}

Only a few model input parameters are required for PLOT_CONTOUR. A multiplication factor was included to convert ADPIC output units of $\mathrm{g} / \mathrm{m}^{3}$ to parts per trillion (ppt) in PLOT_CONTOUR. The molecular weight of $\mathrm{SF}_{6}, 146$ $\mathrm{g} /$ mole, was used with the ideal gas assumption to determine a conversion factor of $1.678 \mathrm{E}+08 \mathrm{ppt} \cdot \mathrm{g}^{-1} \cdot \mathrm{m}^{-3}$. Instantaneous air concentration plots were used in this study as they best represent the one-minute average tracer data set compiled from the measurements. 


\section{CHAPTER 5}

\section{BEST ESTIMATE CALCULATION}

As discussed in Chapter 4, the AFTAC ACEII air sampling experiment of 03 November 1993 (Release 4) was selected as the focus for the integration of numerical modeling and limited measurement data to study tracer dispersion in this complex flow regime. Sensitivity studies provided feedback to determine the most appropriate model input parameters supported by the observed data. The best-estimate model calculation is the result of these input parameters.

The best-estimate modeled wind fields and tracer dispersion are presented with a comparison of calculated $\mathrm{SF}_{6}$ concentration to observed tracer measurements. The primary emphasis is to examine how well the best-estimate calculated concentrations compare to the tracer measurements, which as a result, provides a solution for the overall tracer dispersion.

\subsection{Calculated Wind Fields}

Figures 5.1 through 5.10 show the surface wind inputs (a), the model generated wind fields at $40 \mathrm{~m}$ (b) near mid-plume rise height, $120 \mathrm{~m}$ (c) mixing layer height, and $600 \mathrm{~m}$ (d) midpoint of the vertical grid for the 10-hour study period at hourly intervals beginning at 1315 UTC. The key parameters influencing the modeled wind fields as determined from the sensitivity studies were the boundary layer height, the vertical extrapolation method for the winds, and the 1200 UTC to 0000 UTC sounding changeover time. 
Figure 5.1(a) shows the 1315 UTC surface wind barbs, where light and variable winds are present near the release point and in the mountain canyon outflow region. A stronger southwest flow exists near the southern edge of the domain that becomes more westerly along the eastern edge of the domain. In time, the surface flow near the release point strengthens under the influence of the northwest winds from the canyons to the northwest. Figure 5.4(a) shows that after 1515 UTC the winds begin to strengthen from the south across the southern half of the domain. Figure 5.5(a) shows that by 1715 UTC, the flow in the southern half of the domain becomes more southwesterly and persists throughout the rest of the study period.

Figures 5.1(b) -5.10 (b) show that the low-level $40 \mathrm{~m}$ winds are similar to the surface winds with weak, variable winds in the release area. A flow from the south to southwest strengthens and builds across the southern half of the domain. A light to moderate variable flow is maintained in the northwest quadrant of the domain throughout the whole period, except between 1515 UTC and 1715 UTC, where there is a southerly flow that can also be seen in the surface measurements.

Figures $5.1(\mathrm{c})-5.10(\mathrm{c})$ the mixing layer height $120 \mathrm{~m}$ winds that maintain a consistent southwest flow to 1715 UTC, where the winds moderate and become more westerly after the sounding changeover occurs. This general westerly flow continues throughout the rest of the study period.

Figures 5.1(d) - 5.10(d) show that the winds at the vertical grid mid-point, $600 \mathrm{~m}$, are from the southwest and remain constant through 1715 UTC, when a transition occurs bringing northwest winds for the remainder of the period. This 
transition occurs directly as a result of the changeover from the 1200 UTC to 0000 UTC sounding data which dominates the wind field calculation at this level.

The flows of the two main canyons to the northwest are noteworthy. The western most canyon is deeper and wider than the other. This canyon exhibits moderate down canyon flow for the entire study period. The second canyon which is shallower, less sloped, and less wide has a down canyon flow for the first two hours and then exhibits an up canyon flow when the main valley flow from the south increased. However, when the light and variable winds became established in the northwest quadrant of the domain at 1715 UTC, the flow in the second canyon also became light and variable for the remainder of the period.

Detail from the surface wind data remains in the wind fields below the mixing layer and above the surface as a result of the profile extrapolation method used in MEDIC. If the parameterized method were used, a much smoother transition from the surface to the boundary layer winds would occur. However, this would remove the detail of the wind field below the mixing layer that usually exists when influenced by a surface inversion, which in this complex environment would be undesirable.

\subsection{Calculated Plume Dispersion}

Figures $5.11-5.15$ show overhead and side views of the best-estimate plume dispersion over the 10-hour study period at one hour intervals beginning at 1415 UTC, one hour after the release start, where the marker dots represent $\mathrm{SF}_{6}$ molecules. The key parameters affecting plume dispersion as determined from the sensitivity studies were the mixing layer height, 1200 UTC to 0000 UTC sounding changeover time, and the atmospheric stability. 


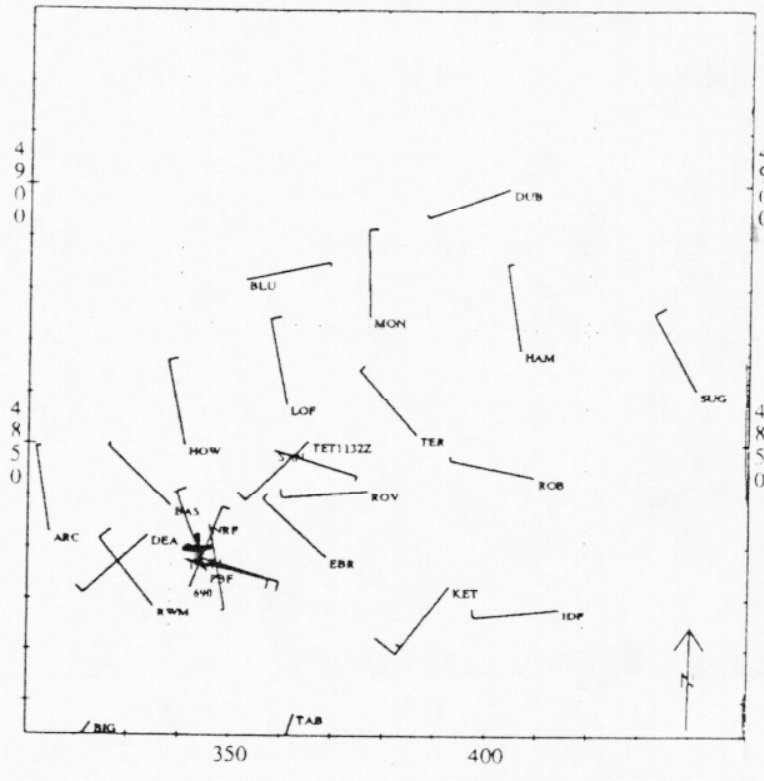

(a) Surface wind barbs.

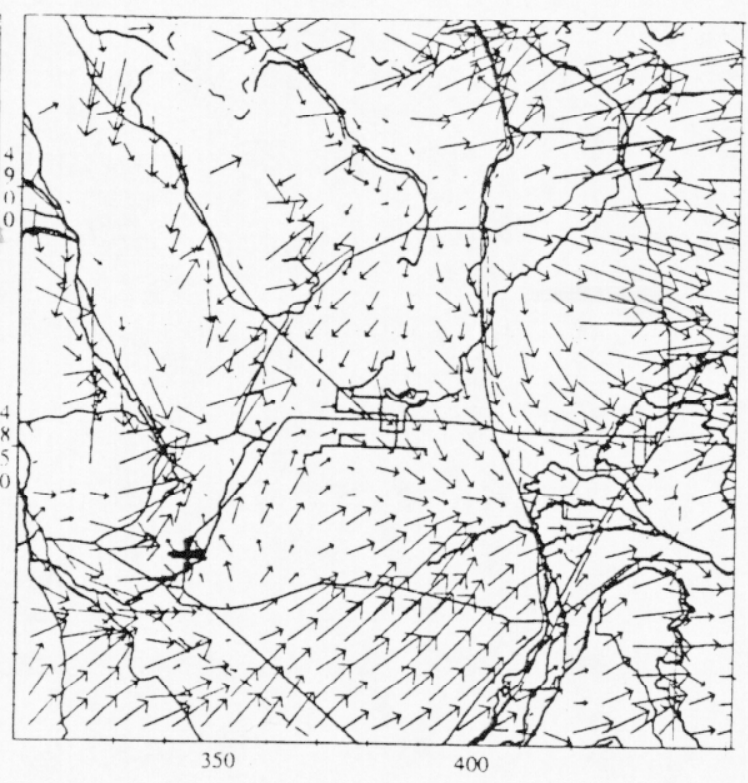

(b) $40 \mathrm{~m}$ AGL

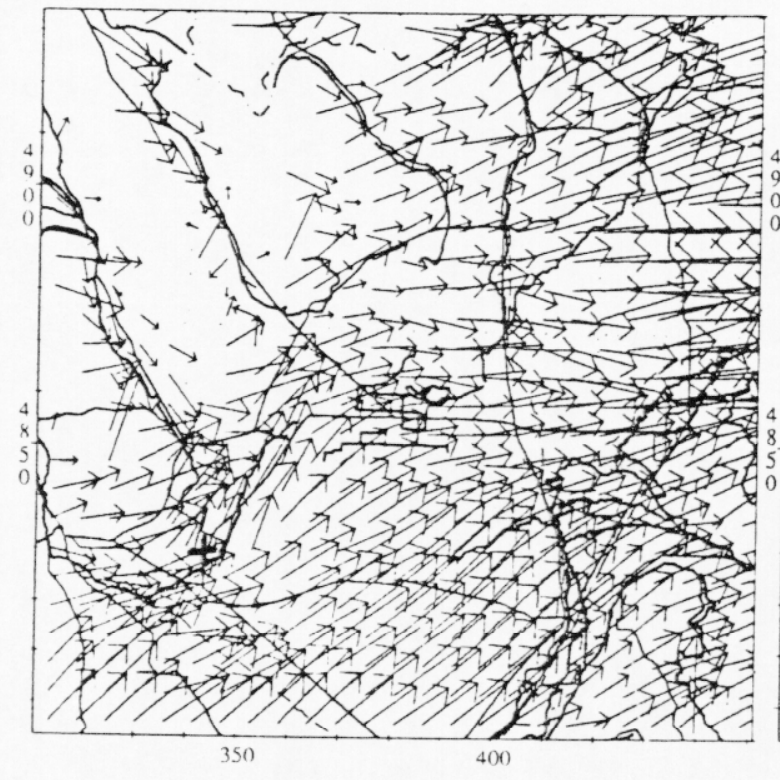

(c) $120 \mathrm{~m}$ AGL

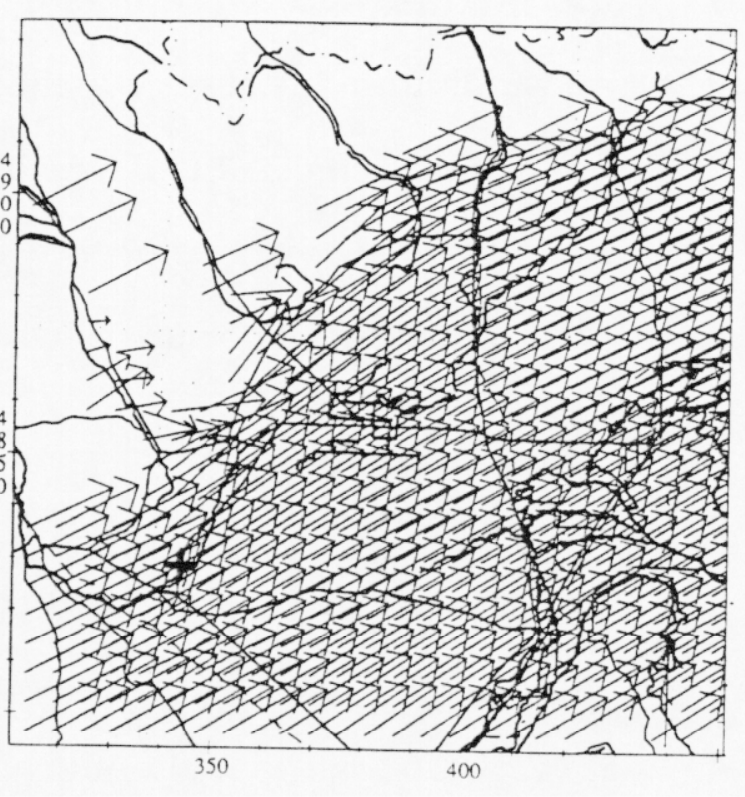

(d) $600 \mathrm{~m}$ AGL

Figure 5.1 Input surface wind barbs and model generated wind fields at 1315 UTC. (Full barb represents $6.5 \mathrm{~m} / \mathrm{s}$ and $\longrightarrow=10 \mathrm{~m} / \mathrm{s}$ ) 


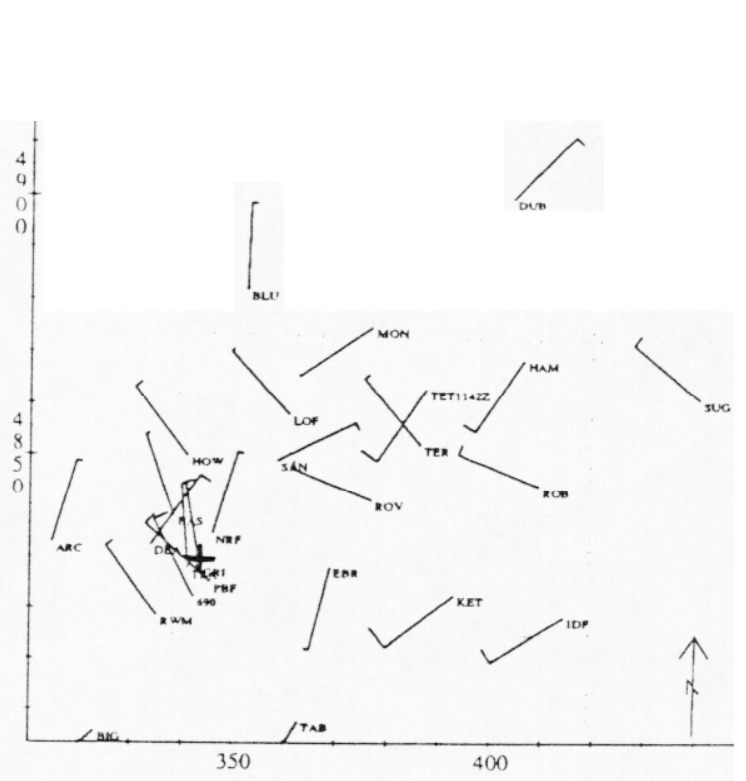

(a) Surface wind barbs.

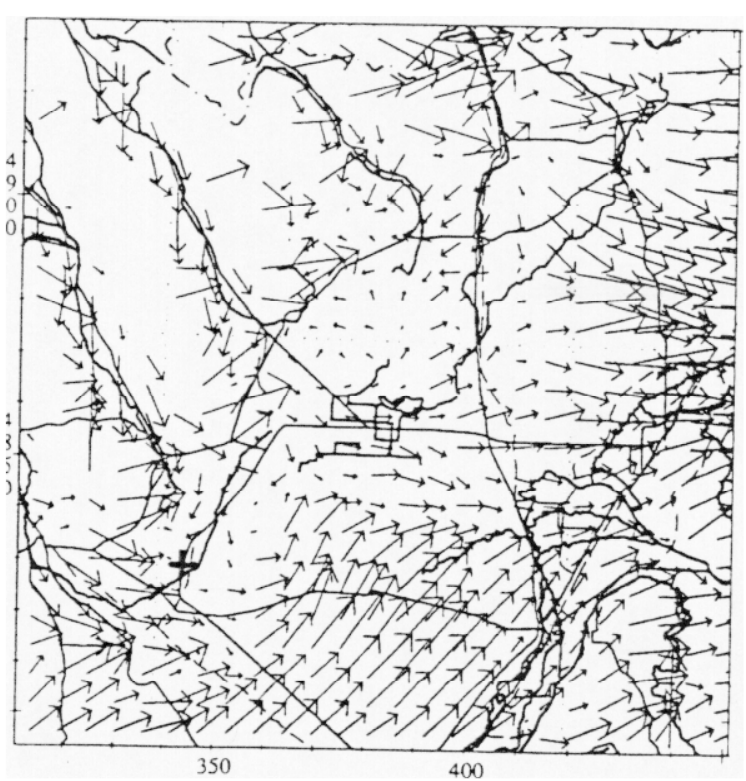

(b) $40 \mathrm{~m}$ AGL

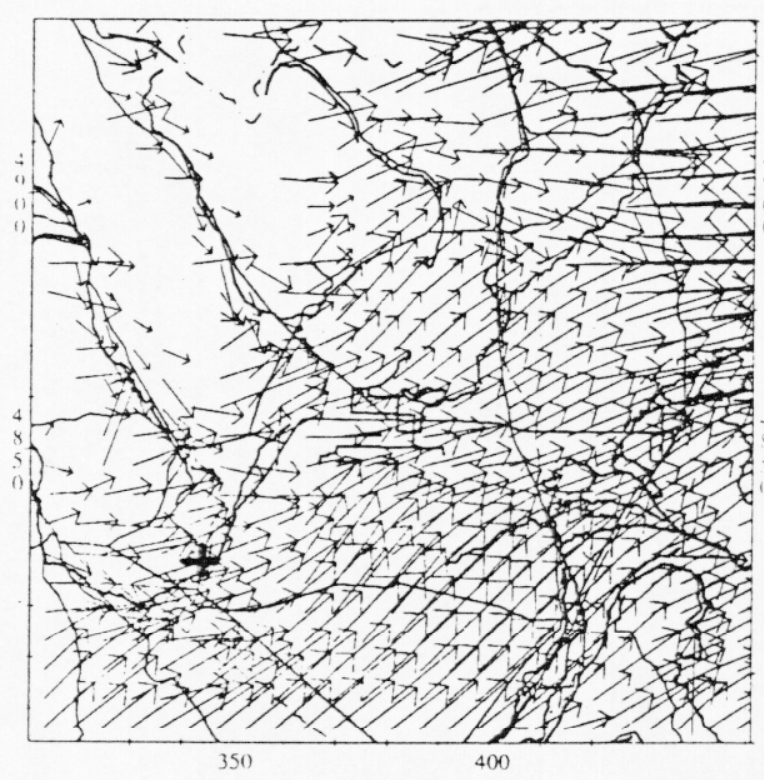

(c) $120 \mathrm{~m} \mathrm{AGL}$

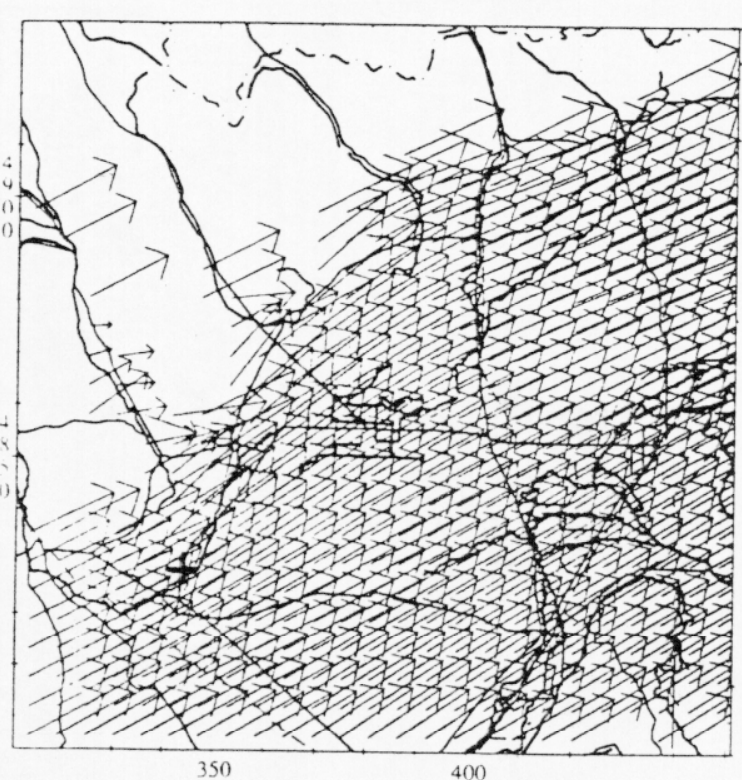

(d) $600 \mathrm{~m}$ AGL

Figure 5.2 Input surface wind barbs and model generated wind fields at 1415 UTC. (Full barb represents $6.5 \mathrm{~m} / \mathrm{s}$ and $\longrightarrow=10 \mathrm{~m} / \mathrm{s}$ ) 


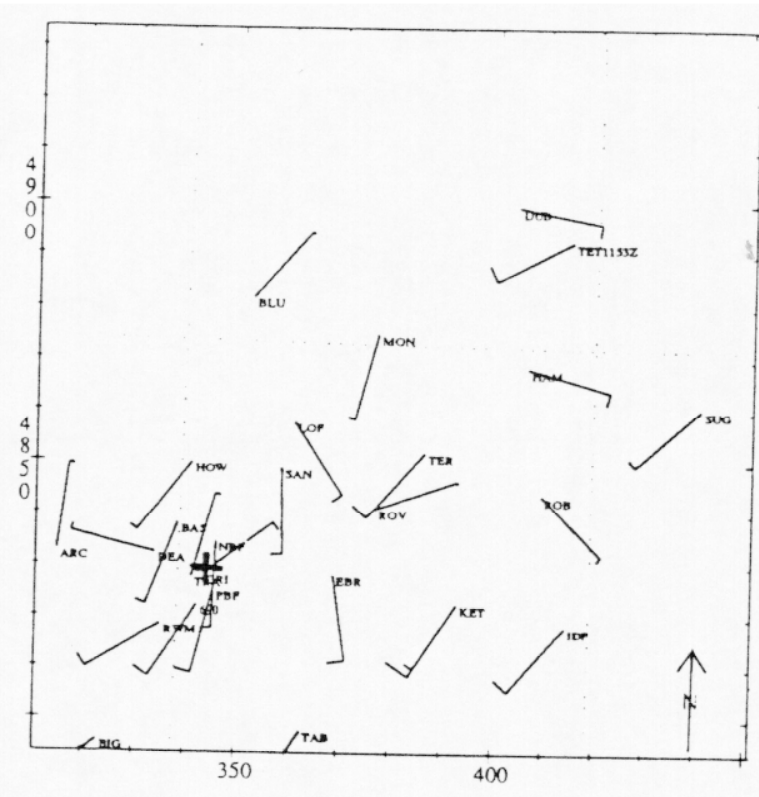

(a) Surface wind barbs.

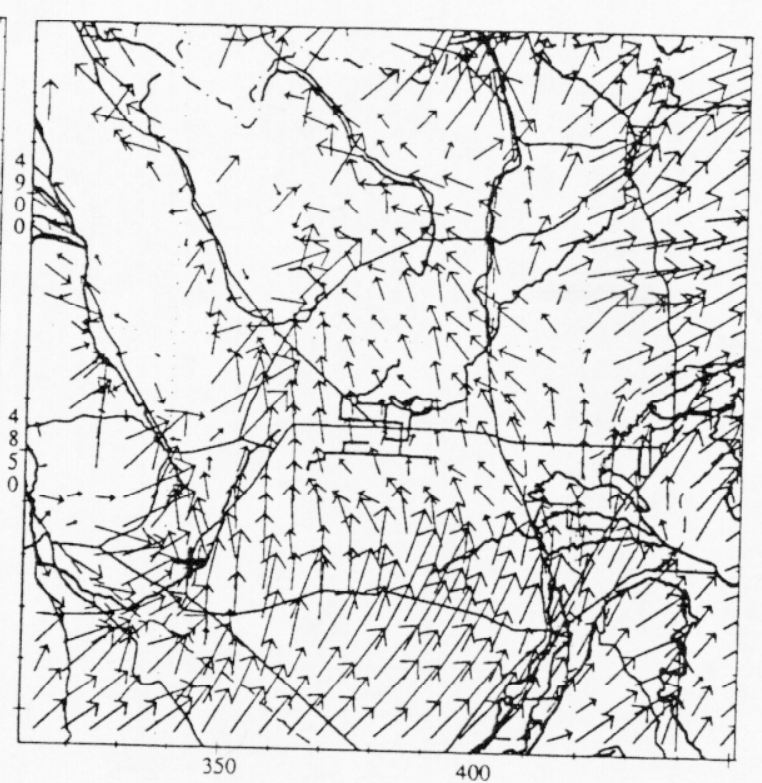

(b) $40 \mathrm{~m}$ AGL

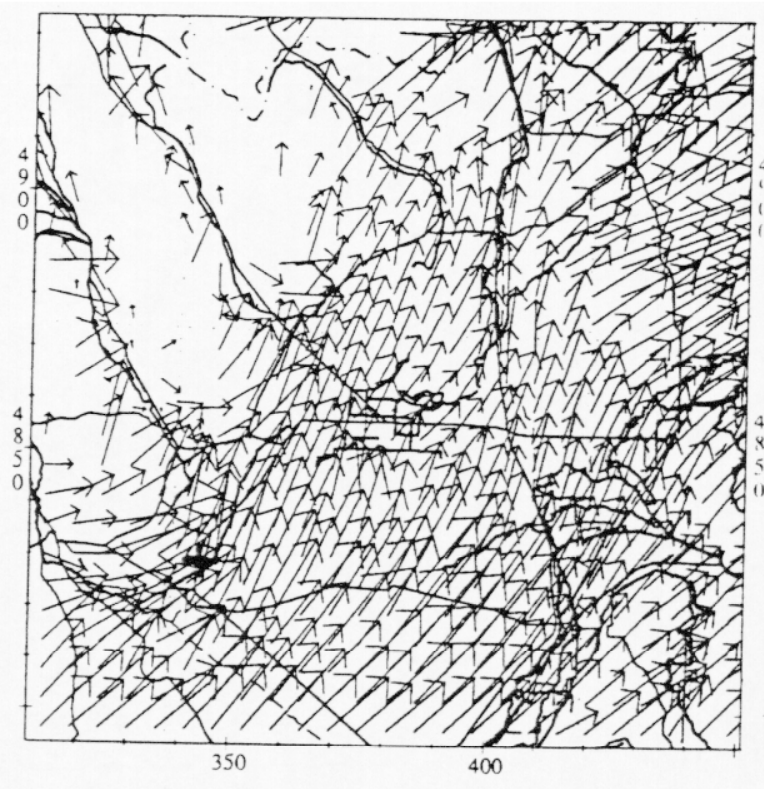

(c) $120 \mathrm{~m} \mathrm{AGL}$

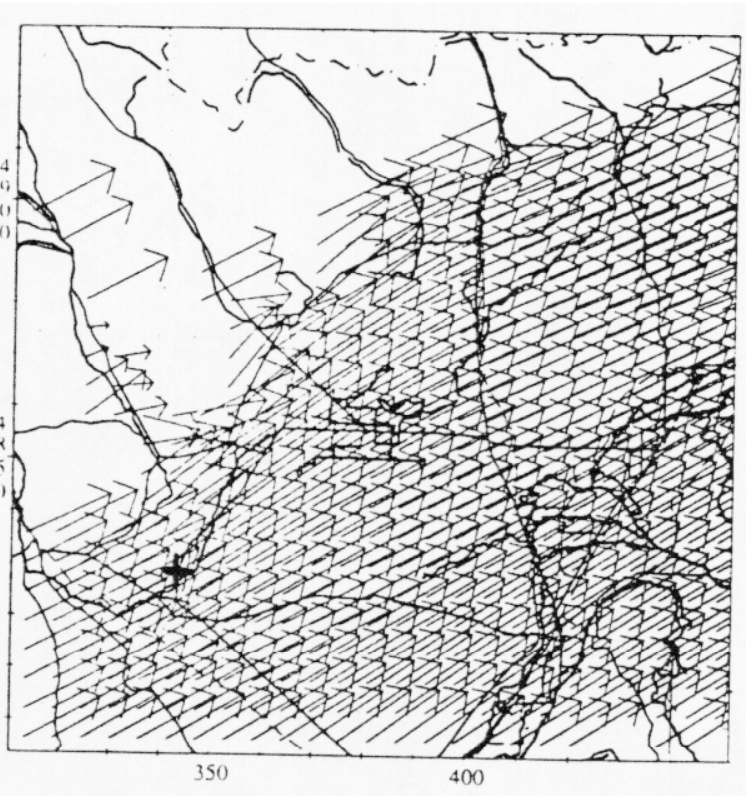

(d) $600 \mathrm{~m} \mathrm{AGL}$

Figure 5.3 Input surface wind barbs and model generated wind fields at 1515 UTC. (Full barb represents $6.5 \mathrm{~m} / \mathrm{s}$ and $\longrightarrow=10 \mathrm{~m} / \mathrm{s}$ ) 


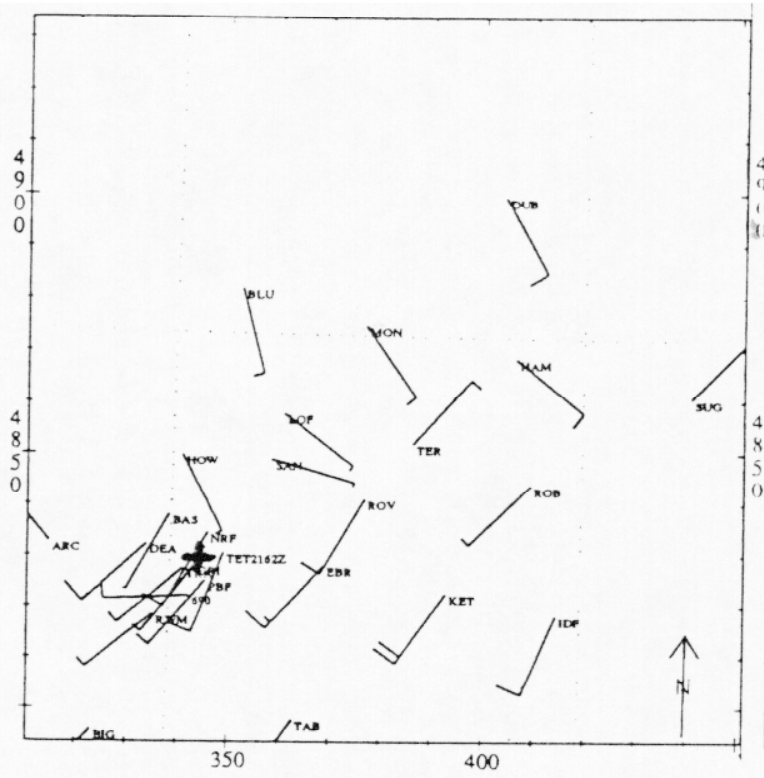

(a) Surface wind barbs.

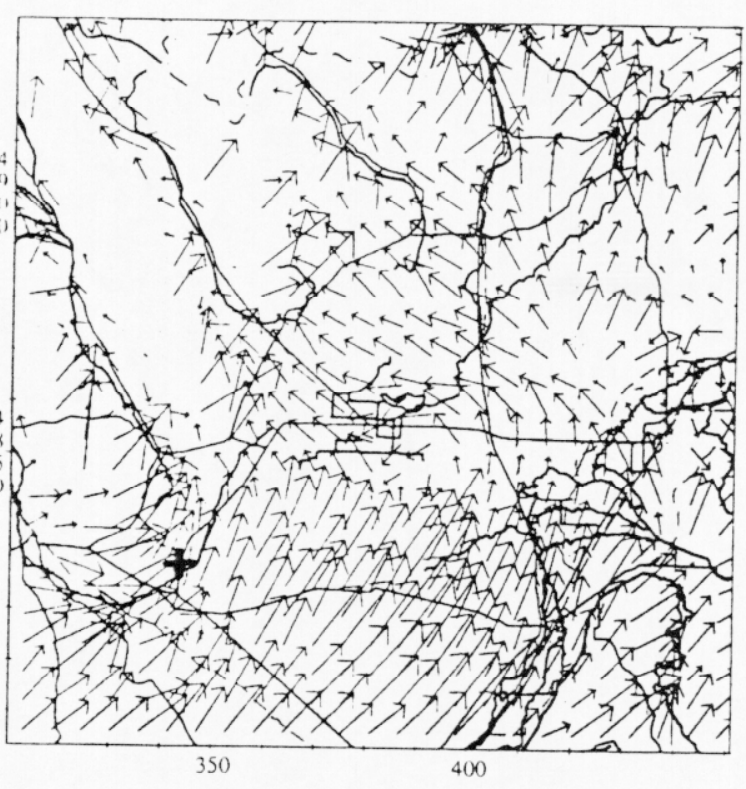

(b) 40 m AGL

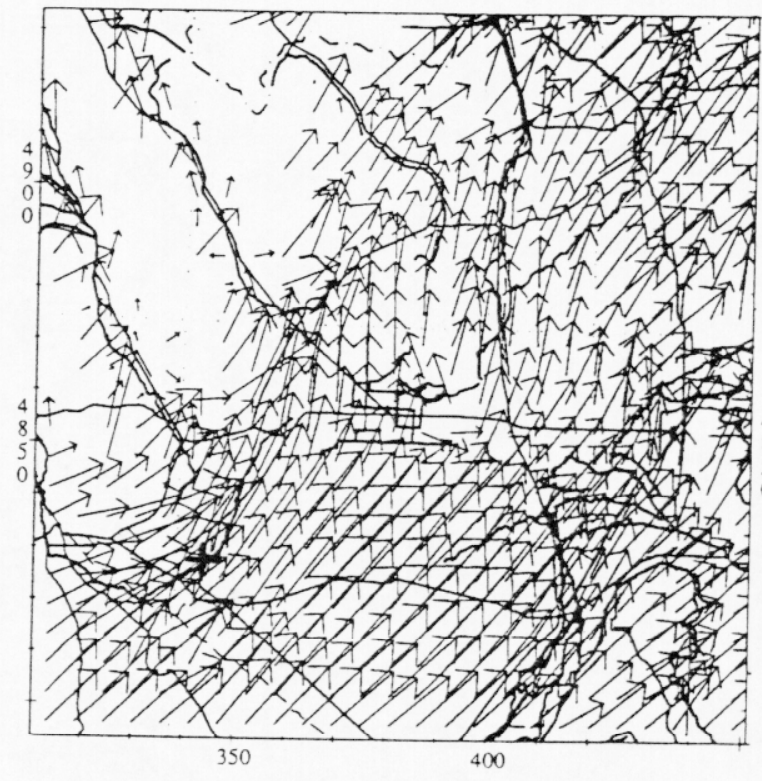

(c) $120 \mathrm{~m}$ AGL

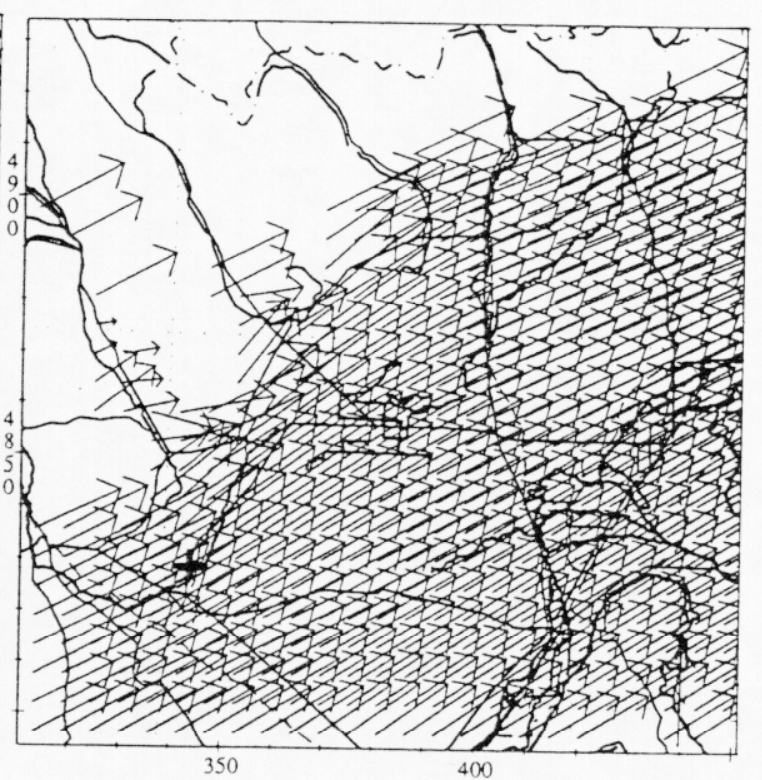

(d) $600 \mathrm{~m}$ AGL

Figure 5.4 Input surface wind barbs and model generated wind fields at 1615 UTC. (Full barb represents $6.5 \mathrm{~m} / \mathrm{s}$ and $\longrightarrow=10 \mathrm{~m} / \mathrm{s}$ ) 


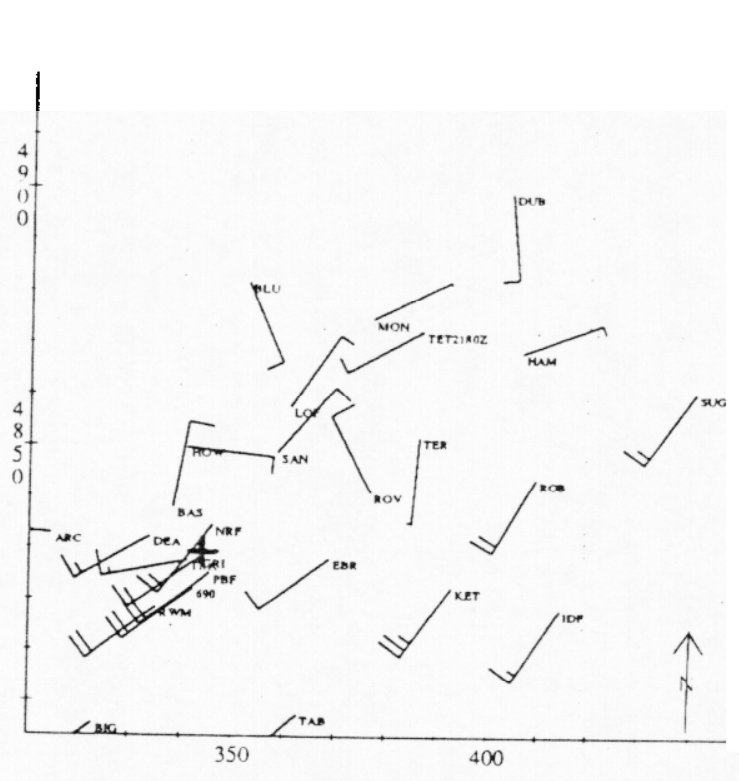

(a) Surface wind barbs.

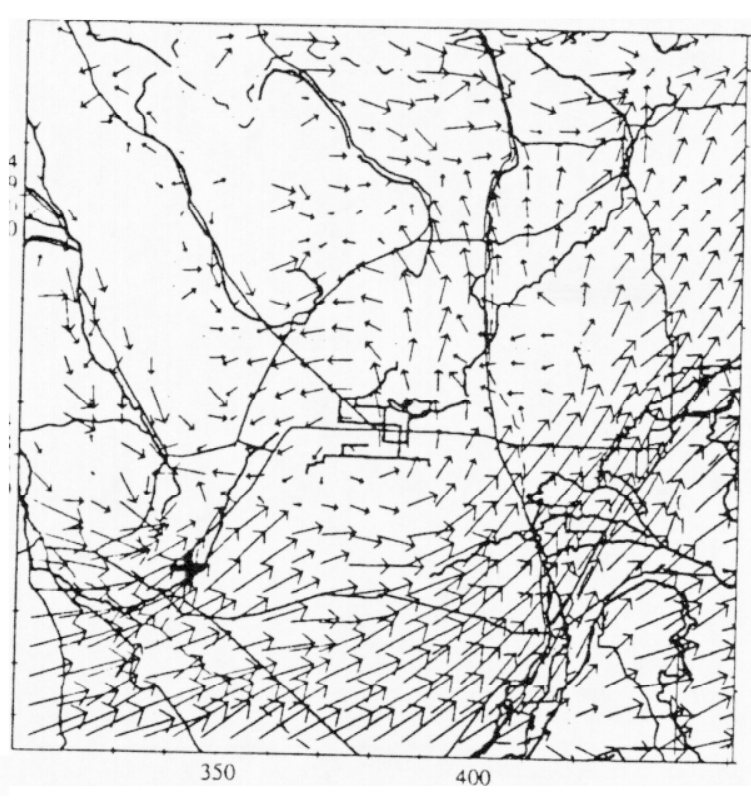

(b) $40 \mathrm{~m}$ AGL

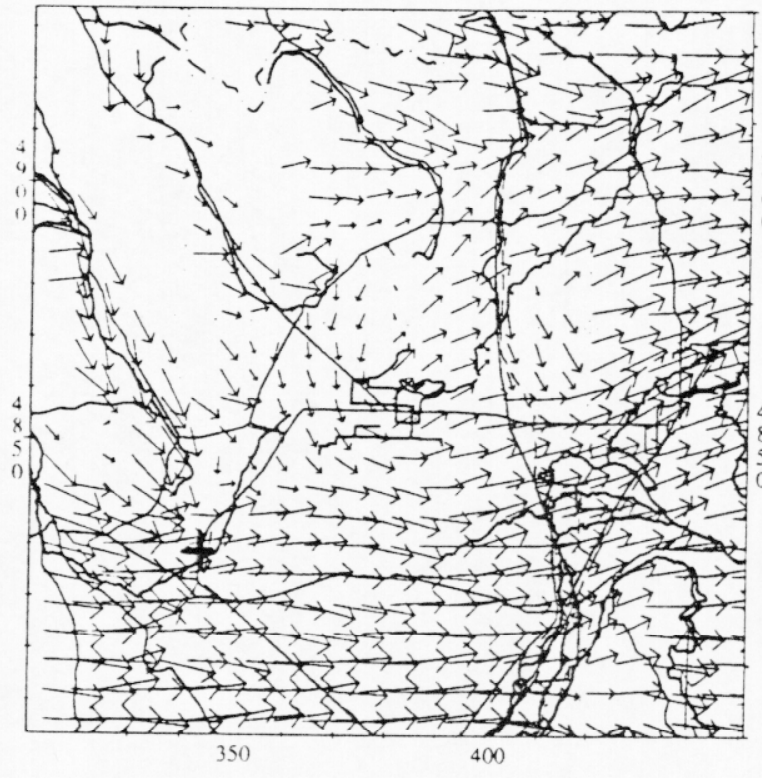

(c) $120 \mathrm{~m} \mathrm{AGL}$

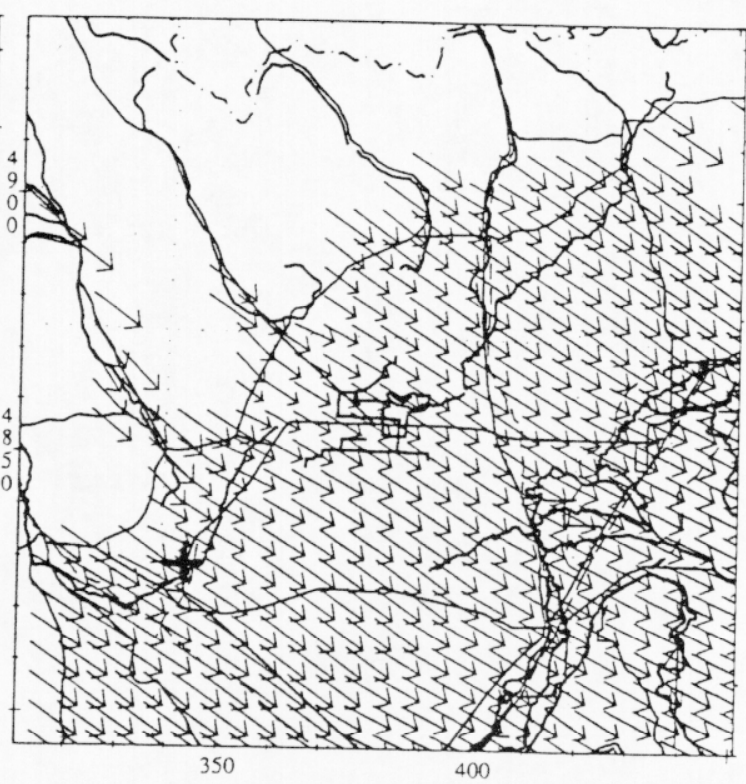

(d) $600 \mathrm{~m}$ AGL

Figure 5.5 Input surface wind barbs and model generated wind fields at 1715 UTC. (Full barb represents $6.5 \mathrm{~m} / \mathrm{s}$ and $\longrightarrow=10 \mathrm{~m} / \mathrm{s}$ ) 


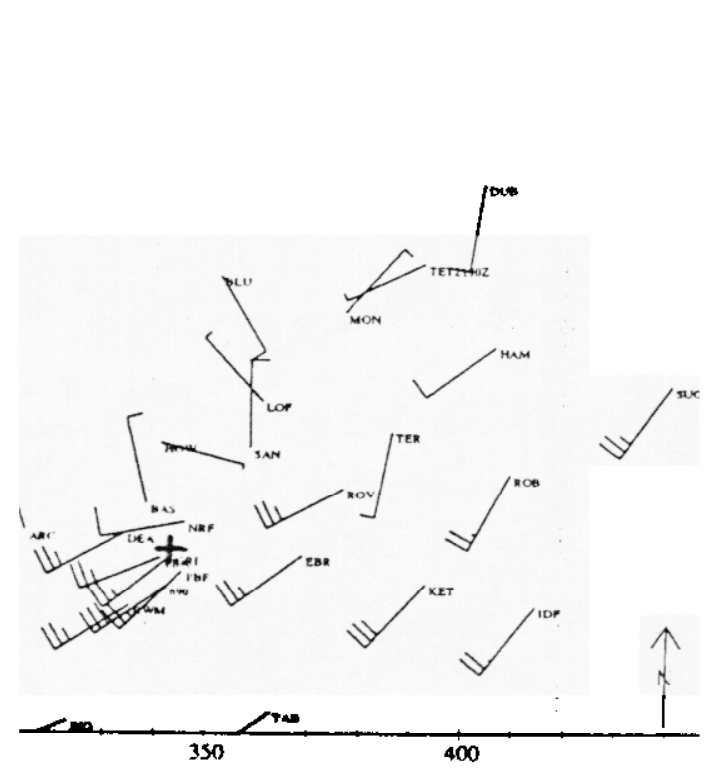

(a) Surface wind barbs.

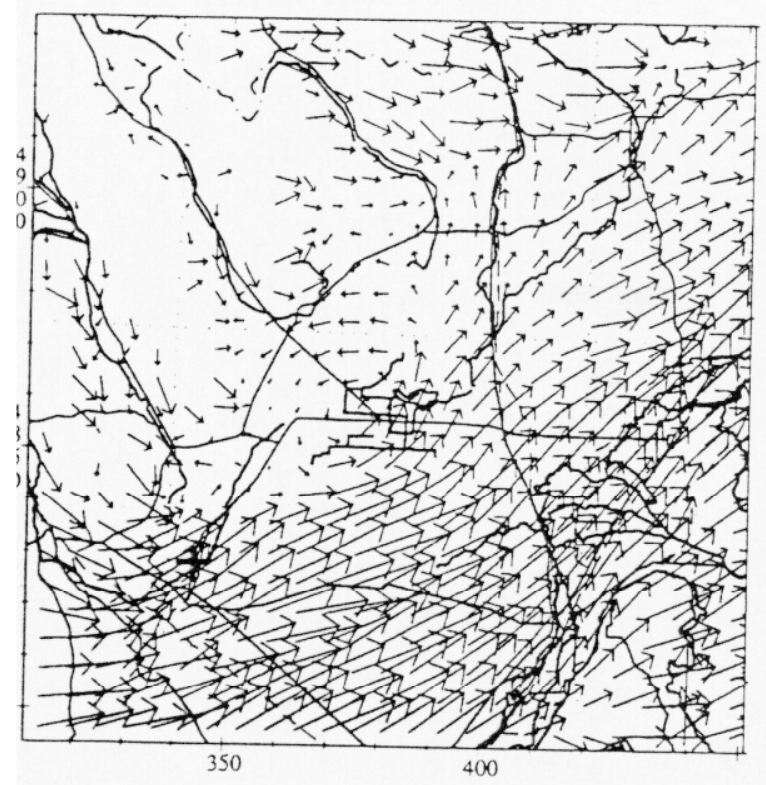

(b) $40 \mathrm{~m}$ AGL

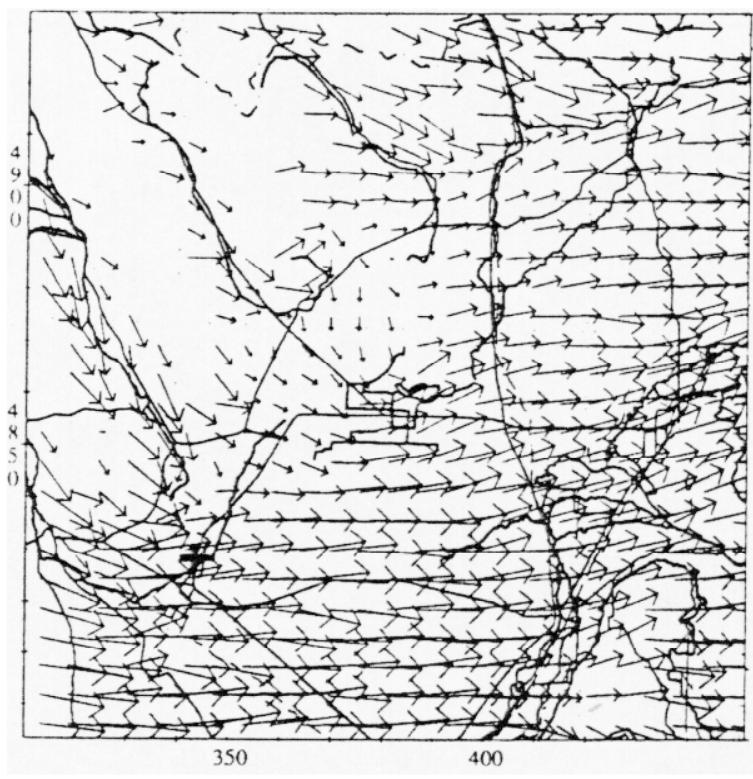

(c) $120 \mathrm{~m}$ AGL

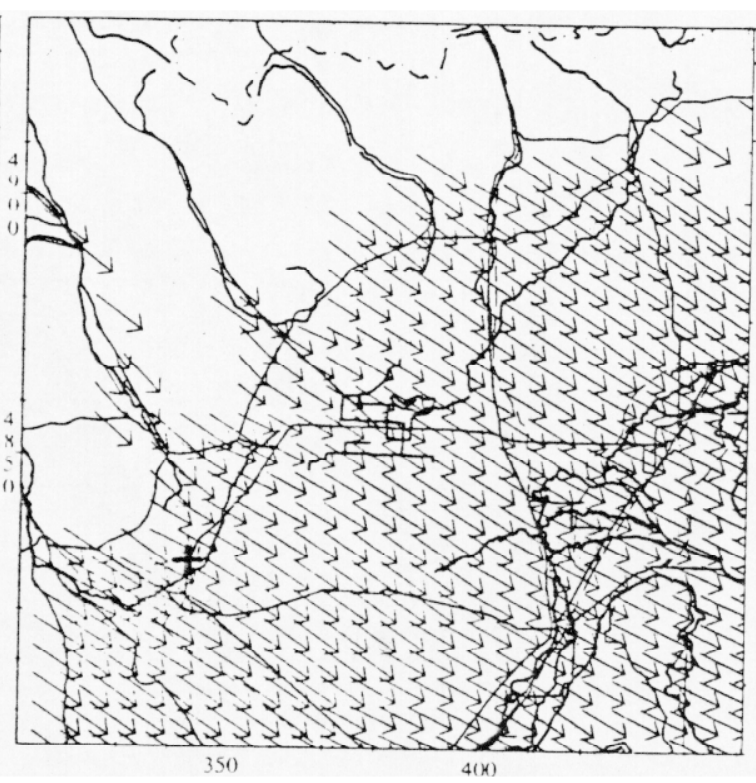

(d) $600 \mathrm{~m} \mathrm{AGL}$

Figure 5.6 Input surface wind barbs and model generated wind fields at 1815 UTC. (Full barb represents $6.5 \mathrm{~m} / \mathrm{s}$ and $\longrightarrow=10 \mathrm{~m} / \mathrm{s}$ ) 


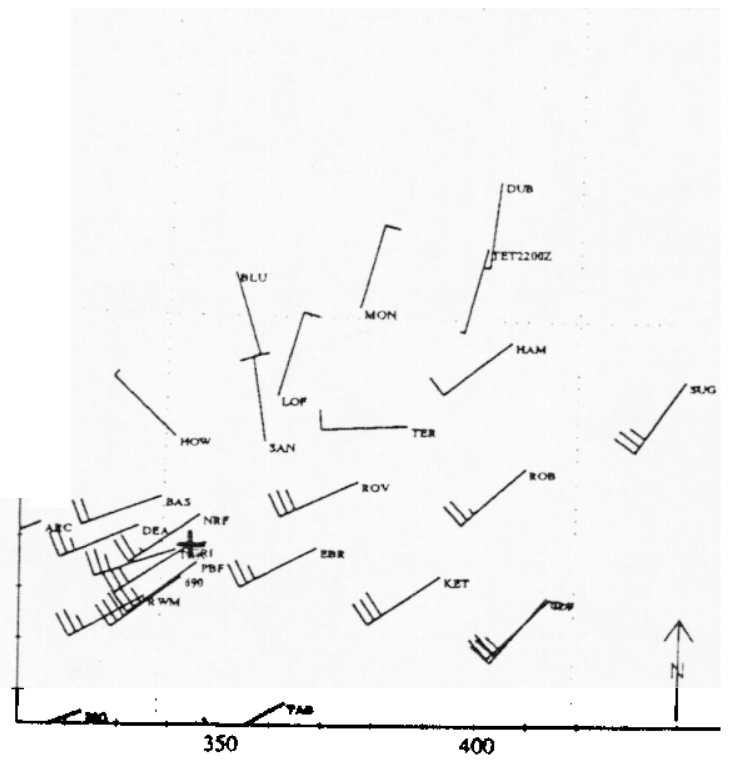

(a) Surface wind barbs.

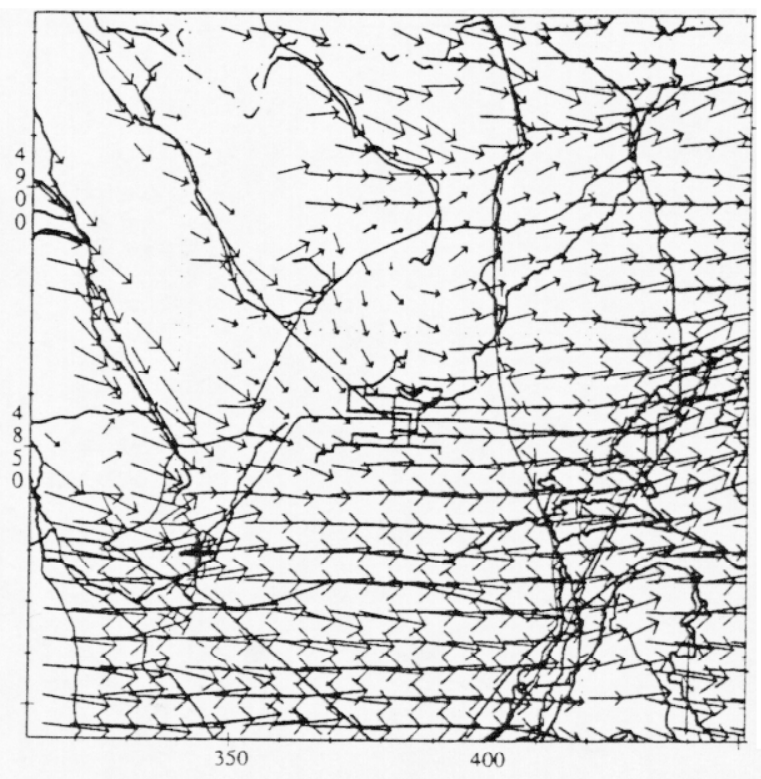

(c) $120 \mathrm{~m}$ AGL

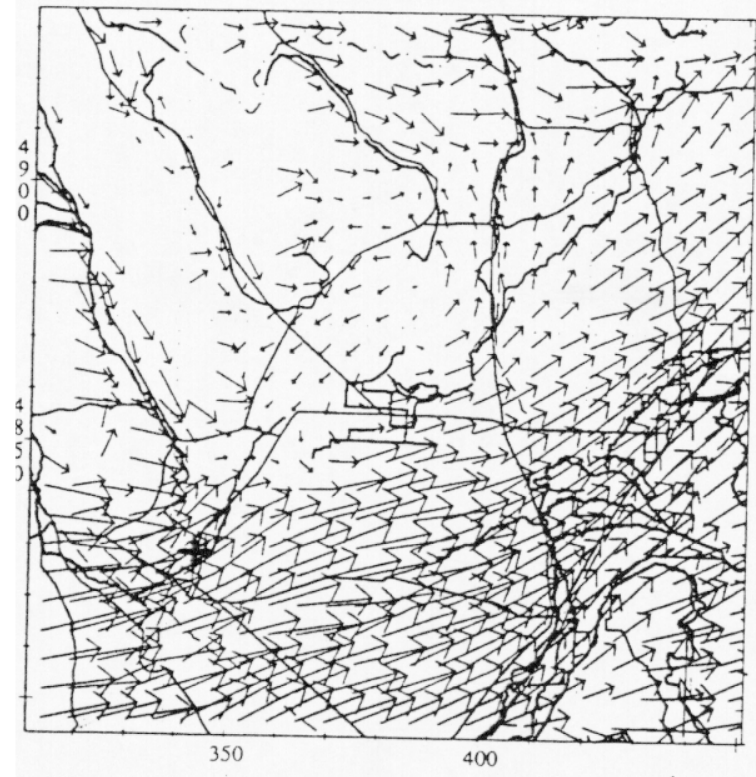

(b) $40 \mathrm{~m}$ AGL

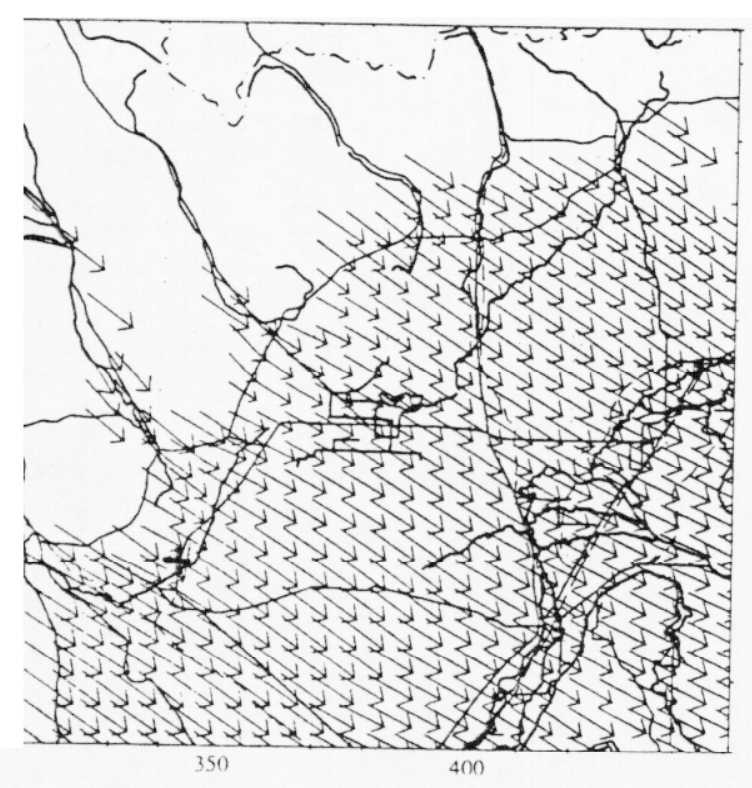

(d) $600 \mathrm{~m}$ AGL

Figure 5.7 Input surface wind barbs and model generated wind fields at 1915 UTC. (Full barb represents $6.5 \mathrm{~m} / \mathrm{s}$ and $\longrightarrow=10 \mathrm{~m} / \mathrm{s}$ ) 


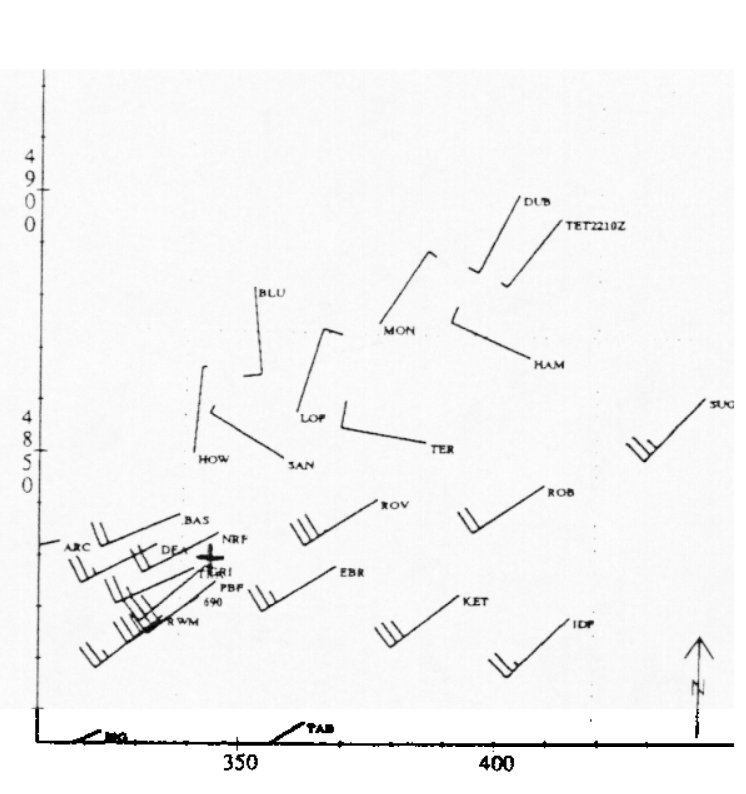

(a) Surface wind barbs.

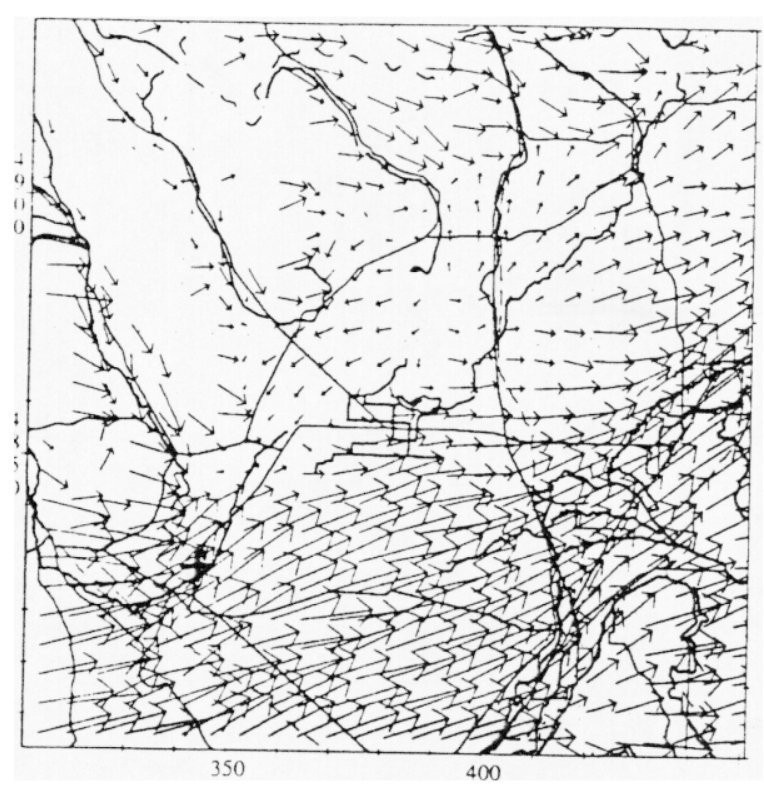

(b) $40 \mathrm{~m}$ AGL

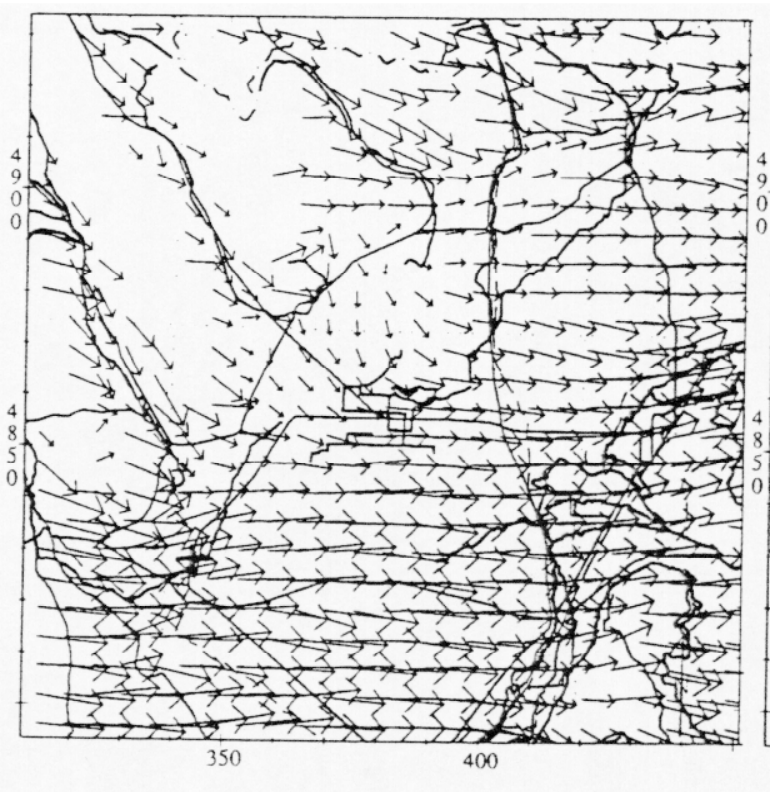

(c) $120 \mathrm{~m}$ AGL

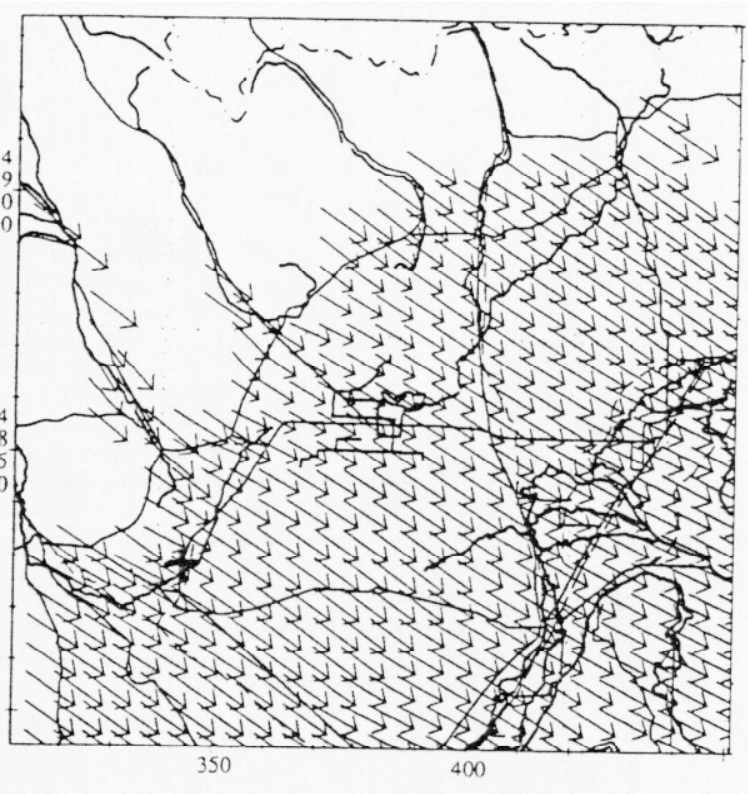

(d) $600 \mathrm{~m}$ AGL

Figure 5.8 Input surface wind barbs and model generated wind fields at 2015 UTC. (Full barb represents $6.5 \mathrm{~m} / \mathrm{s}$ and $\longrightarrow=10 \mathrm{~m} / \mathrm{s}$ ) 


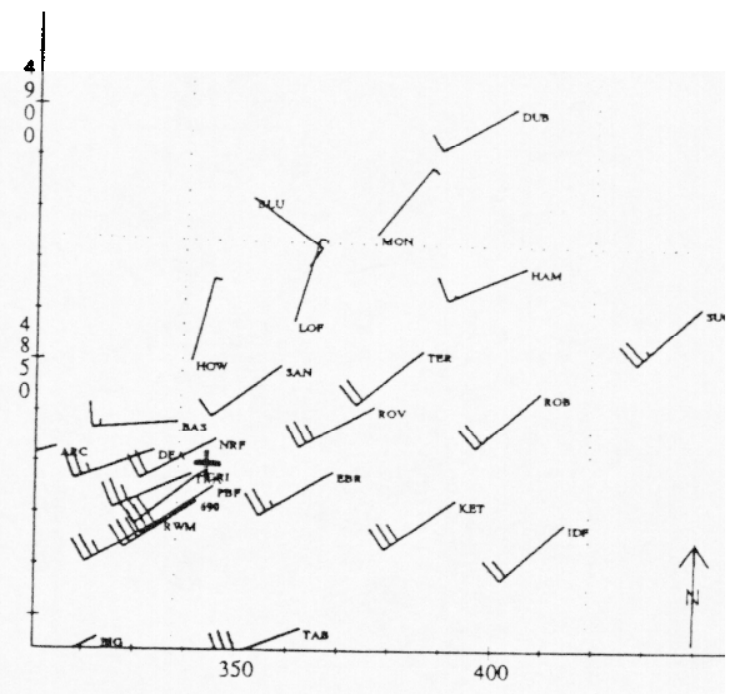

(a) Surface wind barbs.

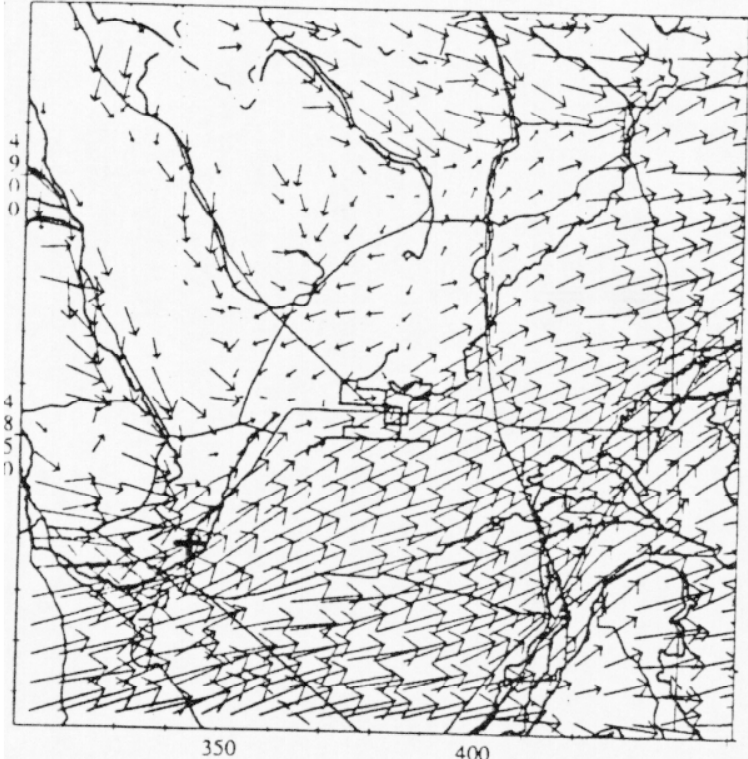

(b) $40 \mathrm{~m}$ AGL

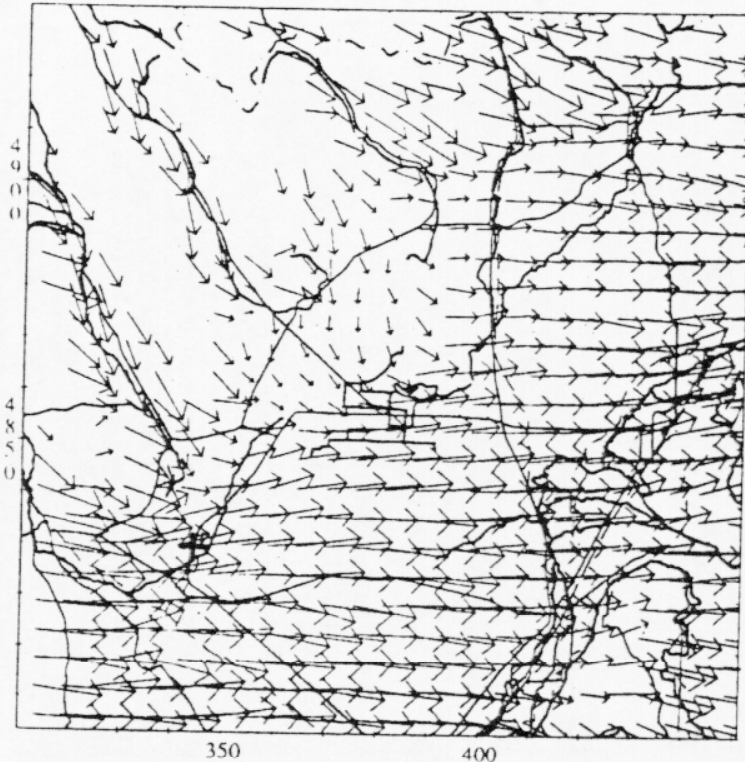

(c) $120 \mathrm{~m} \mathrm{AGL}$

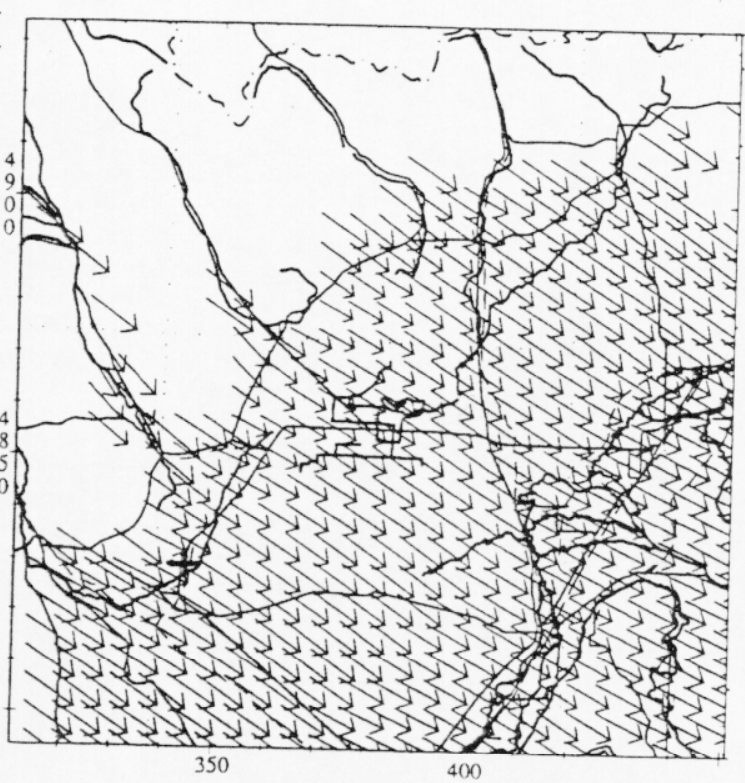

(d) $600 \mathrm{~m}$ AGL

Figure 5.9 Input surface wind barbs and model generated wind fields at 2115 UTC. (Full barb represents $6.5 \mathrm{~m} / \mathrm{s}$ and $\longrightarrow=10 \mathrm{~m} / \mathrm{s}$ ) 


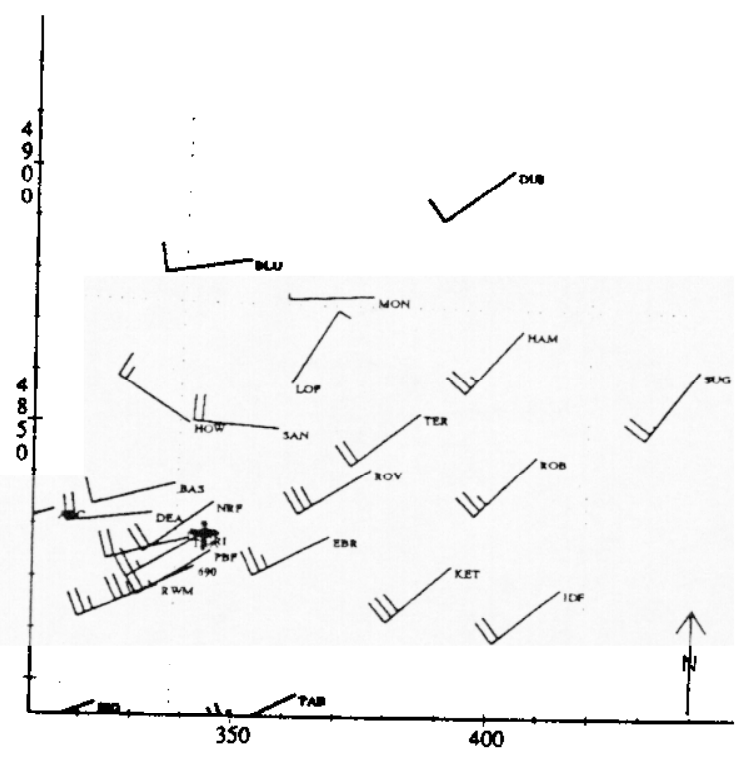

(a) Surface wind barbs.

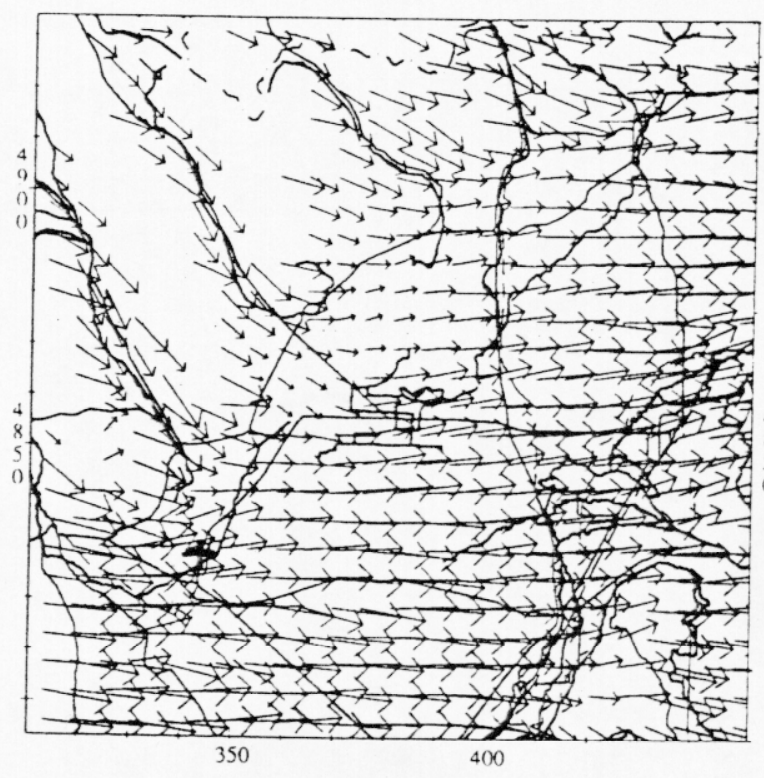

(c) $120 \mathrm{~m}$ AGL

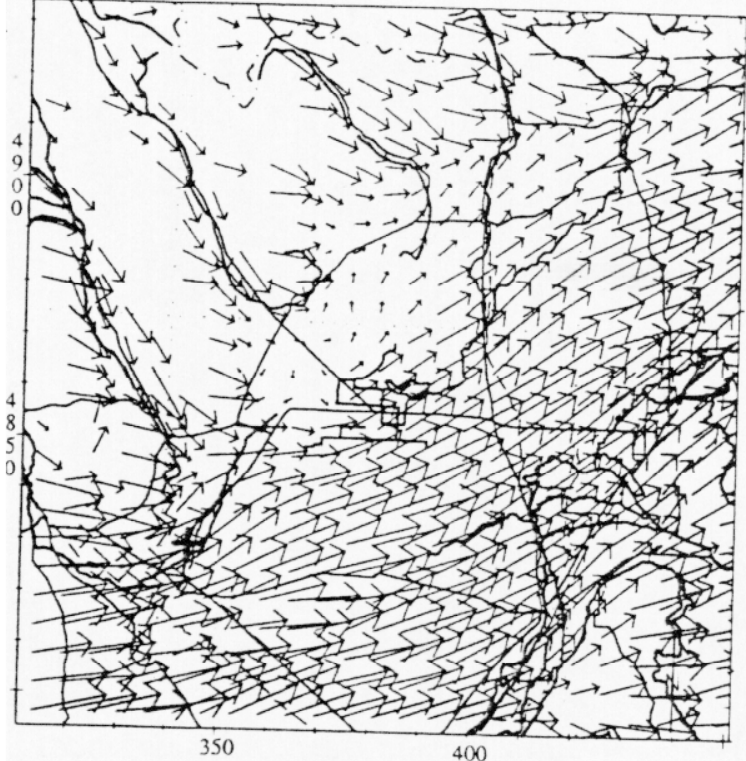

(b) $40 \mathrm{~m}$ AGL

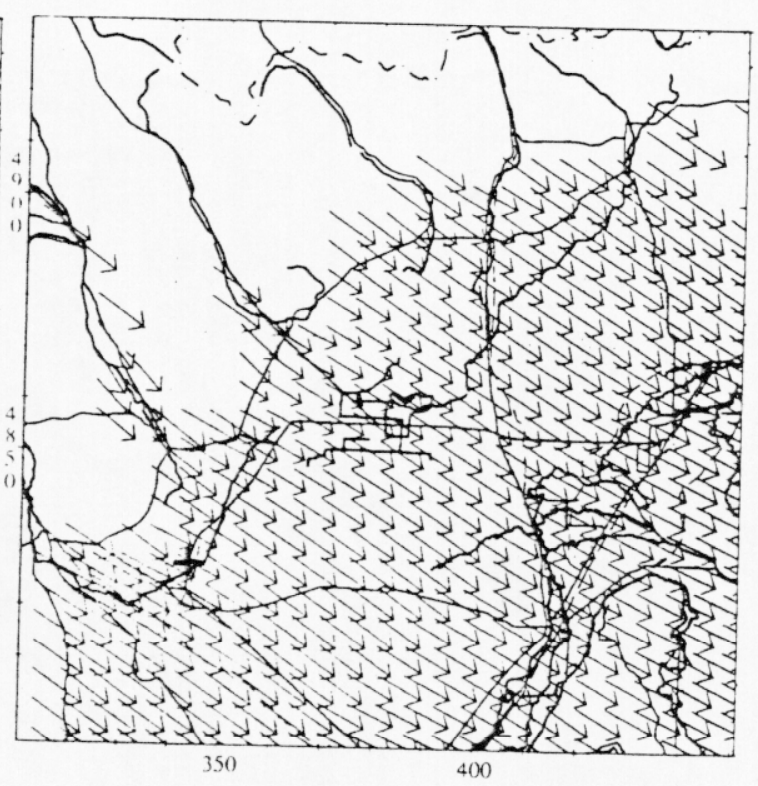

(d) $600 \mathrm{~m}$ AGL

Figure 5.10 Input surface wind barbs and model generated wind fields at 2215 UTC. (Full barb represents $6.5 \mathrm{~m} / \mathrm{s}$ and $\longrightarrow=10 \mathrm{~m} / \mathrm{s}$ ) 


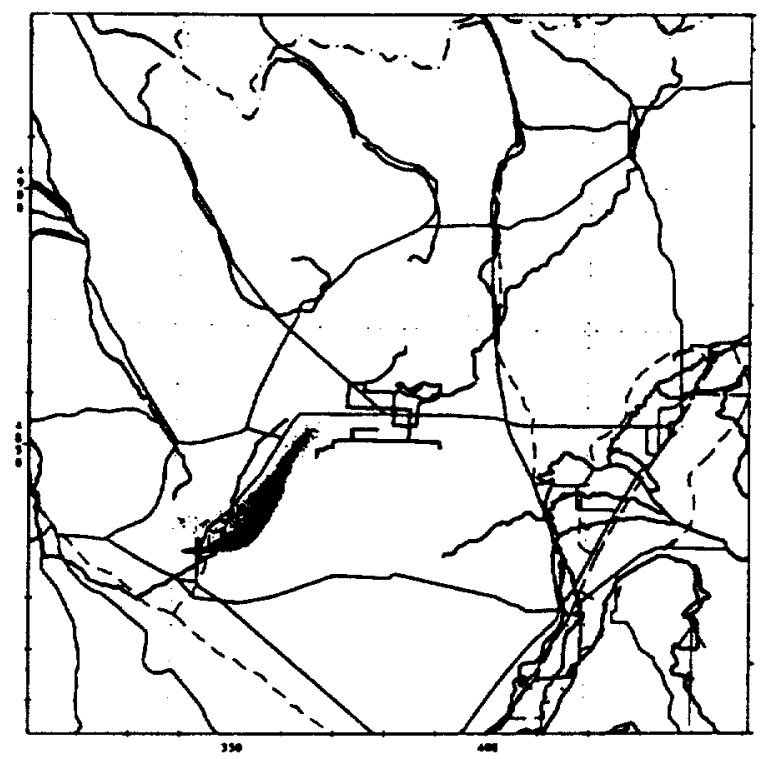

(a) 1415 UTC horizontal view

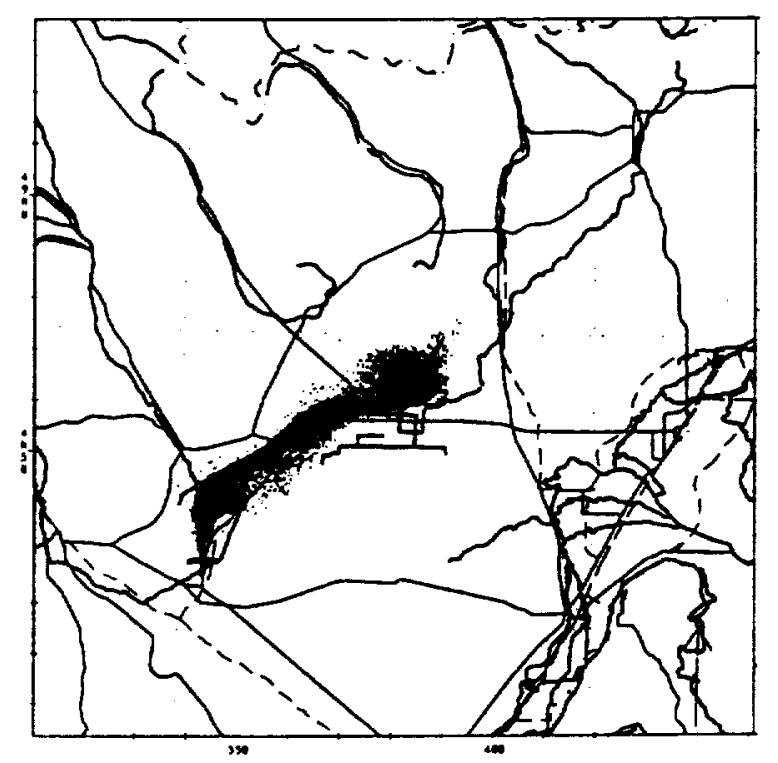

(c) 1515 UTC horizontal view

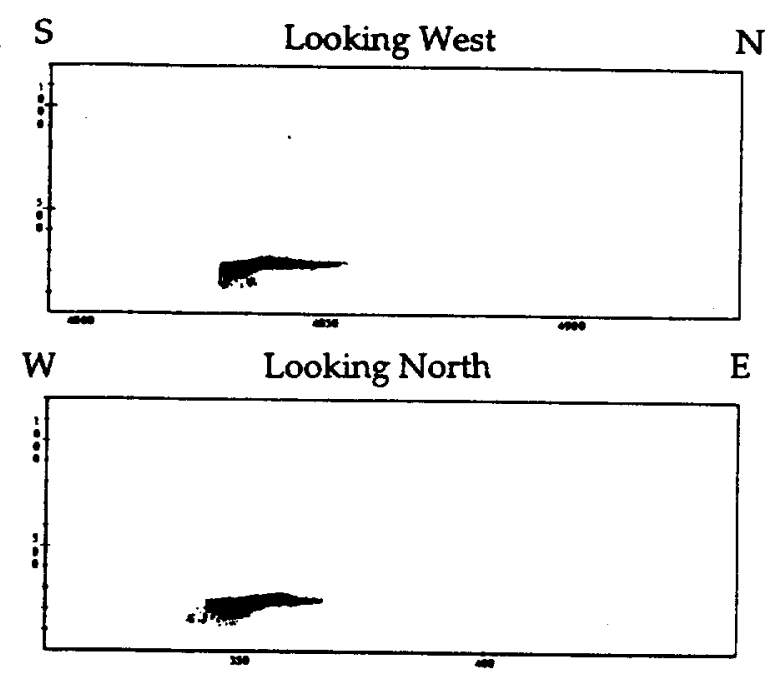

(b) 1415 UTC vertical views

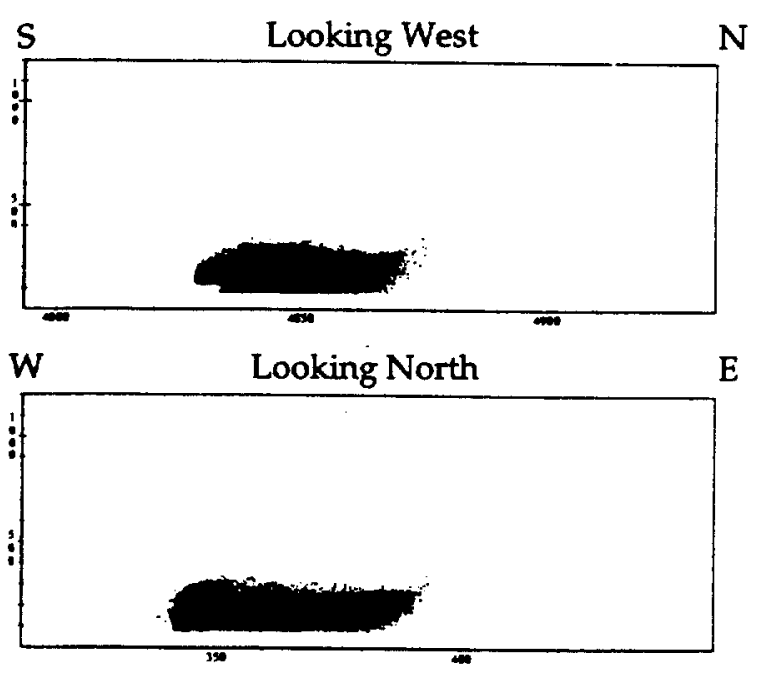

(d) 1515 UTC vertical views

Figure 5.11 Model calculated dispersion. Marker dots represent $\mathrm{SF}_{6}$ molecules. 


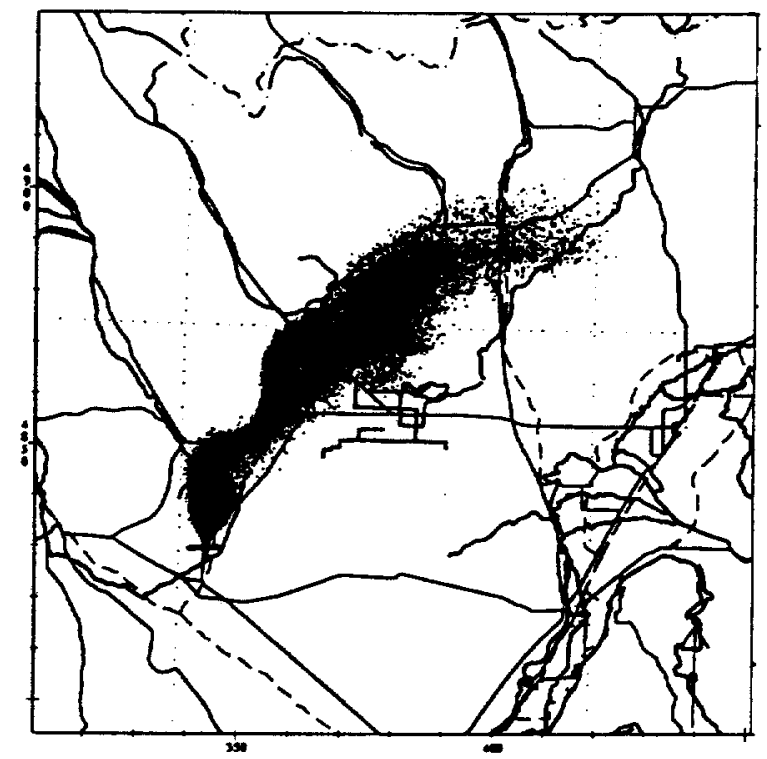

(a) 1615 UTC horizontal view

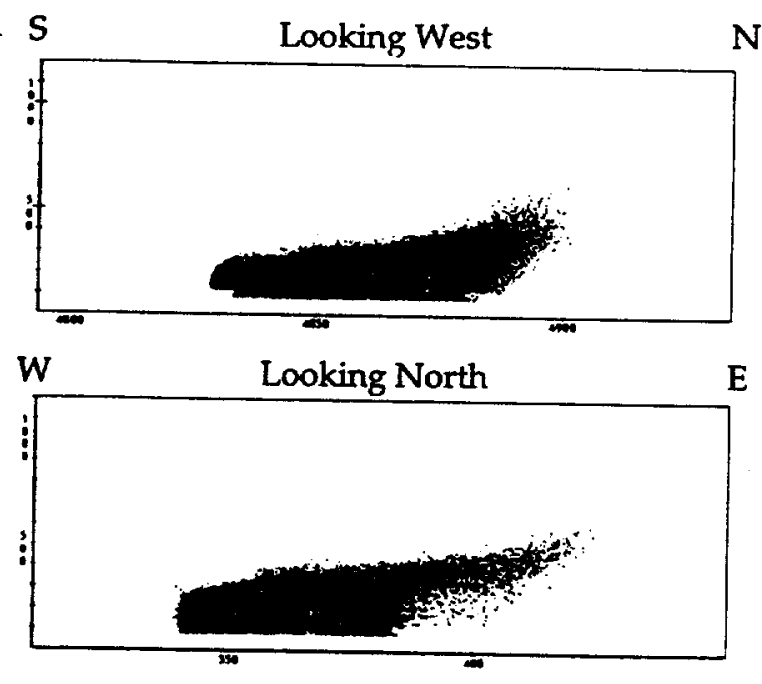

(b) 1615 UTC vertical views

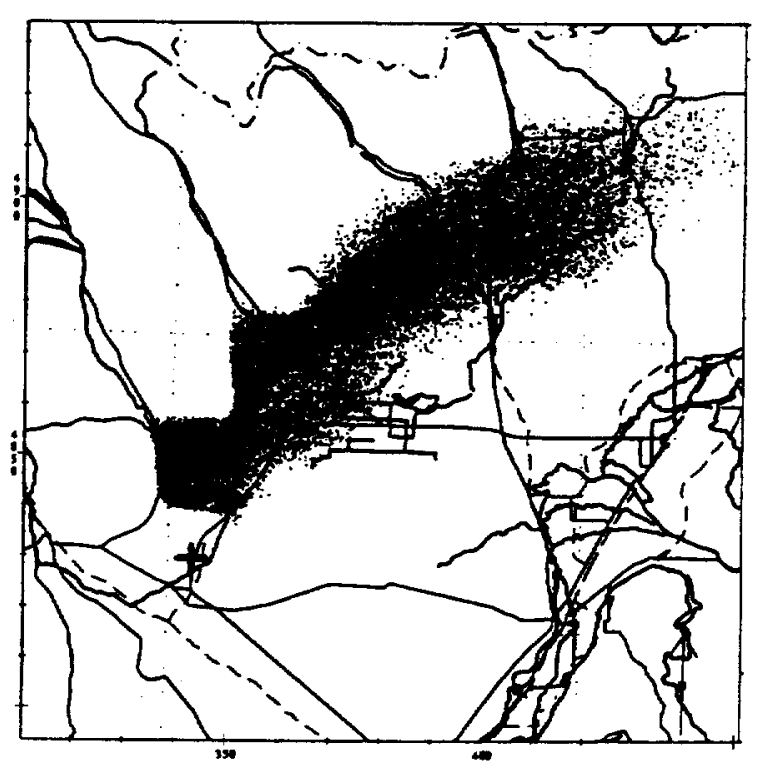

(c) 1715 UTC horizontal view

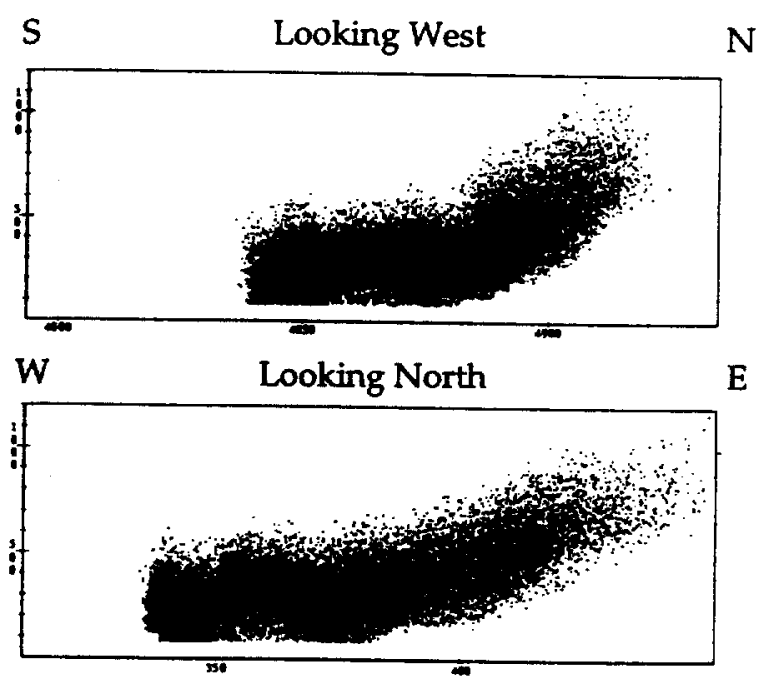

(d) 1715 UTC vertical views

Figure 5.12 Model calculated dispersion. Marker dots represent $\mathrm{SF}_{6}$ molecules. 


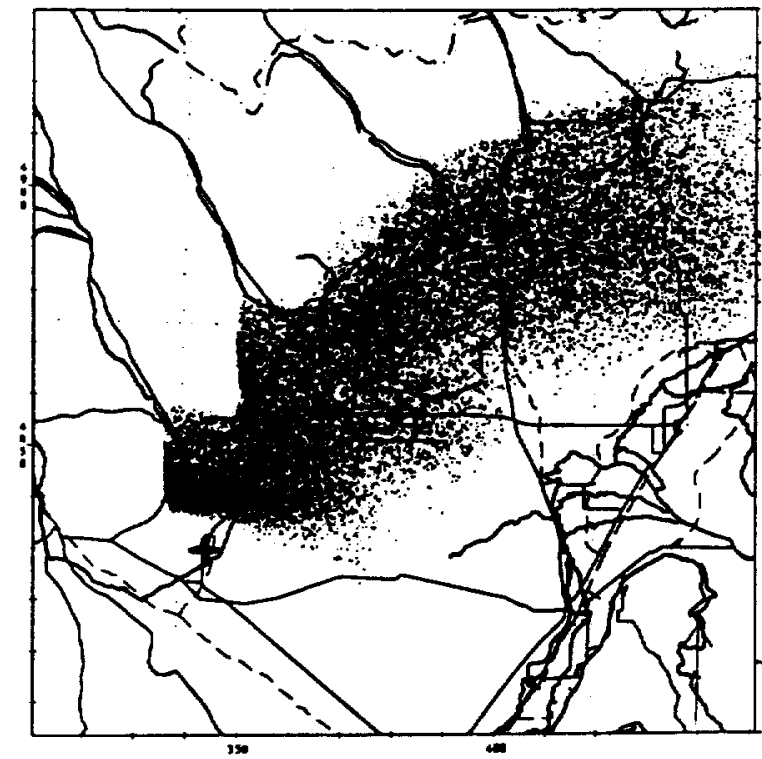

(a) 1815 UTC horizontal view

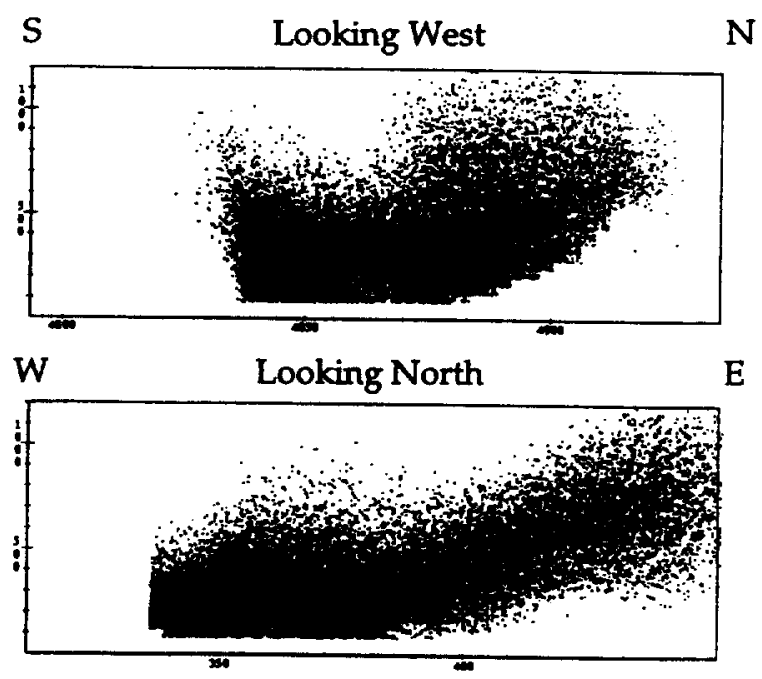

(b) 1815 UTC vertical views

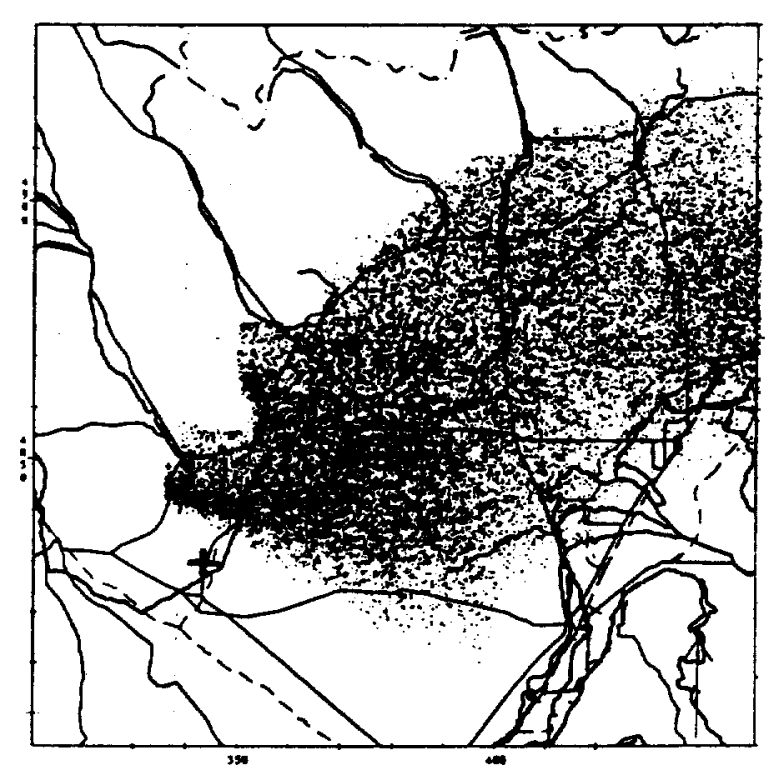

(c) 1915 UTC horizontal view

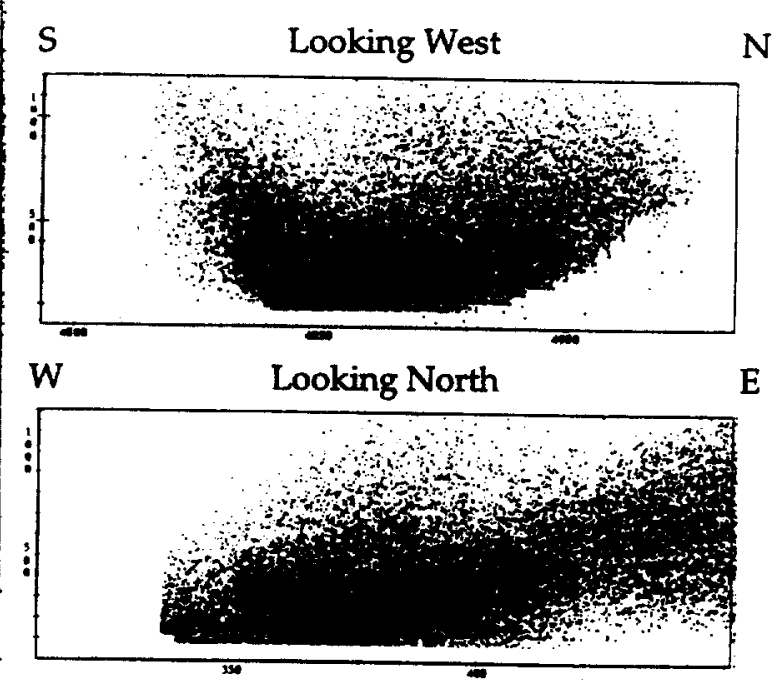

(d) 1915 UTC vertical views

Figure 5.13 Model calculated dispersion. Marker dots represent $\mathrm{SF}_{6}$ molecules. 


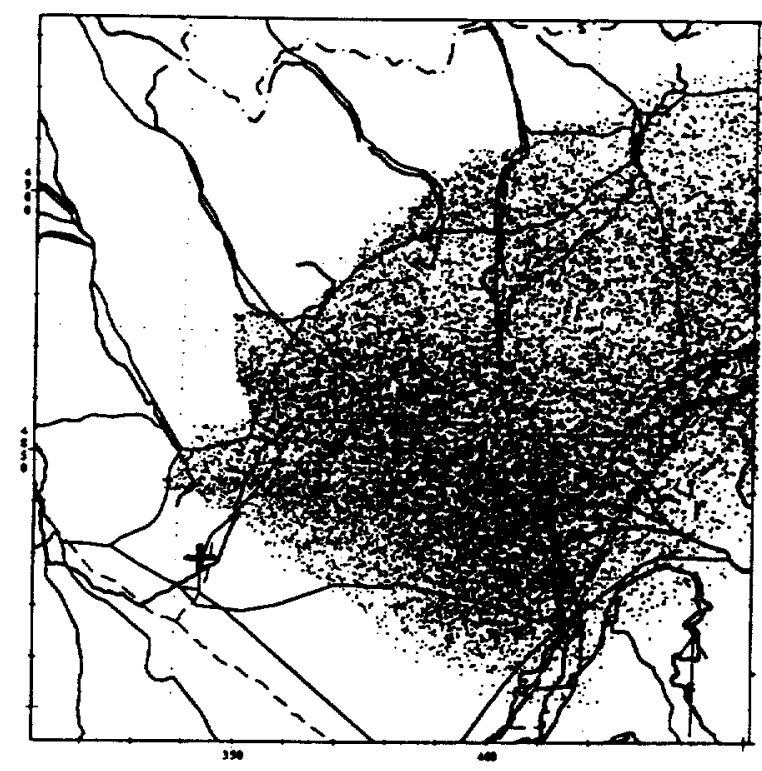

(a) 2015 UTC horizontal view

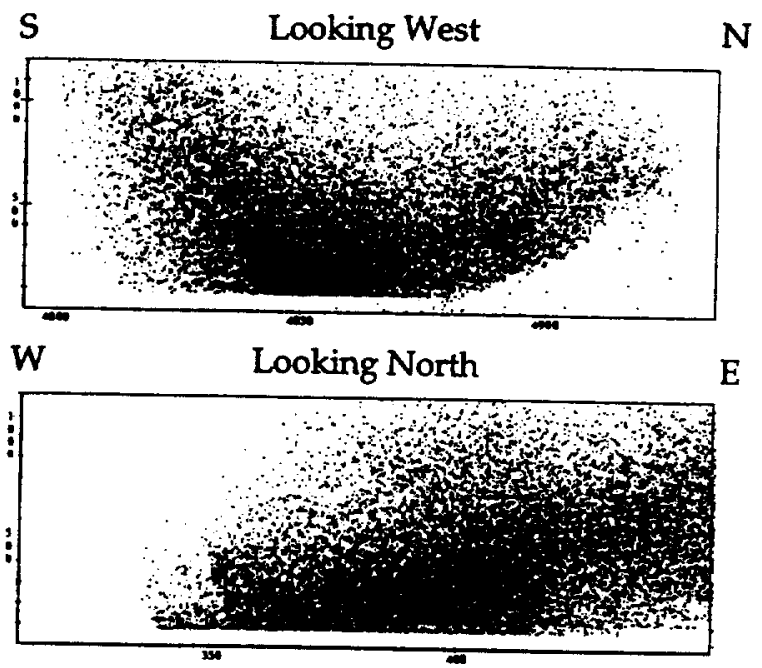

(b) 2015 UTC vertical views

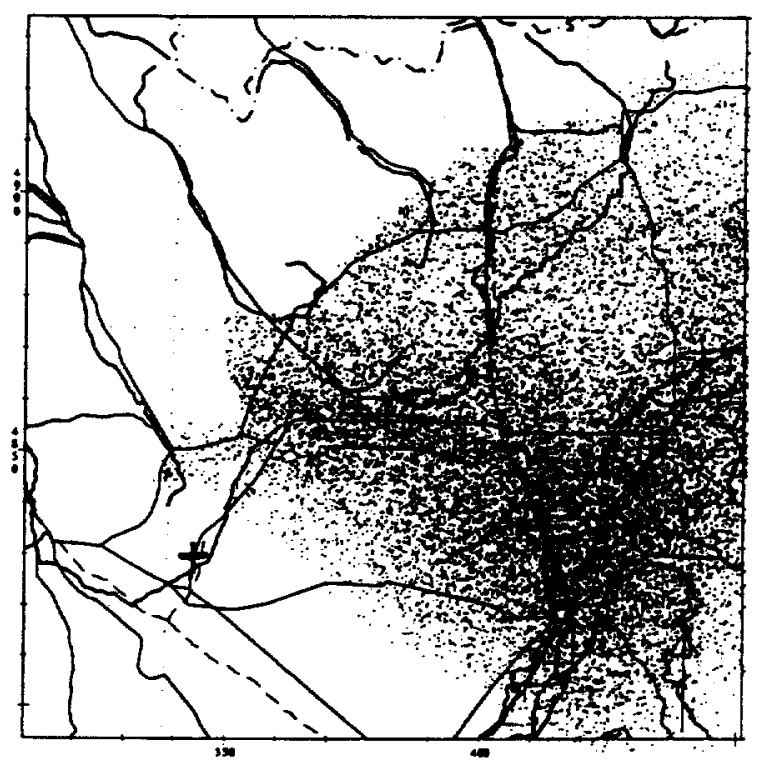

(c) 2115 UTC horizontal view
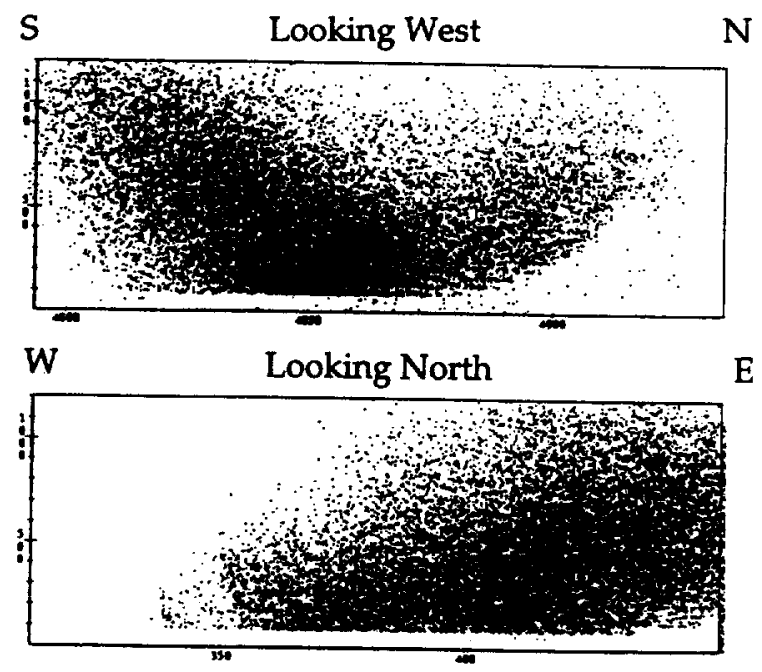

(d) 2115 UTC vertical views

Figure 5.14 Model calculated dispersion. Marker dots represent $\mathrm{SF}_{6}$ molecules. 


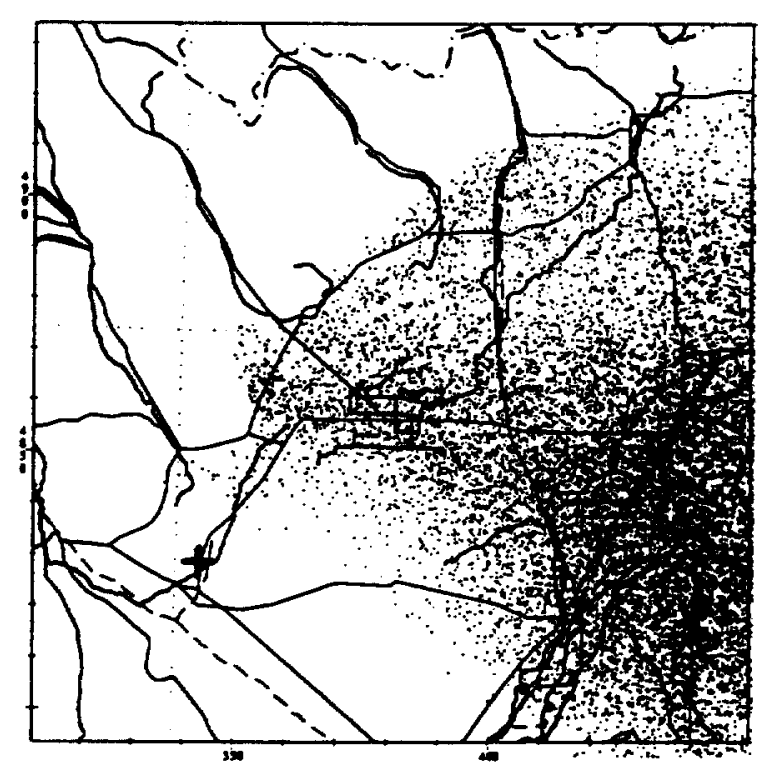

(a) 2215 UTC horizontal view
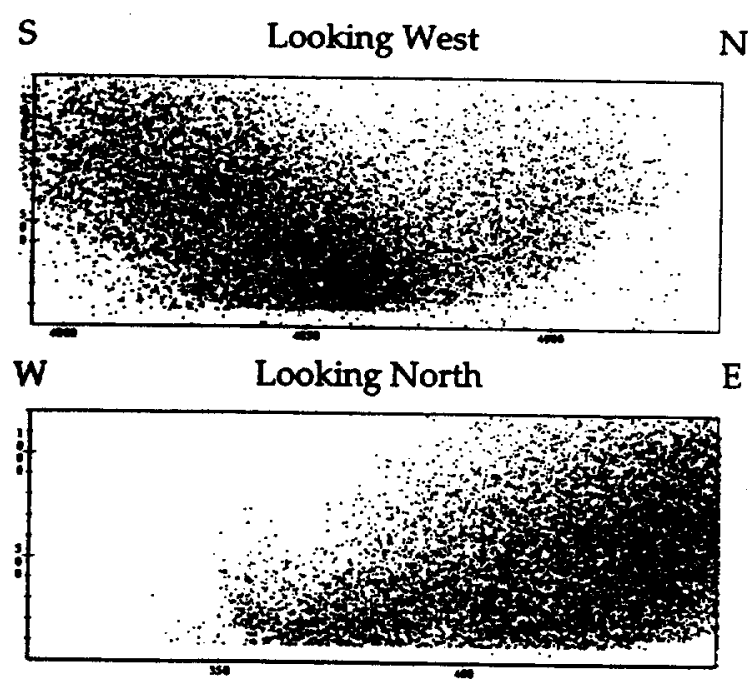

(b) 2215 UTC vertical views

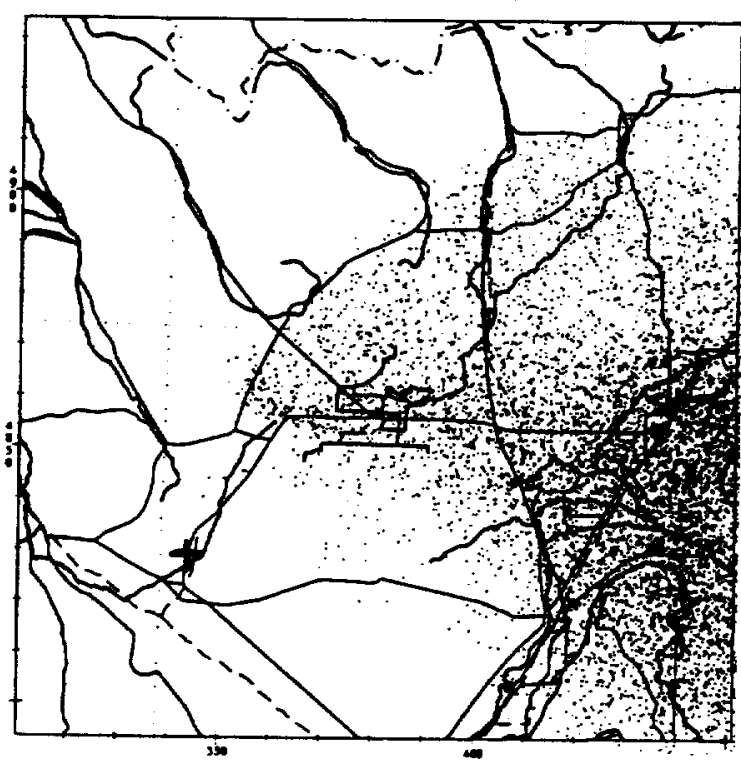

(c) 2315 UTC horizontal view

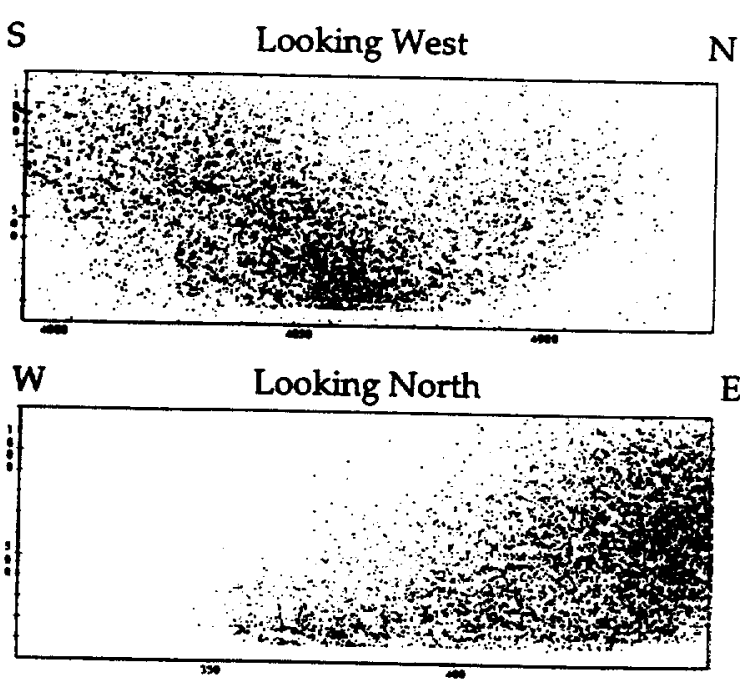

(d) 2315 UTC vertical views

Figure 5.15 Model calculated dispersion. Marker dots represent $\mathrm{SF}_{6}$ molecules. 
The slightly stable atmosphere of the model limits the vertical transport extent of the tracer to the mixing layer height. Therefore, the main transport layer in the first four hours of the model run is below $120 \mathrm{~m}$. Figure 5.11(a) shows that the south winds at the release time, 1315 UTC, were light causing the initial plume to move slowly to the north by 1415 UTC. Figure 5.11(b) shows that as the $\mathrm{SF}_{6}$ dispersed vertically toward the top of the mixed layer, the southwest winds began to shear the top of the plume to the northeast.

The winds in the third hour had a stronger component from the south and transported the plume northward towards the canyons. Figure 5.12(c) shows that as these winds continue through the fourth hour, they cause the plume to impact on the canyon walls and be transported into the two canyons on the western side of the study domain. Figure 5.12(d) shows that as the winds near the top of the mixed layer continue to be from the southwest, the top of the plume is sheared to the northeast. The moderate down canyon flow from the western canyon restricts the plume from being transported deeply into the canyon and causes the tracer to pool near the mouth. However, the weak flow in the second canyon allows a deeper penetration of $\mathrm{SF}_{6}$ into the canyon.

After the 1200 UTC to 0000 UTC sounding changeover and the increase in mixing layer height to $1000 \mathrm{~m}$ at $1700 \mathrm{UTC}$, the plume transport direction changes significantly. As the tracer is transported vertically, the plume shearing to the northeast is replaced by a general eastward motion except near the surface which maintains a flow from the southwest. Figures $5.12-5.15$ (b) and (d) illustrate that since the tracer becomes more yertically distributed with the increase in the mixing layer height, the westerly winds transport the tracer out from the canyon faces and eastward across the study domain. This transport 
continues through the remainder of the study period carrying the $\mathrm{SF}_{6}$ out the eastern edge of the study domain.

\subsection{Measurement to Model Comparison}

The sensitivity studies conducted to determine model input parameters used a subset of the limited tracer measurements taken during the experiment. However, to evaluate the best-estimate of plume dispersion, the calculated $\mathrm{SF}_{6}$ concentrations are compared to all available tracer measurements which allows for an overall assessment of modeled plume dispersion.

Figure 5.16 shows the one-minute averaged aircraft flight altitudes where measurements were taken and when $\mathrm{SF}_{6}$ was detected. The circles represent the height above ground and time where $\mathrm{SF}_{6}$ was detected. This data was used to determine the vertical levels to compare modeled concentrations to observed measurements. The tracer was only detected between 1748 and 1841 UTC at 200 $\mathrm{m}$ AGL. The rest of the flights did not detect any $\mathrm{SF}_{6}$. Figure 5.17 again illustrates all the available surface and aircraft data. Figures $5.18-5.22$ show the modeled $\mathrm{SF}_{6}$ instantaneous air concentrations at altitudes and times where aircraft and truck measurements were taken and comparisons made. The modeled dispersion pattern dot plots will also be used to compare modeled plume position to observed tracer measurements.

The truck provided the first six samples of this experiment beginning at 1413 UTC and continuing to 1619 UTC in about 30 to 60 minute intervals. The first measurement at $1413 \mathrm{UTC}$ detected $\mathrm{SF}_{6}$, but model calculations did not generate detectable levels of tracer at this location and time. However, the

modeled plume was in the area where the measurement was recorded (see 
Figure 5.11(a)), and Figure 5.18(a) shows that the model did produce detectable concentrations within $10 \mathrm{~km}$ of the measurement location. The model transported the tracer to the northeast, and did mix the tracer downward, but not to that distance from the source (see Figure 5.11(b)).

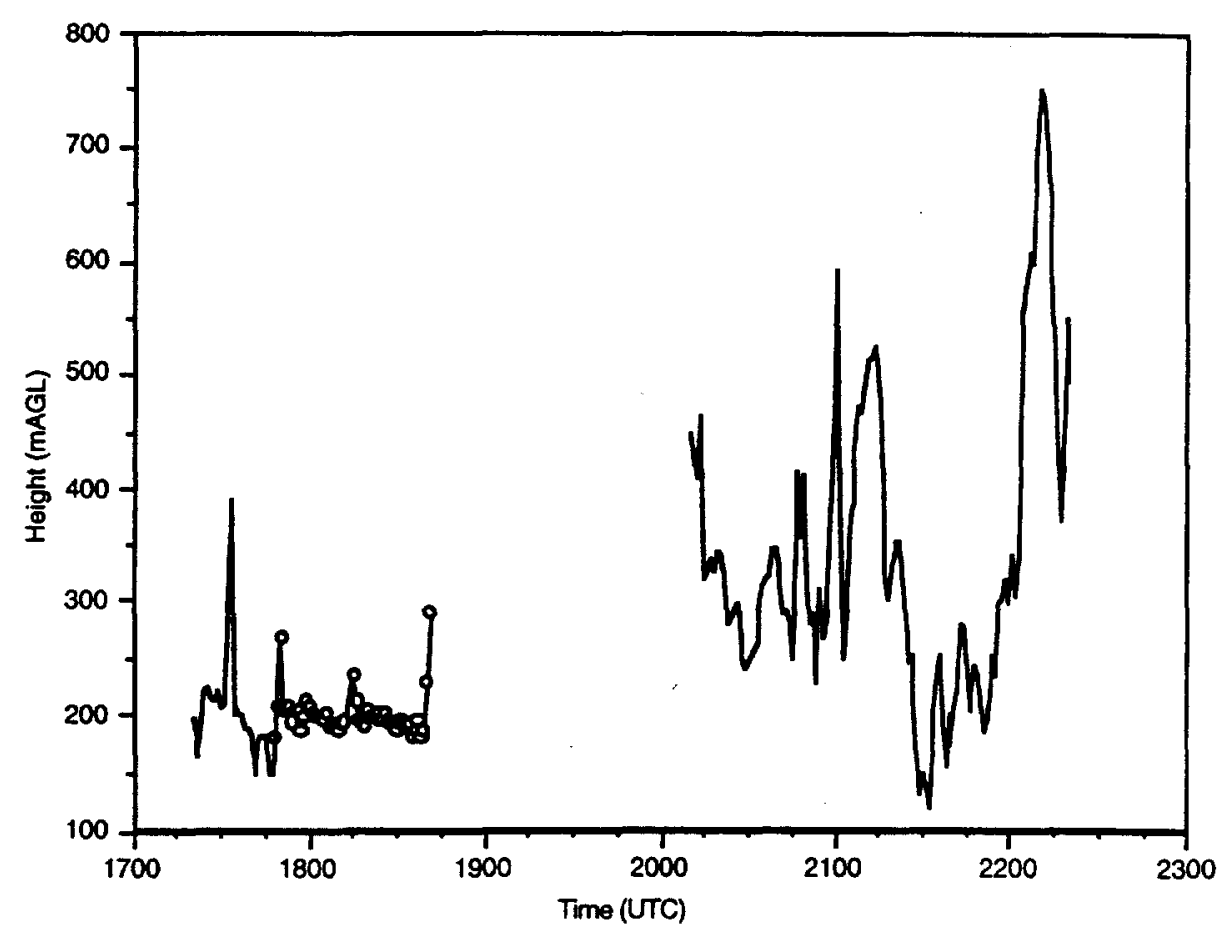

Figure 5.16 One-minute averaged aircraft flight altitudes plotted against time. (Circles indicate positions where $\mathrm{SF}_{6}$ was detected above $10 \mathrm{ppt}$.)

The next truck measurement just north along the same road at 1445 UTC detected no $\mathrm{SF}_{6}$. At this time, Figure $5.18(\mathrm{~b})$ shows that there was no detectable levels of $\mathrm{SF}_{6}$ generated by the model near the surface. However, the model did have the tracer in the area, but it was elevated. The next two truck measurements at 1515 and 1545 UTC near the center of the study domain did not detect any $\mathrm{SF}_{6}$. Figures 5.18 (c) and (d) show that the model did produce detectable tracer levels near these locations, but not at the measurement 
locations. Similarly, Figure 5.18(e) shows that the modeled concentrations compare with the non-detection measurement at 1651 UTC.

The model generated a northeast-southwest oriented tracer plume across the domain impacting on the mountains to the northwest, before it began the eastward transport across the domain at 1700 UTC. A truck measurement near the center of the domain at 1719 UTC detected tracer. Figure 5.18(f) shows that the model did not generate detectable $\mathrm{SF}_{6}$ concentrations at this location and time.

The aircraft measurements began at 1720 UTC as the plane flew north into the center of the domain, veered northeast and then returned to domain center at 1748 UTC, and flew several circles before heading southward and ceased measuring at 1841 UTC. The aircraft flew at a fairly constant $200 \mathrm{~m} \mathrm{AGL}$ and detected no $\mathrm{SF}_{6}$ from 1720 to 1747 UTC, but did detect $\mathrm{SF}_{6}$ from 1748 to 1841 UTC. These measurements were used for the comparison in the sensitivity studies discussed in Chapter 4. Figures 5.19(a) and (b) show that the model did not generate detectable tracer levels at $200 \mathrm{~m}$ AGL between 1715 and 1745 UTC at aircraft locations, but did generate detectable $\mathrm{SF}_{6}$ levels at $200 \mathrm{~m}$ between 1745 and 1845 UTC in the area surveyed by the aircraft, Figures $5.19(\mathrm{~b})$ to (d). The model did agree well with these aircraft measurements.

Approximately 90 minutes passed before the next measurement was taken. The truck detected $\mathrm{SF}_{6}$ at 2019 UTC just east of domain center, and Figure 5.18(g) shows that the model also generated detectable concentrations at this time and location. The aircraft began recording measurements in the northeastern corner of the study domain at varying flight levels. However, between 2015 and 2100 UTC the plane flew an average flight level of $300 \mathrm{~m}$ and detected no tracer. 
Figures 5.20(a) and (b) show that the models generated a similar result, and produced no $\mathrm{SF}_{6}$ concentrations above $10 \mathrm{ppt}$ in the area. The main plume area generated by the model was moving eastward near the center of the study domain.

The final truck measurement was below detection in the extreme north of the study domain at 2106 UTC. Figure 5.18(h) shows that the model did not generate any detectable concentration levels in this area as the main plume area was south and moving east. The remainder of the aircraft flight measurements from 2100 to $2220 \mathrm{UTC}$ at altitudes ranging from $125 \mathrm{~m}$ to $750 \mathrm{~m}$ did not detect any $\mathrm{SF}_{6}$. Figures 5.19(e) and (f), 5.20(c), 5.21 and 5.22 show that the model also did not produce any detectable tracer concentrations in these locations at these times and flight levels.

The model generated plume concentrations had good agreement with the aircraft measurements. Near the surface, some discrepencies were present between modeled and measured values. Several explanations exist for these occurances. Mixing occurs in the lower layers of the atmosphere below the surface inversion that may not be well represented by the models run at this resolution. However, executing the models at a higher resolution involves reducing the study domain, thereby minimizing the examination of the overall tracer transport. Also, with the limited number of surface tracer measurements, it is difficult to determine their accuracy and representativeness. 


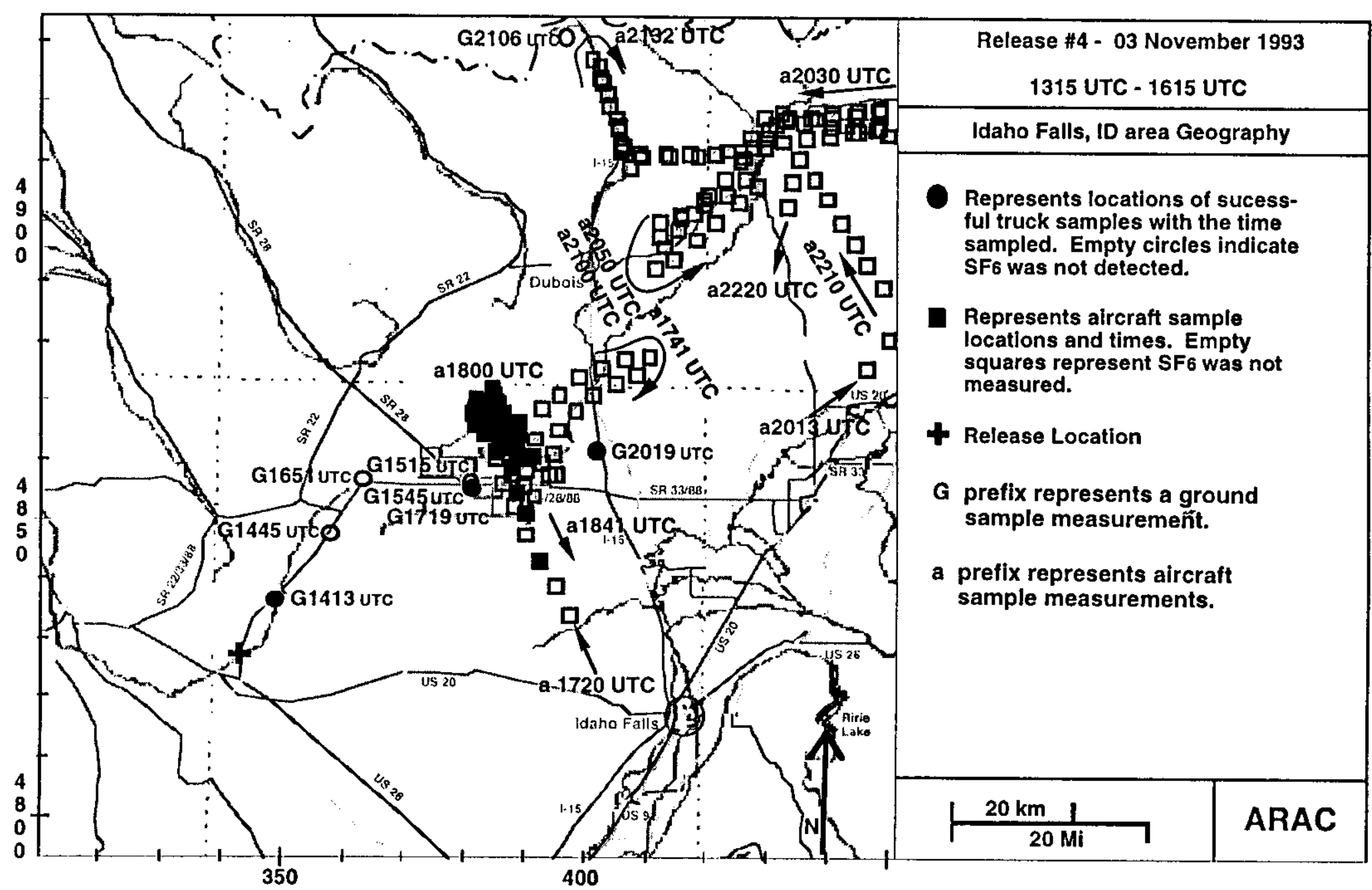

Figure 5.17 Truck (O) and aircraft ( $\square$ ) measurement locations for Release \#4, 03 November 1993. 


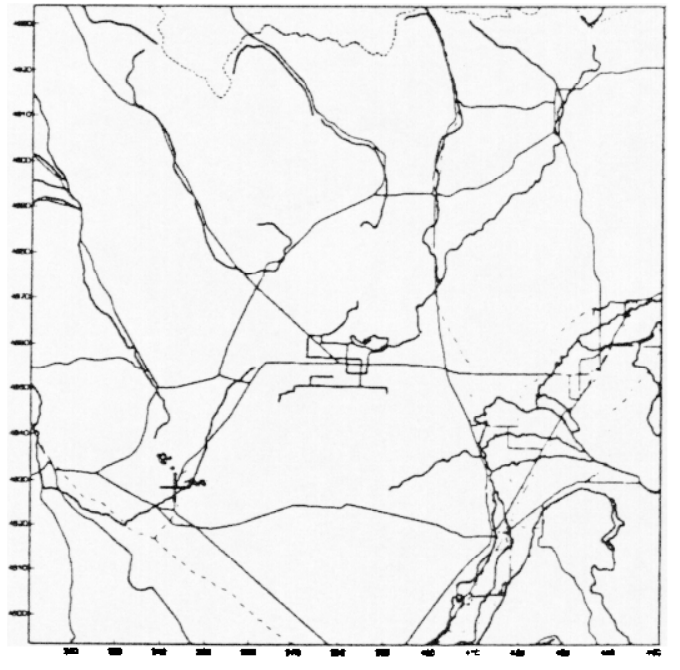

(a) 1415 UTC

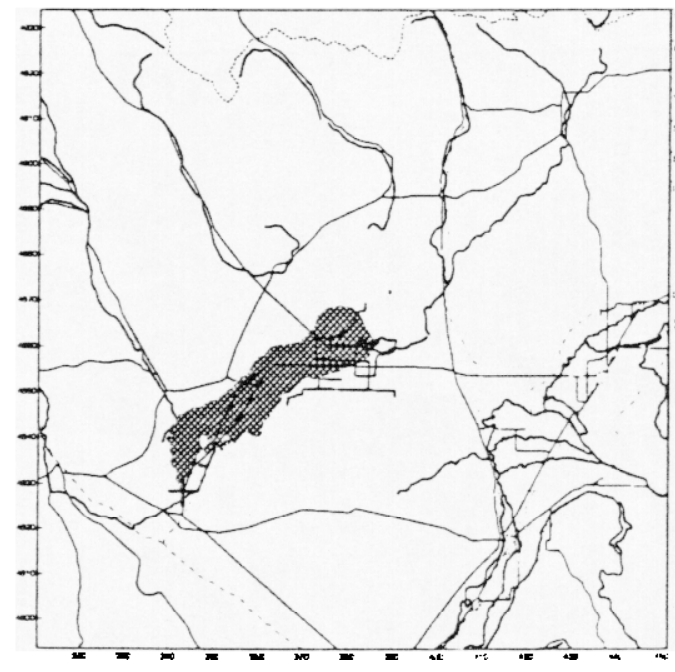

(c) 1515 UTC

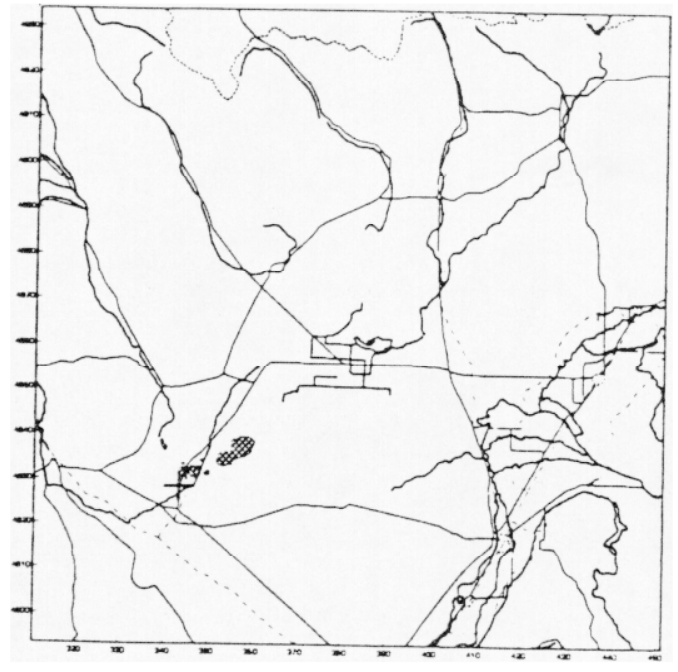

(b) 1445 UTC

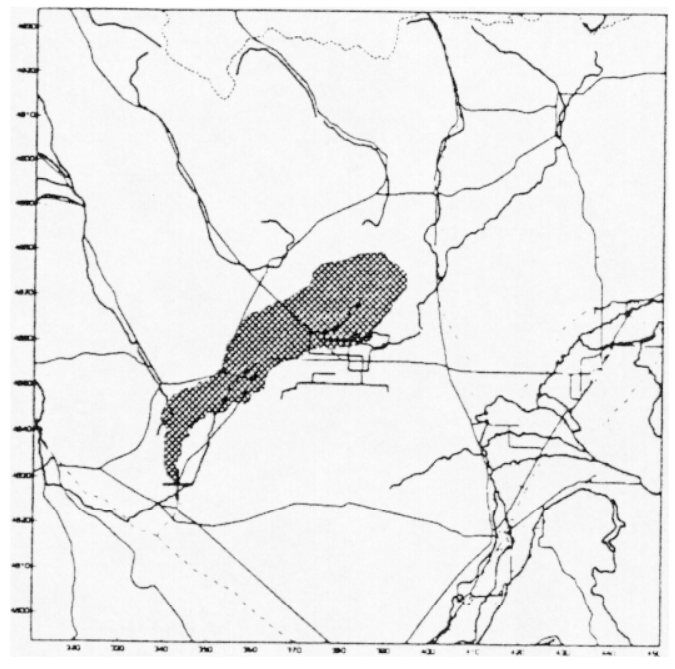

(d) 1545 UTC

Figure 5.18 Modeled Instantaneous Air Concentrations of $\mathrm{SF}_{6}$ at $1.5 \mathrm{~m}$ AGL. (Shaded areas represent areas with concentrations greater than $10 \mathrm{ppt}$ ) 


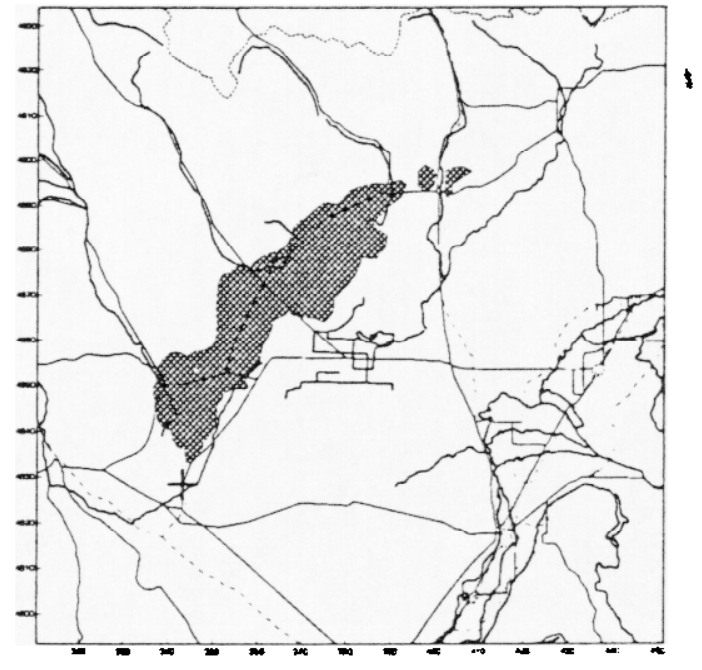

(e) 1645 UTC

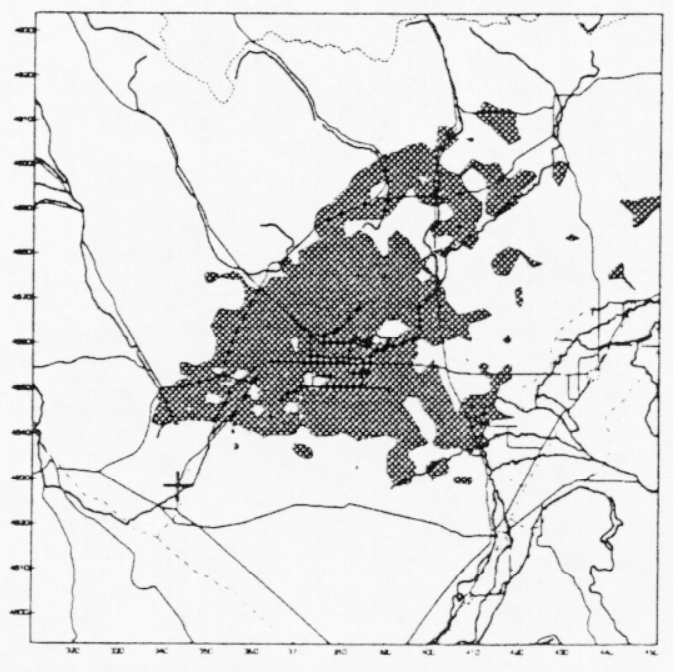

(g) 2015 UTC

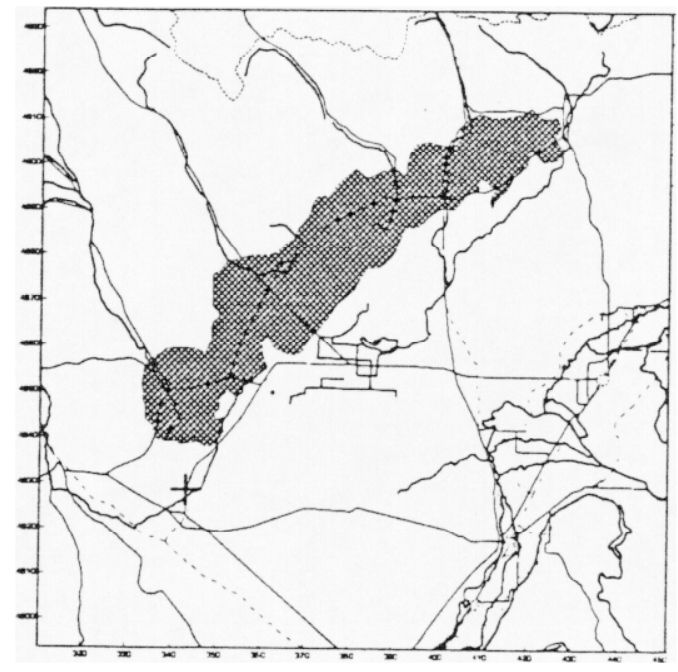

(f) 1715 UTC

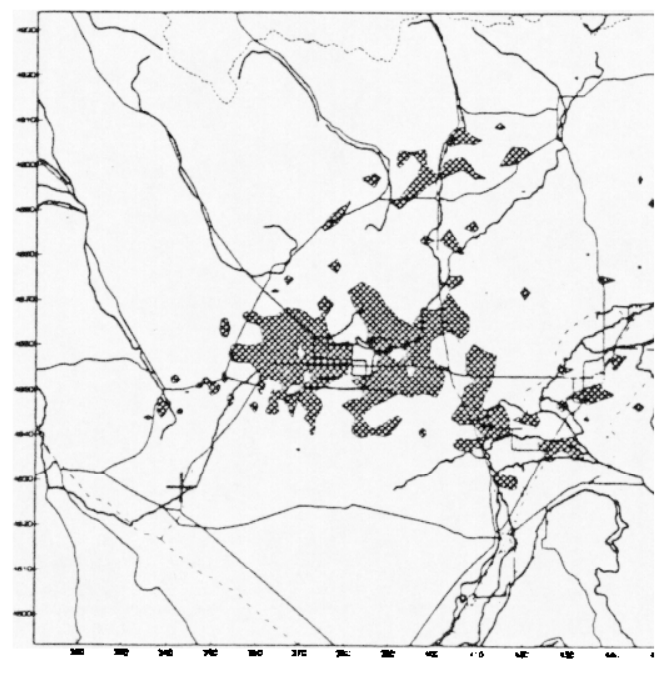

(h) 2115 UTC

Figure 5.18(Completed) Modeled Instantaneous Air Concentrations of $\mathrm{SF}_{6}$ at 1.5 $m$ AGL. (Shaded areas represent areas with concentrations greater than $10 \mathrm{ppt}$ ) 


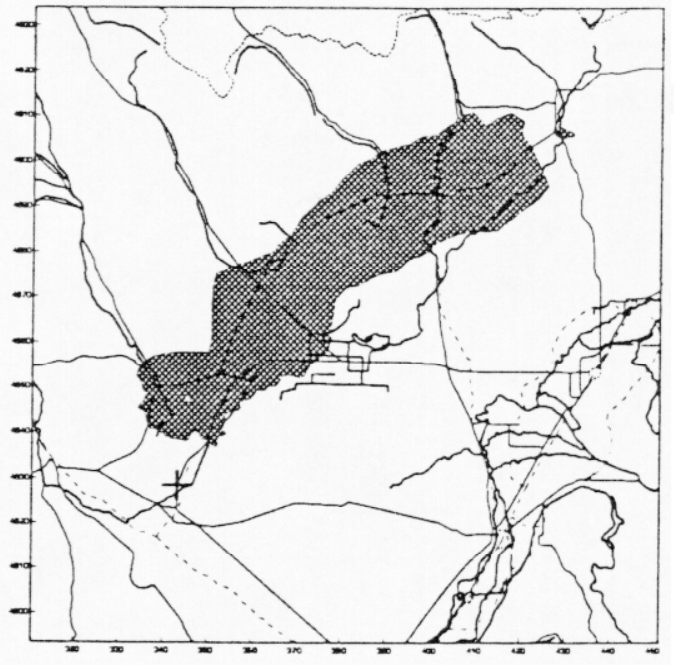

(a) 1715 UTC

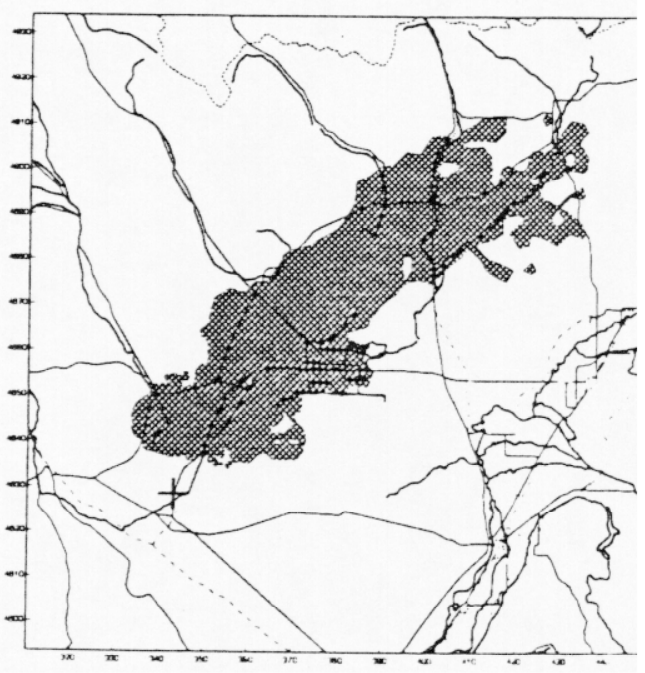

(c) 1815 UTC

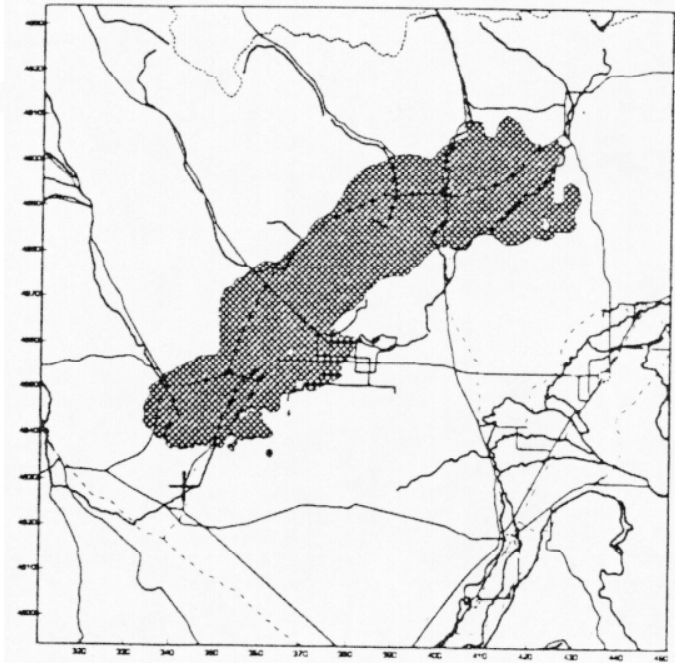

(b) 1745 UTC

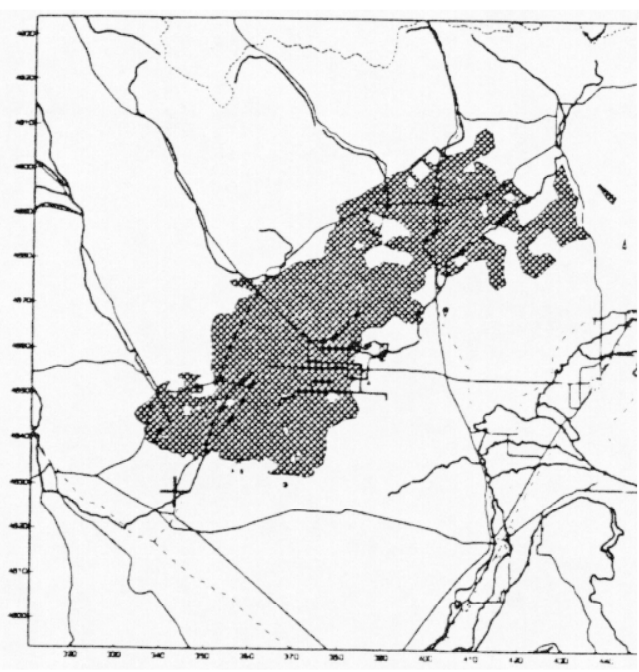

(d) 1845 UTC

Figure 5.19 Modeled Instantaneous Air Concentrations of $\mathrm{SF}_{6}$ at $200 \mathrm{~m} \mathrm{AGL}$. (Shaded areas represent areas with concentrations greater than $10 \mathrm{ppt}$ ) 


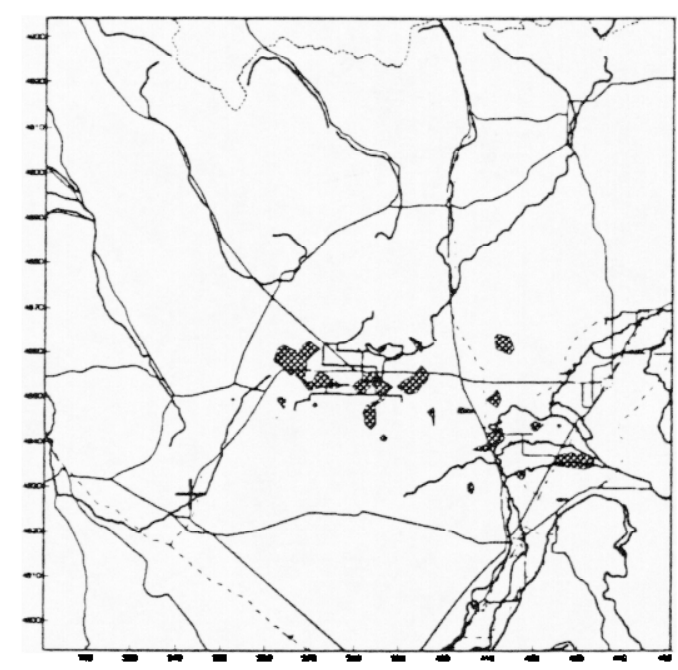

(e) 2115 UTC

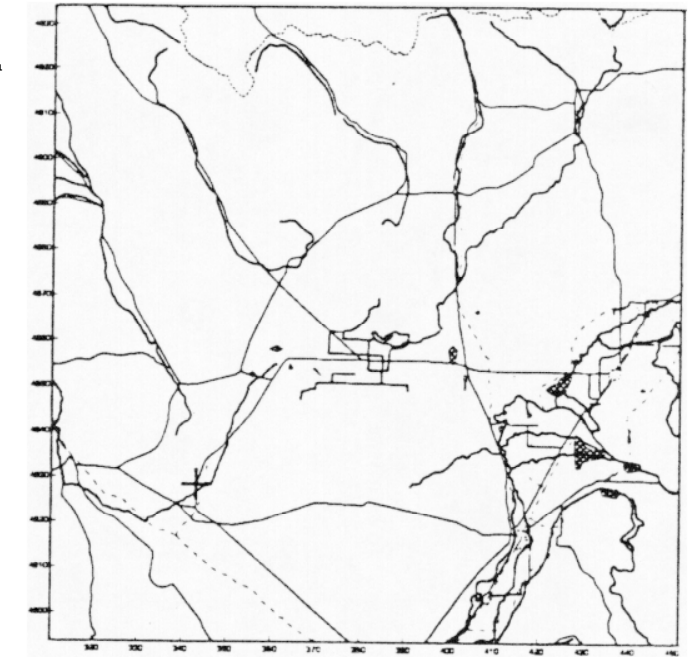

(f) 2145 UTC

Figure 5.19(Completed) Modeled Instantaneous Air Concentrations of $\mathrm{SF}_{6}$ at 200 m AGL. (Shaded areas represent areas with concentrations greater than $10 \mathrm{ppt}$ )

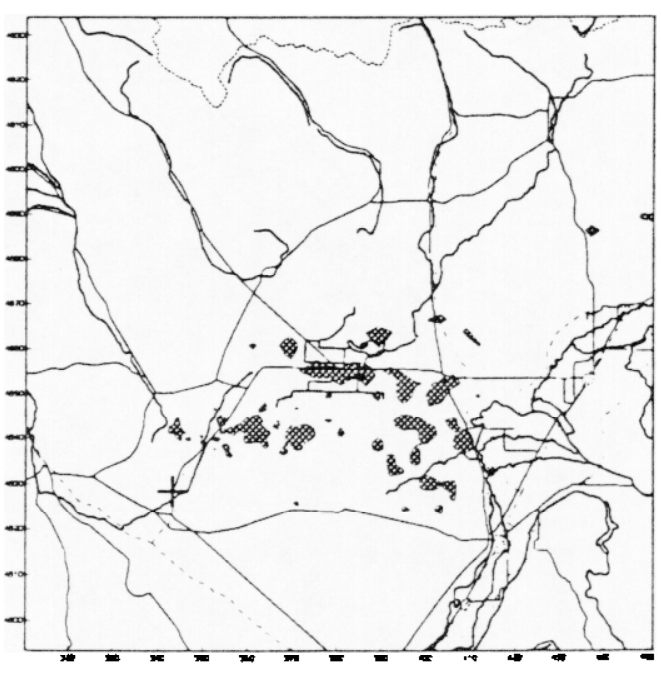

(a) 2015 UTC

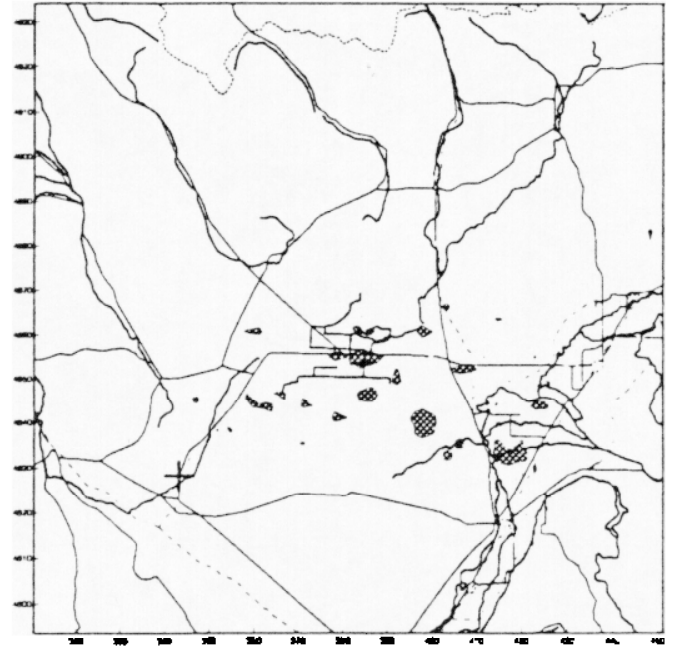

(b) 2045 UTC

Figure 5.20 Modeled Instantaneous Air Concentrations of $\mathrm{SF}_{6}$ at $300 \mathrm{~m}$ AGL. (Shaded areas represent areas with concentrations greater than $10 \mathrm{ppt}$ ) 


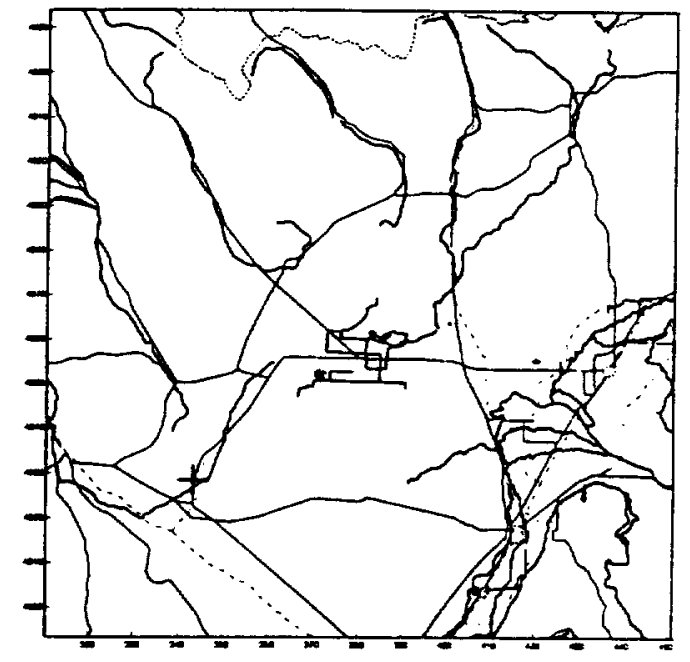

(c) 2200 UTC

Figure 5.20(Completed) Modeled Instantaneous Air Concentrations of $\mathrm{SF}_{6}$ at 300 $\mathrm{m}$ AGL. (Shaded areas represent areas with concentrations greater than $10 \mathrm{ppt}$ )

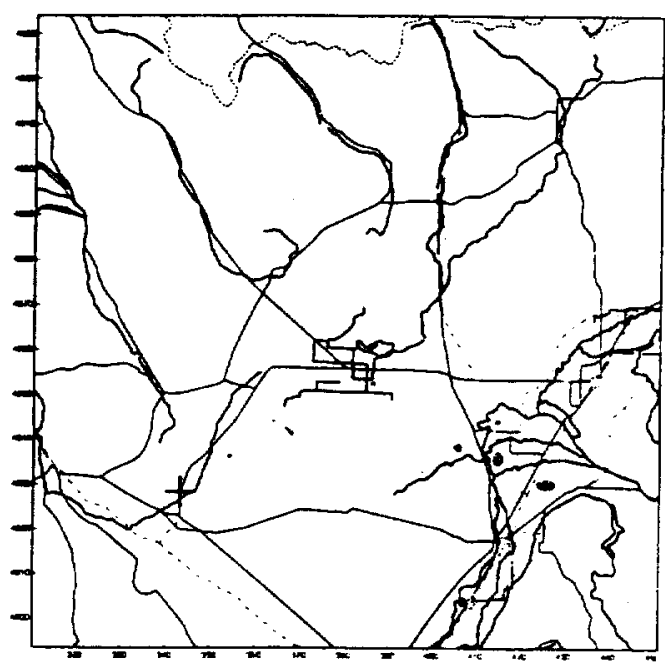

Figure 5.21 Modeled Instantaneous Air Concentrations of $\mathrm{SF}_{6}$ at $400 \mathrm{~m}$ AGL at 2100 UTC. (Shaded areas represent areas with concentrations greater than 10 ppt) 


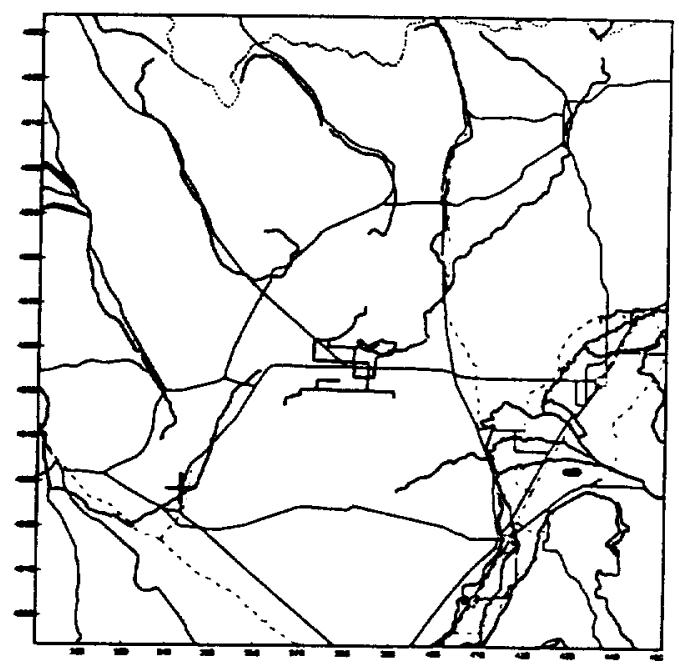

Figure 5.22 Modeled Instantaneous Air Concentrations of $\mathrm{SF}_{6}$ at $550 \mathrm{~m}$ AGL at 2215 UTC. (Shaded areas represent areas with concentrations greater than 10 ppt) 


\section{CHAPTER 6}

\section{CONCLUSIONS}

In the early phases of an emergency response to a hazardous material release to the atmosphere many questions arise, but concrete information to answer these questions is not always available. It is also in these early phases where decision made early on can affect the remainder of the response. Issues of public health and safety most certainly arise and need to be addressed rapidly and as accurately as possible. This study attempts to use a numerical model with a limited tracer measurement dataset to assist in the interpretation of the dispersion pattern similar to the early phases of an emergency response. In addition, the most important model input parameters governing the transport and diffusion of the tracer material are identified.

A higher resolution version of the operational 3-D wind field extrapolation, transport and diffusion models of the ARAC were applied to the meteorological and tracer measurement dataset from the fourth release of the ACEIII air sampling tests conducted by the Air Force near Idaho Falls, Idaho. As is usually the case, much more surface meteorological data was available for model input than was upper air data. The INEL tower network data averaged to 15-minute intervals, supplemented by hourly reports at several NWS sites provided adequate coverage spatially and temporally for input to the models.

Conversely, the most significant data for upper air input were two NWS rawinsonde stations located hundreds of kilometers away in different terrain 
regimes. This is one of the weaker components of the modeling process. As a result, careful scrutiny of this data was done to ensure appropriate use or nonuse of the data. In this study, the lower level winds measured by the rawinsonde stations did not agree with data determined from tetroons released prior to and during the release period. So, an appropriate extrapolation scheme was used in the wind field models that more heavily weighted the surface and tower data in determining the lower level wind fields. In addition, only two soundings from each of these stations were available during the study period. The appropriate timing of when to use these data is also a weak component in modeling. Usually, an abrupt shift in the wind fields occur as a result of the sounding changeover, where in the atmosphere there is usually a time period over which the winds more smoothly shift. A shift in the upper winds occurred at 1700 UTC in this study, when the input was changed from the 1200 UTC soundings to the 0000 UTC soundings.

In some instances, even soundings at a significant distance can yield information that can be used for model input. In this study, both rawinsonde stations measured surface temperature inversions. This is important because the vertical dispersion of material is limited within surface inversions. An inversion was observed within the study domain and the two rawinsonde station observations were used to determine the top of the inversion. Even though the upper air data was limited and distant, important model inputs were able to be determined.

The amount of measurements of the released material are also scarce early in an emergency response. Even though measurements in this experiment were taken over a 10-hour period, a representative determination of plume dispersion 
was not obvious. Ten ground measurements were taken over the 10-hour study period across the 19,600 square $\mathrm{km}$ study domain, and did not give much information to determine the plume dispersion pattern. A single aircraft flew intercept paths at varying altitudes in an attempt to measure the tracer. The aircraft detected the tracer for a 53-minute period in an area approximately 250 square $\mathrm{km}$ about $55 \mathrm{~km}$ from the release point during a total flight time of 3 hours and 28 minutes. Even though more measurements were taken with the aircraft, the data recorded was not able to present an estimate of the plume dispersion. The tracer measurements available from this experiment did provide a limited set of data to compare model calculations to and gave insight to some of the tracer dispersion pattern calculated by the model.

The foundation of all the models is the topographic grid bottom and domain definition. A grid was selected to encompass the measurement locations horizontally so the comparison could be made. In addition, the grid depth was selected so the vertical measurements could be compared and also so topographic features of the surface were represented. Washing out surface terrain features by selecting a vertical grid extent too large reduces the ability of the other models to act realistically.

The available meteorological data were analyzed to determine model inputs. Results from these model calculations were compared to the limited measurement data available. In most cases, the data were re-examined and new model input parameter values were determined and the models re-executed and again compared against the tracer measurements. These sensitivity studies produced best estimates of several important parameters for determining the wind fields and controlling the tracer dispersion. 
The limited upper air data necessitated the use of the Boise and Salt Lake City rawinsonde soundings for model input. The 12-hour interval between observations required a changeover from the 1200 UTC soundings to the 0000 UTC soundings during the 1315 to 2315 UTC study period. The timing of this changeover was found to be extremely critical in producing detectable concentrations at locations and times measured by the aircraft. Changeover times too early moved the plume to the east prematurely, where later changeover times did not transport material into areas where tracer was measured. This parameter becomes important when modeling transport and diffusion for extended periods of time during the day, and should be examined carefully in every event.

A major component in determining a dispersion pattern is generating a realistic wind field with the model to drive the tracer transport. The mixing layer height and boundary layer height were important model input parameters in determining flow layers within the flow field. Model defaults did not take into account the surface inversion and the resulting wind shift above the inversion. By analyzing the data, mixing layer and boundary layer heights were determined and input to model the effects of the surface inversion. As a result the initial dispersion of the tracer was limited to $120 \mathrm{~m} \mathrm{AGL}$, and when the inversion had dissipated, the mixing layer was elevated to the top of the modeling grid to allow more vertical mixing as would be seen in the atmosphere. In addition, atmospheric stability parameters were selected to simulate the slightly stable environment below the inversion top, and then the more neutral stability when the inversion dissipated. 
The best-estimate calculation incorporated the results from the sensitivity studies that determined the best model input parameters. These inputs were used to generate $\mathrm{SF}_{6}$ concentrations that were compared to the measurement dataset from this experiment. The calculated concentrations compared well with the measurements taken by the aircraft throughout the entire study period. In addition, preliminary results of this study were presented to the experiment director, where the model results were verified. However, the agreement between model concentrations near the surface and truck measurements were not as good. At times the model did not appear to mix the tracer to the surface as was measured, but at other times kept the tracer lofted where no tracer was detected. This disparity may be attributed to the grid cell resolution of the model in this study. To examine the overall dispersion pattern a larger grid, as used in this study, is required, however, to examine how the tracer disperses near the surface for a short time period requires a smaller, high resolution grid.

Through the analysis of data, determination of model input parameters, execution of the models, comparison to measured data, and re-execution of the models, numerical models and limited tracer data can be used together to interpret a dispersion pattern. In real-world emergency response events, the combined use of data and models can be used by responders to assist in decision making for minimizing risk to the population and for containing the event.

Based on the findings in this study, several suggestions of future considerations follow. To obtain better resolution in modeling the vertical structure of the atmosphere, the higher resolution models used in this study should be considered for operational emergency response use by ARAC. 
The model sensitivity to mixing layer and boundary layer height point out the need to examine the soundings nearest to the study region. An algorithm could be developed that examines these soundings looking for an inversion, and if found sets the default model input mixing layer height to the level found in the sounding. Since most inversions do dissipate, a timing factor default (say 4 hours), or one determined in a way similar to this study by bringing the inversion top temperature to the surface dry adiabatically and comparing this temperature with surface temperature values in time.

Also, the diurnal cycle of the winds need to be addressed, however, this issue is more difficult to solve diagnostically since soundings may only be available at one time. In addition, during late morning and afternoon responses, sounding data for 0000 UTC is not available for many hours. However, in situations where 12-hourly soundings are available, an algorithm could examine the data and determine a smoother more appropriate transition of wind data, by possibly interpolating over a time period determined by using surface data. A search for previous work would need to be conducted to explore methodologies to determine diurnal wind cycles from one sounding observation time.

These are only a few areas in which work could be done in addition to the improvements being considered and presently being worked. 


\section{BIBLIOGRAPHY}

Baskett, Ronald L., John S. Nasstrom, and Rolf Lange, 1990, "The Value of On-site Sodars Versus Nearest Radiosonde Soundings in Regional Emergency Response Modeling," presented at the 83rd Annual Meeting of the Air and Waste Management Association. Pittsburgh, PA, Air and Waste Management Association; also Lawrence Livermore National Laboratory Report UCRL-JC-103433. [Available from National Technical Information Service, U.S. Dept. of Commerce, Springfield, Virginia 21161.]

Baskett, Ronald L., Phillip J. Vogt, Walter W. Schalk III, Brenda M. Pobanz, Connee S. Foster, and James S. Ellis, 1994, "The Challenge of Emergency Response Dispersion Models on the Meso-Gamma Urban Scale: A Case Study of the July 26, 1993 Oleum Tank Car Spill in Richmond, California," presented at the 5th Topical Meeting on Emergency Preparedness and Response. Savannah, Georgia; also Lawrence Livermore National Laboratory Report UCRL-JC-118082. [Available from National Technical Information Service, U.S. Dept. of Commerce, Springfield, Virginia 21161.]

Foster, K. T., and M. H. Dickerson, 1990, "An updated summary of MATHEW/ADPIC model evaluation studies," presented at the Workshop on Mechanistic Analyses Involving Aerosols in Non-Reactor Facility Accidents. Salt Lake City, Amer. Nucl. Soc.; also Lawrence Livermore National Lab. Rep. UCRL-JC-104134. [Available from National Technical Information Service, U.S. Dept. of Commerce, Springfield, Virginia 21161.]

Greenly, George D., and Marv H. Dickerson, 1983, "Numerical Models and Their Role in Emergency Response: A Perspective on Dispersion Modeling for Emergency Preparedness," presented at the 76th Annual Meeting of the Air Pollution Control Association. Atlanta, Georgia Air Pollution Control Association; also Lawrence Livermore National Laboratory Report UCRL88938. [Available from National Technical Information Service, U.S. Dept. of Commerce, Springfield, Virginia 21161.]

Randerson,Darryl, ed., "Atmospheric Science and Power Production." Oak Ridge, TN: Technical Information Center, United States Department of Energy, 1984, pp.367 - 422.

Reible, Danny D., Frederick H. Shair, and Erwin Kauper. "Plume Dispersion and Bifurcation in Directional Shear Flows Associated with Complex Terrain." Atmospheric Environment. Volume 15, Number 7 (1981), 1165 - 1172. 
Rodriguez, et al., "User's Guide to the CG-MATHEW/ADPIC Models Version 4.2," Lawrence Livermore National Laboratory Report UCRL-MA-103581, 1996. [Available from National Technical Information Service, U.S. Dept. of Commerce, Springfield, Virginia 21161.

Snyder, John P. "Map Projections - A Working Manual". Washington, D.C.: United States Government Printing Office, 1987. 


\section{BIOGRAPHICAL SKETCH}

Walter W. Schalk III

Present Position:

Senior Assessment Meteorologist

Atmospheric Release Advisory Capability

Health and Ecological Sciences Division

Environmental Programs Directorate

Lawrence Livermore National Laboratory

7000 East Avenue, Mail Code L-103

Livermore, CA 94550

Tel (510) 423-9323; Fax (510) 423-4527

Employs a real-time dispersion modeling system for responding to accidental radiological and toxic chemical incidents on local to hemispheric scales. Maintains preparedness by exercising the system, leads assessments and work for others, participates in and plans multi-agency exercises, coordinates the deployment and training of new remote systems, and act as back-up to the Emergency Operations Center Team Leader.

Personal:

DOB: 25 May 1963

POB: Elmhurst, Illinois

Professional Memberships:

American Meteorological Society

Honors:

Chi Epsilon Pi (Meteorology Honor Society)

Golden Key National Honor Society

Pi Mu Epsilon (National Honorary Mathematics Fraternity)

Gamma Theta Upsilon (International Geographical Honor Society)

Outstanding Senior Student in Illinois College Geography

Who's Who in American College Students

Education:

1985: B.S. Meteorology, graduated Magna Cum Laude with University Honors, Northern Illinois University, DeKalb, IL 
Previous Experience:

1985-1988: Research Assistant, Department of Meteorology, The Florida State University, Tallahassee, Florida

Scientific Interests

Numerical Modelling

ARAC Operations

Model Applications

Selected Publications and Reports:

Baskett, R. L.; P. J. Vogt, W. W. Schalk, III, C.S. Foster, and J.S. Ellis. 1995. The Challenge of emergency response dispersion models on the meso-gamma urban scale: A case study of the July 26, 1993 oleum tank car spill in Richmond, California. ANS Fifth Topical Meet. on Emergency Prepared. \& Response, April 18-21, 1995, Savannah, GA. UCRL-JC-118082. 5 pg.

Baskett, R. L., P. J. Vogt, W. W. Schalk III, B. M. Pobanz. 1994: ARAC dispersion modeling of the July 26, 1993 oleum tank car spill in Richmond, California. Livermore, CA: Lawrence Livermore National Laboratory Report UCRLID-116012. $53 \mathrm{p}$.

Sullivan, T.S, J.S. Ellis, C. S. Foster, K.T. Foster, R.L. Baskett, J.S. Nasstrom, W. W. Schalk. 1993: Atmospheric Release Advisory Capability: Real-time modeling of airborne hazardous materials, Bull. Amer. Meteor. Soc. 74: 23432361.

Ellis, J. S., C. S. Foster, K. T. Foster, T. J. Sullivan, R. L.Baskett, J. S. Nasstrom, W. W. Schalk III, and G. D. Greenly. 1992: Daily dispersion model calculations of the Kuwait oil fire smoke plume. Pittsburgh, PA: Air \& Waste Mgmt. Assoc. Proc. of the 85th Annual Mtg. of the Air \& Waste Mgmt. Assoc., Kansas City. Paper 92-76.05.

Sullivan, T. S., J. S. Ellis, C. S. Foster, K. T. Foster, R. L. Baskett, J. S. Nasstrom, and W.W Schalk III. April 1992: Modeling of Air Currents in the Gulf Region, presented at the Workshop on "Environmental Dimensions of the Gulf: Policy and Institu-tional Perspectives," April 19-22, Al-Ain, United Arab Emirates, UCRL-JC-110365.

Sullivan, T. J., J. S. Ellis, W. W. Schalk III, and J. S. Nasstrom. 1992b: Ash Cloud Aviation Advisories, presented at the First International Symposium on Volcanic Ash and Aviation Safety, Seattle, WA, July 8-12, 1991. Lawrence Livermore National Laboratory, Livermore, CA, UCRL-JC-111060. 


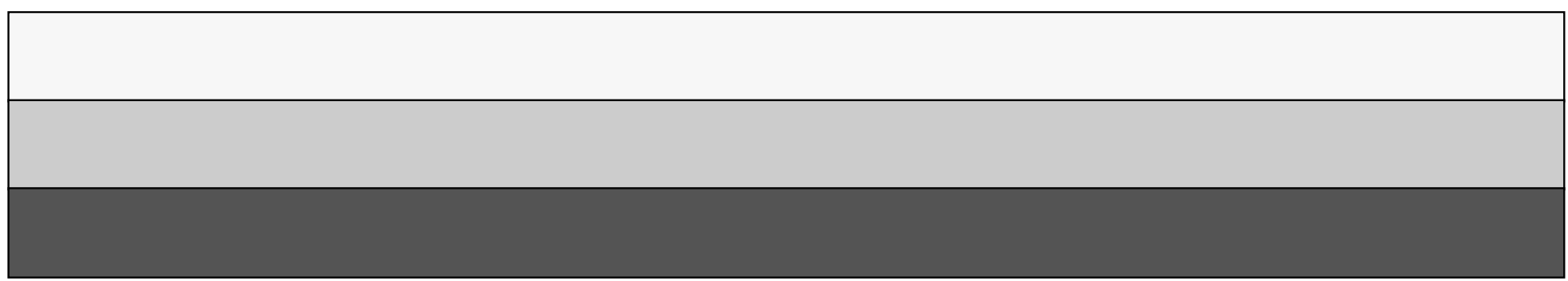

